Ann. Abeille, I967, 10 (3), I39-I97.

\title{
ANALYSE DE DIFFÉRENTS FACTEURS CONDITIONNANT LES ECHANGES ALIMENTAIRES DANS UNE COLONIE D'ABEILLES APIS MELLIFICA L. AU MOYEN DU RADIO-ISOTOPE P' $\left.{ }^{32}{ }^{1}\right)$
}

\author{
Shobha PERSIIAI) \\ Station de Recherches sur l'Abeille et les Insectes sociaux, 91-Bures-sur-Yretle \\ Institul national de la Recherche agronomique
}

SOMMAIRE

Des observations sur la trophallaxie à l'intérieur de la ruche entre ouvrières d'âge connu ont montré que les échanges sont nuls à l'âge de 1 jour, deviennent réguliers entre 2 et 4 jours puis semblent diminuer ensuite. L'intensité des échanges est à son maximum lorsque les abeilles ont 4 jours environ. Le taux de répartition de la nourriture a été étudié à 3 températures différentes, $23^{\circ} \mathrm{C}, 31^{\circ}$ et $37^{\circ}$ pour des durées d'échange de $4,8, I^{6}, 24,36$ et 48 heures. $A 35^{\circ}$ C le nombre de receveuses est le plus élevé, à $37^{\circ} \mathrm{C}$ il est le plus bas. Ia rapidité moyenne des échanges est la même a $3 \mathrm{I}^{\circ}$ et à $23^{\circ}$. La transmission est plus rapide pendant les premières 24 heures à $3 \mathrm{I}^{\circ}$ ( $\mathrm{fu}^{\prime} \mathrm{i} i 3^{\circ}$. La répartition de nourriture est plus importante et plus rapide lorsque les abeilles sont maintenues d'abord à $37^{\circ}$ puis ensuite à $23^{\circ}$, chaque fois pendant 2 jours, que lorsqu'elles sont maintenues à $23^{\circ}$ puis ensuite a $37^{\circ}$. T'rois groupes d'importance variable $(25,50$ et roo receveuses) ont été mis en présence d'une seulc donneuse radioactive pendant des durées de $2,4,8$, I $6,24,36$ et 48 heures. C'est dans le groupe de 25 que le taux de transmission était le plus rapide, il atteignait roo p. I00 en I6 heures. L'homogénéité de la répartition augmente avec le nombre de donneuses. Des expériences effectuées dans les colonies créees artificiellement en étuve ont montré que la distribution de nourriture est meilleure entre abeilles de même origine qu'entre abeilles de colonies différentes pendant les premières 24 heures d'observation. Mais dans les expériences faites sur les abeilles provenant de ruchers l'inverse se produit, les individus de la colonie étrangère sont préférés. La répartition du ${ }^{32} \mathrm{P}$ dans le tube digest if ainsi que l'assimilation des matières radioactives sont étudiées. Dans le cas où les reines vierges sont donneuses on observe un maximum d'échanges lorsque les ouvrières ont 6 jours.

\section{INTRODUCTION GÉNÉRALE}

Les échanges de nourriture et autres substances entre les individus de la colonie constituent un phénomène très important chez les insectes sociaux.

Particulièrement parmi les insectes sociaux supérieurs formant des colonies organisées l'équilibre trophique entre un ou plusieurs sexués et un très grand nombre

(1) Ce travail constitue l'essentiel d'une thèse de Dotorat d'Iniversité, soutenue devant la Faculté des sciences de Toulouse le 29 juin 1967 . 
de non-sexués joue un rôle primordial. Ces derniers possédant une potentialité sexuelle plus ou moins latente (Fourmis et Abeilles ouvrières) ou une tendance à se métamorphoser en sexués (larve de Termite), sont maintenus en leur état principalement par ces échanges mutuels. Les échanges sociaux de nourriture sont donc indispensables à la division du travail et à l'élevage du couvain dans les conditions écologiques optimales du nid et à toutes autres métamorphoses en des formes supérieures de vie sociale parmi les insectes. Ceci peut également être un moyen de communication entre les individus.

Les échanges de nourriture entre insectes sociaux sont connus depuis l'Antiquité puisque Aristote en a donné une description. Grassi et Sandias (I893) décrivirent pour la première fois des échanges de substances entre des Termites.

RoubAUD (I9I6) a appelé " œcotrophobioses ", les relations des guêpes sociales caractérisées par les échanges réciproques de nourriture entre les larves et les parents. WHEEIER (I9I8) a proposé le terme "trophallaxy" de trophe, nourriture et allatein, échanger comme plus approprié que " œcotrophobiose ". Il considère que cette relation entre les jeunes et les adultes est mutuelle et réciproque.

L'extension du concept trophallaxie à tous les échanges de substances entre deux individus eut lieu par la suite. Nous adopterons cette extension tout en soulignant qu'il n'est pas possible de mettre sur le même plan la nourriture proprement dite et toutes les substances diverses qui peuvent être échangées atı moment de la trophallaxie.

GösswALD et KI.OF'T (I956 à I963) ont fait de nombreuses publications, à partir de I956, sur les échanges de nourriture entre les fourmis d'espèces différentes, à l'aide de ${ }^{32} \mathrm{P}$. Les recherches ont porté sur $2 \mathrm{I}$ espèces de fourmis, mais elles furent spécialement orientées vers le genre Formica et plus précisément vers le groupe rufa.

Les premiers travaux montrèrent l'importance des échanges de nourriture : une seule ouvrière peut en nourrir 8 à ro et, par le canal de celles-ci, le radio-isotope peut parvenir à environ 80 individus. Ils ont trouvé que la plus haute fréquence d'échange de nourriture est atteinte à $25-30^{\circ} \mathrm{C}$. Ces chiffres ne sont plus valables pour des genres différents. La sous-famille des Camponotinae, à laquelle appartient le genre Formica est certainement celle qui possède la trophallaxie la plus intense parmi les fourmis étudiées.

Le comportement des fourmis amazones Polyergus rufescens LATR. a été particulièrement étudié (GöSSWAL,D et KLOFT, I960; I96I). Les ouvrières de cette espèce sont capables de se nourrir seules et aussi de recevoir de la nourriture, en particulier de leurs " esclaves ", mais n'en distribuent en aucun cas. L'espèce Proformica nasuta, dont certains individus constituent de véritables réservoirs vivants de miel a été étudiée par Stumper (196I) qui a montré qu'une ouvrière pouvait en nourrir Ioo.

WILSON et EISNER (I957) ont effectué des recherches analogues en utilisant ${ }^{131}$ I. Ils ont observé de très importantes différences dans la vitesse et l'importance des échanges.

Par ailleurs, dès 1959 GösswaLD et KLOFT ont effectué sur le terrain une étude des échanges de nourriture entre différentes colonies de Formica. Les résultats mentionnés au cours d'une discussion au Symposium sur les radio-isotopes et radiations en entomologie à Bombay, en I96o, ont fait l'objet d'une publication (GösswAL, et KLOFT, I963). La transmission de radio-isotopes fournis à une colonie sous forme de 
solution dans un liquide sucré a été observée par GösSWALD et KLOFT à plusieurs reprises. L'exemple le plus remarquable étant la transmission de radioactivité à plus de 200 mètres, à partir d'une colonie artificiellement renforcée de Formica polyctena.

Chauvin, Courtois et LacomTe (I96I) ont observé des échanges de nourriture entre individus appartenant à différentes espèces sur le terrain en marquant la nourriture avec ${ }^{198} \mathrm{Au}$. Dans une série d'articles, CHAUvin et LECOMTE (Ig62 à Ig66) ont étudié le transport des sticres et des protides entre différentes colonies de Formica polyclena, qui sont reliées entre elles par des pistes plus ou moins nettes et possèdent ainsi un certain degré d'unité physiologique.

L'existence et l'importance de la trophallaxie chez les termites avaient été depuis longtemps mises en évidence par Grassé et NOIROT (I945). Les études de trophallaxie au moyen des radioéléments chez les termites ont été commencées en I958 par GössWald et ses collaborateurs (GössWal, I962 ; GössWALD et KLOFT, I958-I959; I96I-I963; Al.IBERT, I959-I960; I966).

Ces auteurs ont recherché, utilisant la nourriture marquée par le radioélément, quels sont, dans une colonie, les individus capables de s'alimenter par eux-mêmes. Ils ont ainsi montré la rapidité des échanges alimentaires chez les termites. Ils ont observé que cette propagation est bien plus lente que celle observée chez les Abeilles et chez les Fourmis du genre Formica.

AliberT (I959, I960, I963 et I966) a étudié la trophallaxie chez le termite, Cubitermes, en utilisant le ${ }^{32} \mathrm{P}$. Elle a étudié les relations entre la colonie et les sexués, la nutrition du couvain et des " castes dépendantes ", l'évolution, avec 1'âge de la société, des liens trophiques unissant les conjoints d'un même couple et le couple royal aux " larves ».

Une étude du même type a été faite par McMahas (I963) chez Cryptotermes brevis (WALKER), en utilisant le traceur ${ }^{57} \mathrm{Co}$ incorporé à la not1riture proctodéale, dans les " colonies artificielles".

Au cours d'une étude portant sur le métabolisme du manganèse chez des Vespidae sociaux, BoWEN (I950) avait remarqué que les mâles ingéraient autant de nourriture que les ouvrières quand ils étaient à l'extérieur dı nid, mais que, par contre, leur radioactivité, et par conséquent leur prise de nourriture, était très faible à l'intérieur du nid.

Montagner et Courtors (I963), MONTAGNER (I963, Ig64 $a$, I964 b, I966) ont étudié les échanges de nourriture des guêpes sociales du genre Vespa au moyen de ${ }^{198} \mathrm{Au}$. L'étude de populations élevées dans des cagettes séparées par des cloisons perforées ne permettant pas le passage a montré que les échanges de nourriture s'effectuaient plus facilement entre ouvrières sœurs qu'entre des ouvrières appartenant à deux colonies différentes. DEIVERT-SALLERON (I963), qui a étudié le même problème sur l'Abeille, n'était pas arrivée à une conclusion aussi nette.

Les auteurs ont également étudié le problème de l'alimentation des mâles. Celui-ci n'est pas aussi simple que le voudrait BowEN. La capacité d'alimentation directe est grande chez les mâles appartenant à des nids actifs où les fondatrices filles ne sont pas encore apparues, elle est plus faible chez les individus provenant de nids appartenant à des colonies avancées. Mais ceci n'est vrai que si l'on considère 
des mâles déjà âgés, les très jeunes individus s'alimentent tous bien, seuls, dans tous les cas.

MoNTAGNER ( I964 b) a également étudié l'alimentation des mâles par les ouvrières. I1 apparaît que les mâles sont très négligés par les ouvrières et cela même s'ils appartiennent au même nid. Ils ne sollicitent de la nourriture que si les ouvrières appartiennent à la même société. Ils sont de même fort capables de solliciter les régurgitations des larves. Il peut aussi y avoir une trophallaxie dans le sens mâles-ouvrières, mais fort réduite, cependant les mâles ne nourrissent le couvain en aucun cas.

Ce même auteur (Montagner, I963) s'est attaqué au problème trop souvent négligé des relations entre le couvain et les adultes ouvrières. Il a montré que les guêpes sont capables de reconnaître du couvain étranger à la colonie et que la larve était nourrie de façon constante en fonction de son degré d'évolution. La taille et l'intégrité de la cellule interviennent également. Il a analysé par cinématographie le mécanisme de la trophallaxie chez Vespa (Ig66, thèse).

Les colonies de Bourdons présentent une double caractéristique : elles sont, au moins partiellement, fermées, c'est-à-dire que les étrangères en sont habituellement chassées, sinon mises à mort ; d'autre part, on n'y observe pas d'échanges de nourriture entre les membres. Dans ces conditions, il est possible de se demander comment s'effectue la reconnaissance et si une odeur commune peut avoir son origine dans un autre phénomène que l'échange continuel de nourriture. L_ECOMTE (I963) a montré une trophallaxie indirecte dans la colonie de bourdons, Bombus hypnorum, au moyen de ${ }^{198} \mathrm{Au}$.

La trophallaxie chez les Abeilles est étudiée depuis très longtemps. Doolitrte (I.890, I907) a observé que les butineuses porteuses de miel retournant à leur ruche ne déposent pas leur miel directement dans les cellules mais le transmettent à d'autres abeilles de la colonie. PARK (I923) a réalisé l'expérience suivante : il a fait absorber de l'eau colorée à quelques ouvrières d'une petite colonie installée dans une ruche d'observation. Le lendemain, les abdomens de $5^{\circ} \mathrm{p}$. Ioo des ouvrières de la colonie semblaient colorés, ceci indique que l'eau stockée avait été distribuée parmi elles. Puisque dans les climats tempérés les abeilles ne stockent pas 1'eau dans les rayons il est donc possible que l'eau soit transmise de l'une à l'autre.

Rösch (I925) a montré qu'une ouvrière est nourrie directement par ses congénères pendant les deux ou trois premiers jours de sa vie et ne se nourrit pas elle même avant d'avoir atteint trois jours. PEREPELOVA (I928) a observé que les abeilles âgées d'un à trois jours étaient nourries par des abeilles dont l'âge allait de 7 à I 4 jours.

VON FRISCH (I946 a, I946 b) a observé qu'une butineuse qui a découvert une source de nourriture particulièrement favorable en donne de petites quantités aux individus qui la suivent pendant la danse.

L'activité d'une abeille a été déterminée, du moins dans une certaine mesure, en fonction de son âge (RÖSCH, I925; PEREPOLOVA, I928 ; LINDAUER, I952 ; SAKAGAMI, I953). OHNESORGE-HAMPERDINCK (I953) a montré que les échanges de nourriture entre des ouvrières âgées et des jeunes ouvrières peuvent influencer le développement des glandes pharyngiennes et la sécrétion des glandes mandibulaires chez ces dernières.

Istomina-Tsvetrkova (I953 $a$, I953 $b$ ) a constaté que les abeilles de tous âges donnent de la nourriture à leurs congénères et en reçoivent, dans des proportions 
importantes. Fille a pensé que le nombre des échanges était en rapport avec le stade de croissance atteint par la colonie et elle a constaté que, lorsque l'élevage du couvain était réduit pendant l'automne, le nombre des échanges était moins grand et qu'ils étaient de plus courte durée que pendant l'été. Il y avait un rapport direct entre le nombre de visites qu'une abeille faisait aux larves et le nombre des échanges de nourriture entre cette abeille et ses congénères. Un accroissement dans la quantité de nectar apporté dans la ruche n'a pas eu pour résultat un accroissement du nombre des échanges mais, à cette occasion, la durée de ces échanges était un peu plus longue. La proportion de nourriture arrivant à la ruche et qui circule entre les individus d'une colonie est plus grande aux époques de disette que pendant les miellées car alors la plus grande quantité est déposée dans les cellules de réserve.

LINDAUER (I954) a décotivert un rapport entre le temps mis par une butineuse pour transmettre sa provision de nectar ou d'eau à une abeille de la ruche et l'activité ultérieure de cette butineuse. S'il y avait une carence d'un de ces deux éléments la provision de la butineuse était évidemment réclamée par les abeilles de la ruche, au contraire si la colonie était bien pourvue il fallait parfois à la butineuse plusieurs minutes pour transmettre sa provision.

FREe et BUTLER (I955) ont montré que la transmission de la nourriture joue un rôle d'attraction des abeilles l'une vers l'autre et ainsi maintient la cohésion de la colonie. FREE (I957) a remarqué également que deux abeilles de même âge ou presque ont tendance à échanger de la nourriture. Il a de plus expliqué que des abeilles de tous âges nourrissent des abeilles d'âges très variés et sont nourries par elles. Il a montré qu'il existe une corrélation étroite entre le nombre de fois où elles offrent la nourriture et la quantité qu'elles en possèdent, ce qui est moins évident lorsqu'il s'agit d'abeilles prises au hasard dans la colonie.

Iśromina-Tsve'TKOVA (I958) a constaté que la quantité de nectar que les butineuses bien pourvues conservent dans leurs jabots après avoir nourri les abeilles de la ruche est en rapport avec la longueur du prochain vol. L'endroit particulier où se trouve l'abeille à l'intérieur de la ruche a peut-être aussi une influence sur la quantité de nourriture conservée dans le jabot. Ainsi les abeilles qui se trouvent à l'extérieur d'une grappe hivernale ont plus de nourriture dans leur jabot (HAI,LUND, I956 ; FREE, I957) et probablement en consomment plus (FREE et SPENCER-BOoTH, I958) que celles qui se trouvent au centre.

L'utilisation des isotopes radioactifs comme traceurs s'avère très efficace pour l'étude de ces phénomènes. En I 952, Nixon et RibBAnDs, ont utilisé pour la première fois la méthode des traceurs dans l'étude des échanges de nourriture à l'intérieur d'une colonie d'abeilles. Ces auteurs ont montré qu'une petite quantité de la nourriture absorbée par les butineuses a été distribuée largement entre les membres de la colonie en quelques heures. Six abeilles étaient dressées à aller chercher leur nourriture dans une boite de Petri contenant $20 \mathrm{ml}$ de sirop du sucre radioactif. Les auteurs ont ensuite étudié la répartition de la radioactivité parmi les abeilles et les larves de la colonie comprenant 24500 abeilles. En l'espace de 27 heures 76 p. Ioo des butineuses et 43-60 p. Ioo de toutes les abeilles étaient nettement moins radioactives que les jeunes abeilles et les butineuses l'étaient nettement plus. Fn l'espace de 48 heures toutes les larves des derniers stades dans les cellules non operculées étaient radioactives. Ces résultats sont attribués à la trophallaxie. Ceci serait à l'origine de la 
répartition du travail à l'intérieur de la colonie et de l'odeur commune aux membres de chaque colonie servant à la reconnaissance mutuelle.

A la suite du travail de Nixon et RiBbANDs (I952), une étude de la transmission de radioactivité des ouvrières aux mâles après ingestion par les premières de sucre marqué au ${ }^{14} \mathrm{C}$ a été effectuée par OERTEL, EMERSON et WHEEI,ER (I953). Les résultats obtenus par les auteurs semblent très nets : bien que du sirop de sucre ait été mis à leur disposition, les mâles ne se nourrissaient pas seuls et préféraient demander à travers un grillage, de la nourriture aux ouvrières qui se trouvaient dans une cage attenante.

Cependant, GösswaLD et $\mathrm{KLOF}_{\text {L }}$ (I958) ont publié des résultats d'expériences effectuées sur les abeilles. De celles-ci, il ressort que les mâles peuvent se nourrir activement et donner de la nourriture aux ouvrières. En ce qui concerne les échanges entre ouvrières, GösswaI,D et KLOFT (I958-I96I) Gösswal,D (I959) dans les publications consacrées principalement aux Fourmis ont fait état d'essais effectués sur l'Abeille qui mettent en évidence l'importance et la rapidité de la transmission de nourriture d'une ouvrière à l'autre.

Cour'ToIs, L,ECOMTE et SALLERon (I96I) ont étudié les échanges de nourriture à l'intérieur de la ruche entre les abeilles ouvrières Apis mellifica. Ils ont constaté que l'emplacement où se trouvait située la reine jouait un rôle très important. Ils ont utilisé pour leurs expériences, la ruche de CHAUvin : ruche à cadre unique de grandes dimensions occupée par une population de 3 à 4 ooo abeilles. Un nourrisseur contenant du miel marqué à ${ }^{198} \mathrm{Au}$ était placé sur la périphérie de la grappe hivernale. 5 à Io abeilles pouvaient pénétrer dans ce nourrisseur qui était ensuite retiré. I1 apparaît de manière certaine que les ouvrières après avoir rempli leur jabot de miel se dirigent très rapidement vers le centre de la grappe et c'est à partir de ce centre où se trouve la reine que s'effectue la diffusion de nourriture à travers l'ensemble de la population. Ce travail a été repris par Douaurt (I967) sur la ruche d'été. Dans ce cas, 1'emplacement du couvain détermine le lieu privilégié des échanges.

DELVERT-SALLERON (I963) a étudié les échanges de nourriture entre individus de castes (reines, butineuses, mâles, etc.) ou de colonies différentes. Le radio-isotope utilisé était le ${ }^{32} \mathrm{P}$ incorporé à une nourriture solide. Les trois points suivants furent étudiés : en ce qui concerne les ouvrières, il semble que les échanges s'effectuent plus volontiers avec les abeilles sours pendant les deux premiers jours, pour s'inverser ensuite et se faire plutôt avec les étrangères. D'autre part, les mâles sont capables dans une certaine mesure de se nourrir seuls mais, en présence d'ouvrières, ils préfèrent se faire nourrir par ces dernières. On constate aussi, dans certains cas, un transfert de radioactivité des mâles vers les ouvrières. Pour ce qui est des échanges entre reine et ouvrières ils ne sont le fait que d'un très petit nombre d'abeilles spécialisées, aussi bien dans la ruche que dans les colonies expérimentées très restreintes composées d'une vingtaine d'ouvrières.

Mais Delvert-Salleron n'a pas obtenu des résultats complets et définitifs sur ces points. Il n'a pas été possible de démontrer une préférence absolue des abeilles pour leurs sœurs ou pour des abeilles étrangères. Dans son travail, elle n'a pu qu'effleurer les principales questions qui se posent au sujet de la trophallaxie entre reines et ouvrières. 


\section{I. - MATÉRIEI, ET MÉTHODE}

Étant donné l'influence importante de l'âge, sur le comportement des abeilles, attestée par de nombreux travaux depuis Rösciı (1925) il nous a paru nécessaire de travailler sur des individus d'âge connu.

Nous décrirons la technique permettant d'obtenir des abeilles naissantes en grand nombre et en parfaite condition.

\section{Recherche du courain naissant}

Le couvain doit être prélevé très mûr, c'est-à-dire sur le point d'éclore, ce qui se reconnaît facilement à ce que les opercules des cellules fondent et s'amincissent. A ce moment, on vérifie le degré de maturité en désoperculant au hasard quelques cellules à l'aide de pinces souples. Le cadre est bon à prendre lorsque la tête et les antennes de l'ouvrière apparaissent noirâtres et s'animent de mouvements caractéristiques. Les cadres de couvain operculé, transportés trop tôt à l'étuve, ne sont pas dans des conditions optimales de développement et ils éclosent plus tardivement. Les ouvrières de ces cadres paraissent aussi moins vigoureuses et vivent moins longtemps encagées. Les cadres de couvain, une fois choisis, sont alors transportés du rucher jusqu'au laboratoire dans des boîtes à deux cadres, munies de couvercle, construites en isorel dur, de $33 \mathrm{~cm}$ de hauteur, $45 \mathrm{~cm}$ de longueur et $8 \mathrm{~cm}$ de largeur intérieure, préalablement maintenues à $35^{\circ} \mathrm{C}$, car il est très important de ne pas refroidir le couvain au cours du transport. I'ne fois au laboratoire, les cadres de couvain sont immédiatement entreposés dans, une étuve ì $33^{\circ} \mathrm{C}$.

\section{Répartition des éclosions}

Les abeilles naissantes sont encagées par petits groupes, toutes les vingt-quatre heures. A. MAURizio (1954) opère de la même façon. DE Groot (I953) les encage au fur et à mesure des naissances, c'est-à-dire toutes les huit heures : mais il pense qu'il eût été préférable de répartir également par cagettes les abeilles de chaque période d'éclosion. Nous avons choisi une période d'éclosion de 24 heures. De cette façon les individus plus nombreux se répartissent plus facilement et d'une manière plus homogène dans les cagettes. On a ainsi plus de chance de réduire les variations dues au hasard. Les abeilles sont saisies à l'aide de pinces souples et introduites directement dans les cagettes, par groupes de cent abeilles. Dans la mesure du possible, nous avons toujours utilisé des abeilles de début et de milieu d'éclosion, jamais de fin d'éclosion, parce que ces dernières sont en général plus fragiles, quelques-unes même petites et malformées.

Les cagettes, une fois peuplées, sont maintenues dans une étuve à $30^{\circ} \mathrm{C}$. I des températures supérieures, on observe une agitation intense et une augmentation de la mortalité.

\section{Description des cagettes d'élevage}

La cagette expérimentale décrite par J. PAIN (1966) a été conçue pour l'élevage des abeilles en milieu confiné. Flle a été entièrement réalisée par l'atelier de la Station de Recherches sur l'Abeille et les Insectes sociaux.

Ce nouveau modèle s'inspire de celui de la Station de Liebefeld en Suisse, mais les dimensions en sont très différentes ainsi que la matière employée pour sa construction. La forme générale est un parallélépipède rectangle de i cm de haut sur $9,5 \mathrm{~cm}$ de large et $7,5 \mathrm{~cm}$ de profondeur.

L'altuglas (polyméthacrylate de méthyle) est employé pour la fabrication de ces cagettes. Le socle et les deux petits côtés sont blanc opaque. Par contre, les deux grands côtés sont transparents, ce qui leur permet de faire office de vitres. Le dessus, qui forme toit, déborde de $3 \mathrm{~mm}$ environ sur les petits côtés. Il est formé de deux parties : un entourage en altuglas blanc opaque ajouré au centre sur une surface de $7 \times 5 \mathrm{~cm}$ et sur lequel repose un couvercle transparent de $8,5 \times 5,8 \mathrm{~cm}$ maintenu par les deux côtés transparents. Ceux-ci, de dimensions i I $\times 8,8 \mathrm{~cm}$, sont percés d'orifices d'aération de $3,5 \mathrm{~mm}$ de diamètre disposés en triangle. Ils peuvent être retirés facilement car ils glissent dans des rainures pratiquées dans les plaques des deux petits côtés ainsi que dans deux entailles dans l'entourage blanc opaque du toit.

Le couvercle transparent du toit peut être garni d'un support en cire : feuille gaufrée ou morceau de rayon. Les ouvrières se groupent plus facilement sur la cire (SENDI,ER, I940) que sur n'importe quel autre support. 
Il possède un orifice de $1,4 \mathrm{~cm}$ de diamètre dans lequel on glisse un abreuvoir en pyrex d'une capacité de $4 \mathrm{ml}$. Cet abreuvoir est percé à l'une de ses extrémités par un bouchon de liège. Il est rempli d'eau pure. L'importance de l'eau, distribuée en quantité suffisante, a été démontrée par WoODrow (194I) et A. MatrRizio (1946). La longévité des abeilles maintenues en captivité augmente de huit fois, si, à côté du miel ou du candi, on leur fournit de l'eau.

Les plaques formant les petits côtés sont perforées, comme les parois transparentes, d'orifices d'aération de mêmes dimensions nais disposés en triangle. Sur l'un de ces petits côtés, deux perforations de $2 \mathrm{~cm}$ de diamètre ont été ménagées a in de recevoir deux mangeoires contenant l'une la nourriture sucrée (candi), l'autre la nourriture azotée (pollen). Sur le socle de la cagette de dimensions $10,5 \times 5,7 \mathrm{~cm}$, on dispose intérieurement une plaque mobile transparente de $7 \times 8,3 \mathrm{~cm}$ sur laquelle a été creusée, sur la plus grande longueur, une rainure dans laquelle vient s'emboîter et se bloquer l'une des parois transparentes fonctionnant comme vitre.

La nourriture est facilement administrée dans les mangeoires que l'on met en place à la façon de tiroirs. Chacune d'elles peut contenir $10 \mathrm{~g}$ de candi ou tout autre aliment pâteux ou solide.

La ventilation est suffisante. Le nettoyage est facile. On peut changer aisément les deux parois transparentes ainsi que la plaque mobile posée sur le socle. Cent abeilles peuvent y séjoumer sans difficulté.

Comme l'importance du rôle de la reine sur le développement et le comportement des ouvrières d'abeilles est bien connu, nous avons élevé des ouvrières en présence de la reine dans la cagette décrite par Pain ( 1966 ). Ces reines ont été utilisées ensuite pour l'étude de la trophallaxie entre les reines et les ouvrières.

\section{Nourriture}

Les aliments utilisés sont le pollen et le candi se trouvant dans des mangeoires.

Pollen: Le pollen est très important dans la vie des abeilles parce qu'il fournit la nourriture nécessaire à la croissance et au développement normaux. Les abeilles naissantes ont besoin de pollen non seulement pour la préparation de la nourriture larvaire mais aussi pour leur croissance. IIAYDAK ( I96I) a montré que le pollen frais permet le développement des glandes nourricières des abeilles (avec une efficacité de 100 p. I0o).

Le pollen frais perd de sa valeur nutritive au cours du stockage. Ainsi, nous avons toujours utilisé du pollen frais pour nourrir les abeilles dès leur naissance dans les cagettes d'élevage. Pais (1963) a noté que la consommation de pollen est très importante pendant les $4-5$ premiers jours de la vie des jeunes abeilles à l'intérieur des cages, ensuite la consommation s'abaisse pour devenir presque nulle vers le dixième jour. Elle a observé (jue inversement les consommations en sucre aug. mentent progressivement jusqu'à ce même dixième jour.

Candi: Après bien des recherches nous avons abandonné la nourriture liquide d'eau sucrée ou miellée. En effet, sous cette forme les abeilles qui sont dans l'impossibilité de sortir pour évacuer l'excès de liquide, se gonflent rapidement; les excréments accumulés dans l'abdomen ne peuvent ètre rejetés facilement, si bien qu'elles meurent au bout de très peu de temps. Nous avons préféré une nourriture solide, composée de sucre candi. Ce candi est un mélange de sucre-glace et de miel dans les proportions de $2 / 3$ de sucre pour $1 / 3$ de miel. Le mélange se fait au bain-marie jusqu'à l'obtention d'une pâte visqueuse qui durcit par la suite à l'air sans devenir friable. Il est très important d'éviter la caramélisation ; car un candi trop chauffé devient toxique pour l'Abeille.

\section{Température}

La température du milieu a une influence importante sur la longévité des abeilles encagées. Bien (ju'une température de $34^{\circ} \mathrm{C}$ soit maintenue sur le couvain dans la colonie d'Abeilles, une température inférieure favorise la longévité (KelleR-Kitzinger, I935; MAURizio, r946). Ce dernier auteur étudiant la longévité à 20,30 et $37^{\circ} \mathrm{C}$ a obtenu un optimum à $3^{\circ} \mathrm{C}$. En conséquence nous avons réglé la température de l'étuve à $30^{\circ} \mathrm{C}$. Cependant les rayons à couvain avec les abeilles naissantes ont été toujours conservés à $33-35^{\circ} \mathrm{C}$.

\section{Cagettes expérimentales}

Pour les besoin des expériences, nous avons utilisé des cagettes de type "I.iebefeld ". Elles mesurent $17 \mathrm{~cm}$ de hauteur, I $4,5 \mathrm{~cm}$ de long et $4 \mathrm{~cm}$ de large. Elles se composent d'un socle et d'un couvercle en bois, réunis l'un à l'autre par deux rectangles de bois munis de rainures dans lesquelles peuvent glisser deux vitres latérales, de dimensions 13 sur $18 \mathrm{~cm}$.

Les abeilles sont introduites par l'un des orifices ménagés à la base du rectangle de bois. Par l'autre orifice, nous introduisons un abreuvoir en verre de I $2 \mathrm{~mm}$ de diamètre, coudé à $90^{\circ}$, perforé à une extrémité et fermé à l'autre par un bouchon de liège. Ces abreuvoirs sont remplis d'eau pure. 
Pour les expériences destinées à étudier l'influence de l'odeur de la colonie, nous avons utilisé des cagettes de même type, mais trois fois plus larges et divisées en trois compartiments par deux grilles. Nous avons utilisé des plaques de matière plastique perforée. Lees trous doivent avoir un diamètre de $3,75 \mathrm{~mm}$, de manière que les abeilles puissent passer la tête, mais que le thorax reste de l'autre côté. Nous nous trouvons dans les normes prescrites par FrEE (1958) qui estime qu'une ouverture de $2,5 \mathrm{~mm}$ représente le minimum nécessaire pour que les échanges aient lieu.

Nous avons également utilisé des caget tes du type "Liebefeld", mais deux fois plus larges, pour étudier les échanges entre la reine et les ouvrières. Chaque cagette a été divisée en deux compartiments par une plaque en plastique. La plaque en plastique comporte un trou près du bord supérieur pour permettre les échanges. Cette ouverture est recouverte d'une toile en nylon dont les mailles ont $3 \mathrm{~mm}^{2}$ : Les mailles de cette toile permettront aux ouvrières de nourrir la reine, sans toutefois qu'elles puissent atteindre d'autres parties de son corps que les pièces buccales.

\section{Isotope utilisé}

L'isotope que nous avons employé était le ${ }^{32} \mathrm{p}$, fourni par le Commissariat à l'Énergie atomique sous la forme de phosphate monosodique. Cet isotope a été choisi à cause de sa période adaptée à nos recherches ( 14,3 jours) ainsi que de son rayonnement facilement décelable et des facilités de son utilisation. Il émet un rayonnement $\beta$ de $1,707 \mathrm{MeV}$. Il est facilement métabolisé par l'organisme et il s'incorpore sans difficulté à la nourriture. Il se dissout facilement dans l'eau miellée, nous obtenons alors une solution à taux de radioactivité homogène. Nous avons introduit dans la nourriture une quantité suffisante de matière radioactive pour que chaque abeille puisse absorber à peu près un microcurie.

\section{Introduction de l'isotope}

Delvert-Salleron (1963) a introduit l'isotope dans le candi pour étudier les échanges de nourriture entre abeilles. Mais DouAult ( $\operatorname{gg} 66 a$ ) a montré que les pattes des abeilles présentent une contamination de 2 p. Ioo lorsque l'aliment marqué est du candi. Cette radioactivité est due à des fragments de sucre marqué, collés aux pattes de l'abeille. De plus, l'incorporation de l'isotope dans le candi a présenté certaines difficultés. C'est pourquoi nous avons choisi un aliment liquide : l'eau miellée. L'incorporation d'un produit radioactif à une solution d'eau miellée offrait bien des avantages. Cette opération peut se faire à froid sans répandre dans l'atmosphère des substances radioactives et sans danger de contamination pour l'expérimentateur. De plus on obtient facilement une solution homogène.

Le nourrisseur contenant le miel radioactif était une cupule en matière plastique de $1,5 \mathrm{~cm}$ de diamètre et $\mathrm{I}, \mathrm{o} \mathrm{cm}$ de profondeur. Cette cupule était remplie avec de la cire aux trois quarts de sa hauteur afin que seule une petite quantité du miel marqué soit utilisable. Le miel marqué était versé sur la surface de la cire jusqu'au bord de la cupule. Un couvercle en matière plastique percé de trous ayant $\mathbf{2 , 5} \mathrm{mm}$ de diamètre était placé sur cette cupule. L'épaisseur de ce couvercle permettait à l'abeille d'atteindre facilement le miel avec sa langue. Les trous étaient assez larges pour permettre a la langue de l'abeille de passer (fig. I et 2).

\section{Toxicité du rayonnement}

Courtors et Lecomte (1959) ont montré (qu'un rayonnement de 18000 rountgens est toléré par l'Abeille alors que la dose létale pour l'homme est de 600 rontgens. Cet te résistance permet d'opérer des marquages à l'aide de radio-éléments artificiels d'une assez forte activité, sans crainte de faire mourir prématurément les insectes ni de modifier leur comportement de façon appréciable.

\section{Conditions expérimentales}

Nous avons employé un compteur Geiger-Müller du type cloche sous tension de $I, 475$ volt. Le mouvement propre de l'appareil (dit aussi bruit de fond) est compris entre $\mathrm{r} 8$ et zo coups par minute ; ce dernier est déterminé avant chaque expérience par un comptage d'au moins ro minutes.

Le tube G. M. est placé dans un château de plomb, dans lequel on introduit les objets ou les animaux à compter. Le mouvement propre de l'appareil (bruit de fond) a été déterminé avant chaque comptage et les résultats exprimés en coups nets, c'est-à-dire, les coups bruts moins le bruit de fond. 


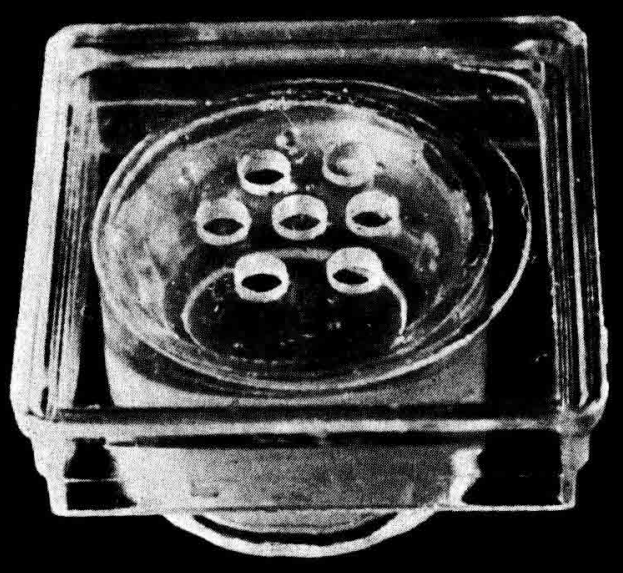

Fig. I. - Nourrisseur

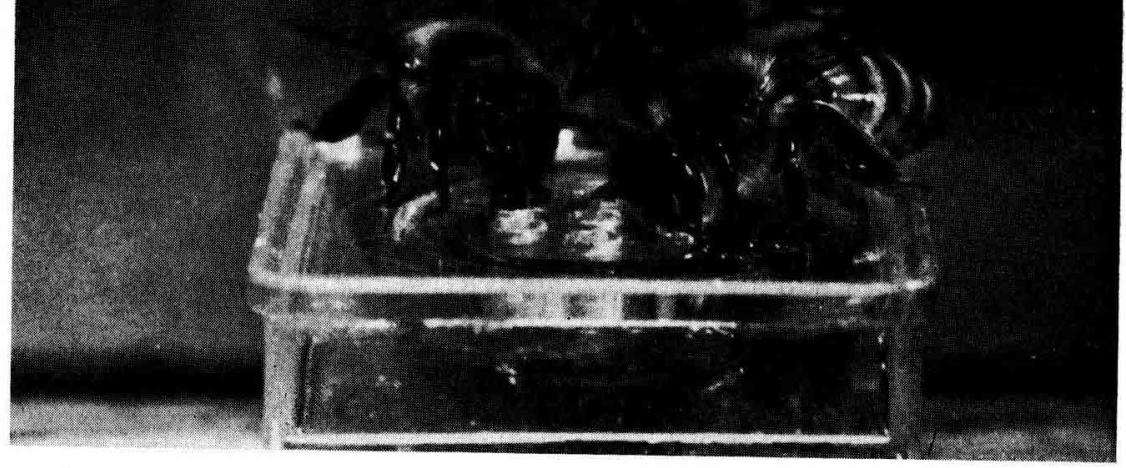

FIG. 2. - Abeilles se nourrissant 


\section{Withode de complage}

Les animaux sont placés près du tube dans les meilleures " conditions de géonétrie ". On désigne sous le nom de "géométrie " la position de l'échantillon par rapport au tube, ainsi que sa forme et sa dimension. Pratiquement on travaille avec une source très proche du compteur, mais de telle manière que la position de l'objet soit constante et reproductible dans les différentes expériences. I.'excentration de la source est une cause d'erreur, ainsi que la variation de la distance à la paroi de mica.

Il faut bien préciser que les chiffres donnés par le compteur ne sont pas des valeurs absolues, mais ils représentent des chiffres proportionnels à la radioactivité réelle.

C'est pourquoi dans nos résultats nous ne nous attachons pas à leur valeur absolue, mais à leur signification par rapport aux autres chiffres. vivant.

l.e comptage s'opère de façon différente selon que l'on a affaire à un animal mort ou à un animal

L'insecte mort est introduit tout simplement sous le compteur au moyen d'un porte-objet sur lequel on le dépose et dont il est isolé par un papier-filtre ; ceci pour éviter toute contamination du porte-objet ; une mesure de bruit de fond tous les dix comptages permet de s'assurer qu'il n'y a pas eu de contamination du porte-objet.

Pour les insectes vivants il existe un probleme. Nous avons utilisé, dans ce cas, la technique de Dovalut (1966 b) qui consiste à immobiliser l'abeille dans un tube de cellophane, dont le diamètre est approximativement le mêtme que celui du thorax et de l'abdomen de l'insecte, les extrémités du tube étant obturées avec du coton. Le tube de cellophane peut se faire par découpe d'une bande de cellophane de $10 \mathrm{~cm}$ de long environ et de $3 \mathrm{~cm}$ de large maximum. On roule cette bande sur un tube de verre de $6 \mathrm{~mm}$ de diamètre préalablement bien talqué afin de faciliter le démoulage. Finsuite, on colle légèrement à la jointure de la bande et on retire la baguette de verre. Nous avons donc un tube de cellophane du diamètre d'une abeille, légèrement rigide tout en restant souple. L'abeille, ne peut faire aucun mouvement et garde pendant toute la durée du comptage, une position rigoureusement constante. Les deux extrémités du tube sont bouchées par un léger tampon de coton afin de permettre à l'abeille de respirer.

A la fin du comptage, l'insecte est récupéré facilement et cette manipulation peut se répéter plusieurs fois sans inconvénient. Dans ces conditions, l'abeille est parfaitement immobilisée et ne subit aucun dommage, de plus l'absorption du rayonnement $\beta$ par la cellophane est parfaitement négligeable. Cette méthode permet d'éviter l'usage d'un anesthésiant qui n'est pas sans influence sur le comportement des abeilles (RibBands, r950).

\section{Marquage des abeilles à la peinture}

Dans certaines expériences où l'on a mis les ouvrières-donneuses directement avec les ouvrièresreceveuses les abeilles ont été marquées pour en permettre la reconnaissance.

En suivant l'exemple de VON FRISCH, nous les avons numérotées à l'aide de taches colorées. La peinture utilisée sèche rapidement (elle sert à peindre les modèles réduits). Elle présente de plus l'avantage d'être fournie par petites quantités dans de multiples coloris (marque Humbrol-plastic Enamel). En variant la couleur des taches et leur nombre sur le thorax, c'est avec la plus grande facilité que nous pouvons distinguer un assez grand nombre d'abeilles.

Pour marquer les abeilles individuellement, nous avons utilisé un tube cylindrique en matière plastique transparente muni d'un piston mobile (1) qui emprisonne une abeille contre un filet. Une marque est ensuite appliquée sur le côté dorsal du thorax de l'abeille à travers le filet.

\section{II. - L'INFLUENCE DE L'AGE SUR LES ÉCHANGES DE NOURRITURE ENTRE LES OUVRIÈRES}

Nous avons voulu dans ce travail préciser plus spécialement l'influence que pouvait avoir l'âge des individus sur les échanges de nourriture. Un certain nombre d'informations concernant l'influence de 1'âge, les comportements alimentaires et les échanges de nourriture peuvent se rencontrer dans la littérature.

(1) Fourni par Chr. Graze K. G., I 4 a. lindersbach, Stuttgart, Allemagne. 
Selon Rösch (I925), une jeune abeille se procure de la nourriture uniquement en la demandant à ses sœurs et ne se nourrit aux dépens des réserves situées dans les alvéoles qu'à partir du troisième jour suivant sa naissance. PEREPELOVA (1928) a pu voir que si les abeilles d'un âge peu avancé avaient tendance à nourrir les ouvrières de I à 3 jours, cela pouvait aussi être le fait d'abeilles âgées de plus de I 4 jours.

Istomina-TsvetKova (I953) a pu observer que des abeilles âgées de I à 2 jours sont capables de donner de la nourriture à d'autres ouvrières, mais qu'elles le font moins souvent que les plus âgées. FrEE (I957) a fait les mêmes constatations, il observe également qu'au fur et à mesure que l'ouvrière avance en âge, l'âge moyen des abeilles avec lesquelles elle entretient des contacts alimentaires dans le sens don ou réception, augmente parallèlement. Il existe une tendance à ce que les échanges de nourriture aient lieu entre abeilles de même âge.

Ce sont ces différents points que nous avons cherché à préciser en utilisant la méthode des radio-isotopes, alors que les recherches précitées ont surtout été effectuées par le moyen de l'observation directe, sans estimation quantitative des échanges alimentaires autre que celle de la durée et la fréquence des rencontres interindividuelles.

Les expériences furent conduites de la manière suivante : une abeille marquée d'une couleur donnée et d'âge connu était introduite dans une cagette "Liebefeld " et nourrie avec du sirop du sucre contenant le radio-isotope. Après que cette abeille, que nous désignerons sous le nom de "donneuse ", ait ingurgité une certaine quantité de sirop, celui-ci était remplacé par du candi ordinaire et la cagette replacée dans l'étuve pendant I5 à 30 minutes.

La radioactivité du sirop absorbé par cette donneuse était ensuite mesurée dans les conditions déjà décrites, puis cette abeille était introduite dans une autre cagette contenant 20 ouvrières provenant de la même ruche. Ces 20 ouvrières seront appelées "receveuses ", elles sont gardées dans la cagette durant 24 heures, puis passées individuellement sous le compteur. Les expériences ont été conduites avec des abeilles donneuses et receveuses d'un âge variant entre 2 et 9 jours. Les expériences projetées avec des abeilles d'un jour n'ont pu être réalisées, celles-ci étant incapables de s'alimenter par elles-mêmes.

Pour l'interprétation statistique des résultats nous avons appliqué le test $F$ de Snedecor. Il porte sur les chiffres de radioactivité distribuée entre les receveuses au cours de la durée totale de l'expérience. On effectue alors la somme totale $(X=22 \mathrm{I})$ des radioactivités distribuées dans tous les lots de différents groupes d'âges. On introduit un terme de correction :

$$
\frac{\left(\sum \mathrm{X}\right)^{2}}{n}=\frac{4884 \mathrm{I}}{40}=\mathrm{I} 22 \mathrm{I}
$$

( $n=40$ ) étant égal au nombre de lots (expériences) où l'on a enregistré les radioactivités.

La variation totale est égale à la différence entre la somme totale des radioactivités élevées au carré et le terme de correction :

$$
\sum \mathrm{X}^{2}-\frac{\left(\sum \mathrm{X}\right)^{2}}{n}=244 \mathrm{I}, 7-\mathrm{I} 22 \mathrm{I}=\mathrm{I} 220,7
$$


La variation entre les différents traitements (groupes d'âges), S. C. E. Tr. est représentée par l'expression :

$$
\frac{\left(\sum \mathrm{X}_{1}\right)^{2}}{n^{1}}+\frac{\left(\sum \mathrm{X}_{2}\right)^{2}}{n^{2}}+\frac{\left(\sum \mathrm{X}_{3}\right)^{2}}{n^{3}}+\frac{\left(\sum \mathrm{X}_{8}\right)^{2}}{n^{8}}-\frac{\left(\sum \mathrm{X}\right)^{2}}{n}
$$

$\left(\mathrm{X}^{1}, \mathrm{X}^{2} \ldots, \mathrm{X}^{8}\right.$ étant mesurés pour les traitements I à 8$)$ ( $n$ étant le nombre des expériences où l'on a enregistré les radioactivités dans un groupe).

$$
\frac{\left(\sum \mathrm{x}\right)^{2}}{n}=\text { terme correctif }
$$

S. C. E. Tr $=79 \mathrm{I}+73,7+19,8+63,3+\mathrm{IOI}, 2+403,2+76,8+\mathrm{I} 37,2-$ I $22 \mathrm{I}$ $=445$.

La variation à l'intérieur des groupes (variation résiduelle), S. C. E. R. s'exprime par la différence entre la variation totale et la variation entre les groupes. Le nombre de degrés de liberté est égal à la somme du nombre des données de chaque groupe, diminuée chaque fois de I $(\mathrm{N}$ - I).

Le nombre de degrés de liberté pour la variation résiduelle est la différence entre le nombre de degrés de liberté pour la variation totale et le nombre de degrés de liberté pour la variation entre les groupes:

$$
(n-\mathrm{I})-(\text { ntr }-\mathrm{I})=39-7=32 .
$$

La variance due aux différents traitements (groupes d'âges), Vtr est exprimée par l'expression :

$$
\frac{\mathrm{SCETr}}{n t r-\mathrm{I}}=\frac{445}{7}=63,5
$$

\begin{tabular}{|c|c|c|c|}
\hline Variation & $\begin{array}{l}\text { Somme } \\
\text { des carrés } \\
\text { des écarts }\end{array}$ & Degré de liberté & Variance \\
\hline $\begin{array}{l}\text { Totale (SCET) .............. } \\
\text { Due au traitement SCET } \ldots \\
\text { Résiduelle } \\
\quad(\text { SCER }=\text { SCET }- \text { SCET } r)\end{array}$ & $\begin{array}{l}1220,7 \\
4 ! 5 \\
775\end{array}$ & $\begin{array}{l}(n-1)=39 \\
(n t r-1)=7 \\
(n-1)-(n t r-1)=32\end{array}$ & $\begin{array}{l}\mathrm{VT} r=\mathrm{SCET} r / n t r-1=63,5 \\
\begin{aligned} \mathrm{VR} & =\mathrm{SCER} /(n-1)-(n t r-1) \\
& =24,2\end{aligned}\end{array}$ \\
\hline
\end{tabular}

et la variance résiduelle, VR :

$$
\frac{\mathrm{SCER}}{(n-\mathrm{I})-(\text { ntr }-\mathrm{I})}=\frac{775}{32}=24,2
$$

TABLEAU D'ANALYSE DE VARIANCE

Le test $\mathrm{F}$ de signification est donné par la relation:

$\mathrm{F}$ calculé $=\frac{\text { Variance due au traitement }}{\text { Variance résiduelle }}=\frac{\mathrm{Vtr}}{\mathrm{VR}}=\frac{63,5}{24,2}=2,62$

$\mathrm{F}$ de table au $5 \mathrm{p}$. Ioo pour 32 degrés de liberté $=2,33$

F calculé, $2,62>F$ de table, 2,33. 
Le $F$ significatif indique qu'il existe une différence entre les lots soumis aux différents " traitements ».

\section{Résultats}

Le tableau I résume les résultats de nos expériences. Dans tous les cas, 1'abeille " donneuse " et les "receveuses " sont de même âge et proviennent de la même ruche. L'échange de nourriture est étudié en utilisant l'expression $\frac{A}{C_{d}}$ dans laquelle A est la radioactivité, bruit de fond déduit, de la donneuse au moment du début de l'expérience, avant son introduction dans la cagette contenant les " receveuses ». C est la somme de la radioactivité distribuée parmi celles-ci et $d$ représente la décroissance de la radioactivité due à la période du radioélément, c'est-à-dire, 3 p. Ioo dans le cas $\mathrm{du}{ }^{32} \mathrm{P}$.

TABLEAU I

Échanges de nourriture entre "donneuses " et "receveuses" de même âge

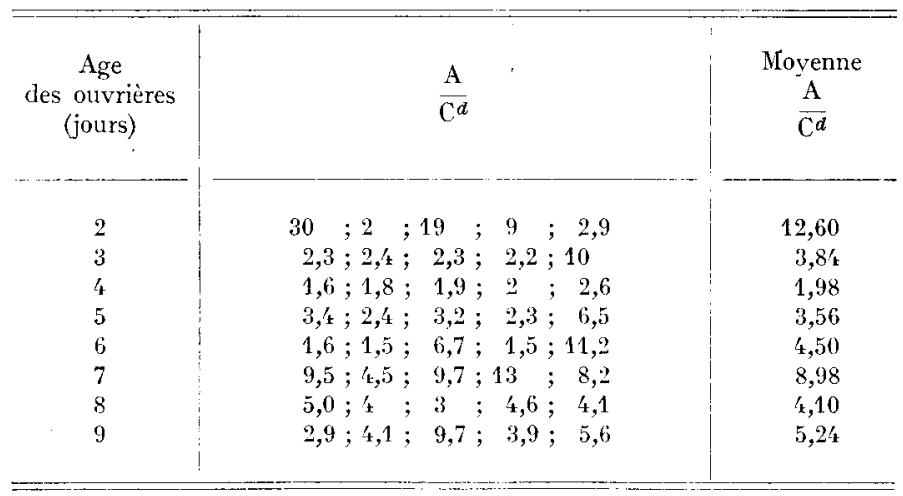

La valeur obtenue sera d'autant plus faible que les échanges sont meilleurs.

Ces résultats nous permettent de tracer le tableau suivant de l'évolution des capacités d'échanges entre abeilles de même âge. Ces capacités sont nulles à l'âge de un jour puis s'accroissent régulièrement du deuxième au quatrième jour. En particulier, les résultats du deuxième jour sont significativement inférieurs à tous les autres.

Les capacités d'échanges semblent ensuite diminuer à partir du cinquième jour et en particulier les résultats du septième jour sont très faibles. Cependant, les fluctuations observées et l'amélioration des échanges après le huitième jour n'auront sans doute une valeur réelle que quand il nous aura été permis de retrouver ces résultats sur un plus grand nombre de groupes. Dans les limites des âges que nous avons étudiées nous pouvons cependant admettre que les échanges alimentaires passent par un maximum vers l'âge de quatre jours.

Pour confirmer ces résultats, nous avons fait quelques expériences avec des abeilles receveuses d'âge différent. Dans la première série d'expériences, nous avons mis une " donneuse » de 4 jours avec les " receveuses " de 8 jours et une "donneuse " de 8 jours avec les " receveuses " de 4 jours. Dans la deuxième série les conditions étaient les suivantes : une "donneuse » de 5 jours avec des « receveuses » de 9 jours et 
une "donneuse " de 9 jours avec les " receveuses" de 5 jours. Le tableau 2 résume les résultats de ces expériences (la valeur de $\mathrm{F}$ a été significative). Nous voyons dans la première série que les abeilles "donneuses" de 4 jours nourrissent mieux les " receveuses " de 8 jours que les "donneuses " de 8 jours ne nourrissent les " receveuses " de 4 jours.

TABLEAU 2

Échanges de nourriture entre des ouvrières d'àge connu en faisant varier l'âge des "donneuses "et celui des "receveuses"

\begin{tabular}{|c|c|c|c|}
\hline $\begin{array}{c}\text { Age } \\
\text { des } \\
\text { " donneuses" } \\
\text { (jours) }\end{array}$ & $\begin{array}{c}\text { Age } \\
\text { des } \\
\text { "receveuses" } \\
\text { (jours) }\end{array}$ & $\frac{\mathrm{A}}{\mathrm{C}^{d}}$ & $\begin{array}{c}\text { Moyenne } \\
\text { A } \\
\mathrm{C}^{d}\end{array}$ \\
\hline & & - & $\cdots$ \\
\hline / & 8 & 3,$82 ; ' 4,52 ; 2,61 ; 3,65$ & 3,65 \\
\hline 8 & 4 & 7,$20 ; 6,80 ; 7,45 ; 5,95$ & 6,85 \\
\hline 5 & 9 & 3,$90 ; 4,56 ; 5,82 ; 2,90$ & 4,29 \\
\hline 9 & 5 & 8,$50 ; 9,5^{\prime} ; 6,48 ; 8,52$ & 8,26 \\
\hline
\end{tabular}

Dans la deuxième série d'expériences, les " donneuses " de 5 jours nourrissent mieux les " receveuses " de 9 jours que les "donneuses " de 9 jours ne nourrissent les " receveuses " de 5 jours.

Ainsi ces résultats nous permettent de dire que les abeilles de 4 jours et de 5 jours sont les meilleures nourrisseurs.

Nous avons ensuite étudié l'influence de l'âge des ouvrières sur le phénomène des échanges de nourriture au moyen des expériences suivantes:

une abeille " donneuse " de 4 jours a été nourrie de miel marqué au phosphore selon le procédé déjà décrit. Elle a été placée dans une cagette contenant 20 abeilles receveuses. Nous avons réalisé ces expériences avec des ouvrières d'âge variant de I à 9 jours. Chacune de ces expériences a été répétée 4 fois.

De la même façon, nous avons choisi une adulte " donneuse " de 8 jours nourrie de miel radioactif et mise en contact avec des ouvrières « receveuses " variant en âge de I à 9 jours. Ces expériences ont été répétées 4 fois.

Les résultats sont consignés dans le tableau 3. Avec une "donneuse " de 4 jours, nous voyons que les meilleurs échanges ont lieu dans le cas où les ouvrières sont âgées de 4 jours. En même temps nous observons qu'une donneuse de 4 jours nourrit aussi bien les jeunes abeilles de 2 à 3 jours que les abeilles âgées de 5 à 9 jours.

L'échange de nourriture avec une " donneuse » de 8 jours est plus faible qu'avec une " donneuse " de 4 jours. La "donneuse " de 8 jours nourrit moins bien les jeunes abeilles que celles de 4 jours. Il semble qu'elle soit plus attractive pour les ouvrières plus âgées.

Fille nourrit mieux les ouvrières de son âge que celles d'un autre âge. Ainsi elle se comporte comme la donneuse de 4 jours. Mais quand nous comparons les résultats 
globaux, nous observons qu'une donneuse de 4 jours participe mieux aux échanges alimentaires avec les ouvrières de tous âges. Elle est dans tous les cas la meilleure donneuse.

\section{TABLEAU 3}

Échanges de nourriture entre une donneuse de 4 jours, une donneuse de 8 jours et des receveuses âgées de 1 à 9 jours

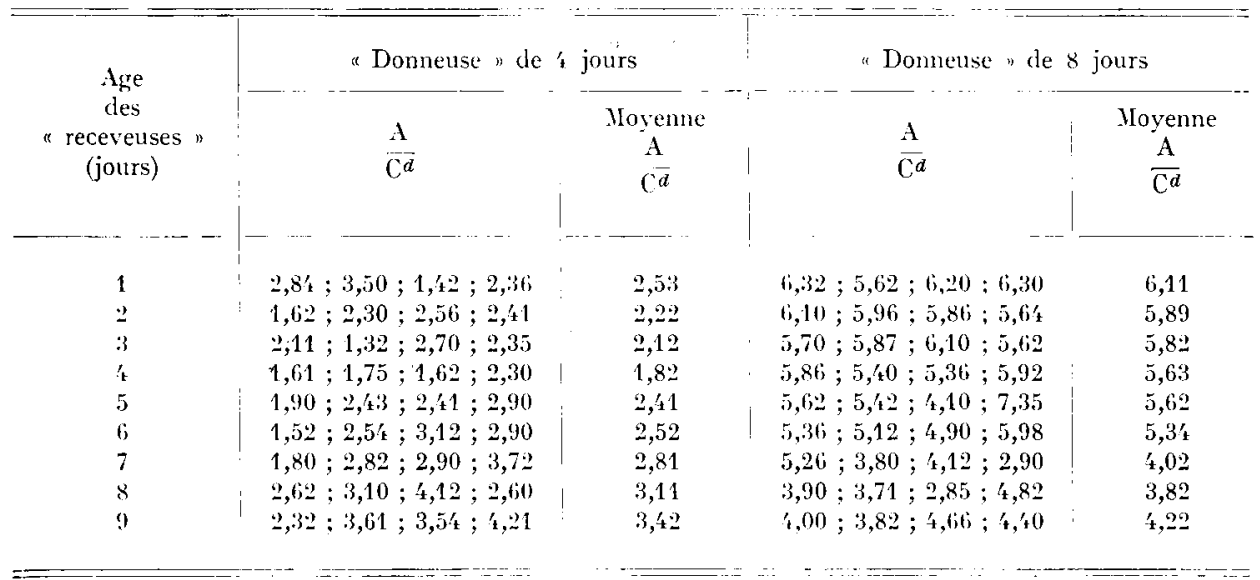

\section{III. - INFLUENCE DE LA DURÉE E'T DE LA TEMPÉRATURE SUR LES ÉCHANGES ALIMENTAIRES}

\section{La répartition de la radioactivité en fonction de la durée des échanges}

Nixon et Ribbands (1952) marquant six abeilles avec du miel radioactif les ont mises dans une colonie de 24500 abeilles, 62 p. Ioo des butineuses et 16 à $2 \mathrm{I} \mathrm{p}$. 100 des abeilles de la ruche sont devenues radioactives en 4 heures. 76 p. Ioo des butineuses et 43 à 60 p. Ioo des abeilles sont devenues radioactives en 27 heures. Avant 48 heures toutes les grandes larves sont aussi devenues radioactives. Ces résultats montrent que la répartition de nourriture chez l'abeille est plus rapide que chez les autres insectes sociaux.

Nous avons effectué nos expériences avec des groupes de $5^{\circ}$ abeilles en variant la durée. Une abeille marquée au miel radioactif était mise dans une cagette avec 50 receveuses. Nous avons étudié la répartition de nourriture au bout de $\mathrm{I} / 2 \mathrm{~h}$, I h, $2 \mathrm{~h}, 4 \mathrm{~h}, 8 \mathrm{~h}, \mathrm{I} 6 \mathrm{~h}, 24 \mathrm{~h}, 36 \mathrm{~h}$ et $48 \mathrm{~h}$ en étudiant la radioactivité des abeilles sacrifiées à la fin de chacun de ces temps. Les résultats sont exprimés en histogrammes dans la figure 3 .

On voit que le nombre d'abeilles radioactives augmente et que l'activité de chaque individu radioactif s'élève avec la durée des échanges, pour des durées de $\mathrm{I} / 2 \mathrm{~h}, \mathrm{r}$ h et $2 \mathrm{~h}$. Il y a plusieurs individus qui ne sont pas radioactifs et quelques-uns qui sont très 

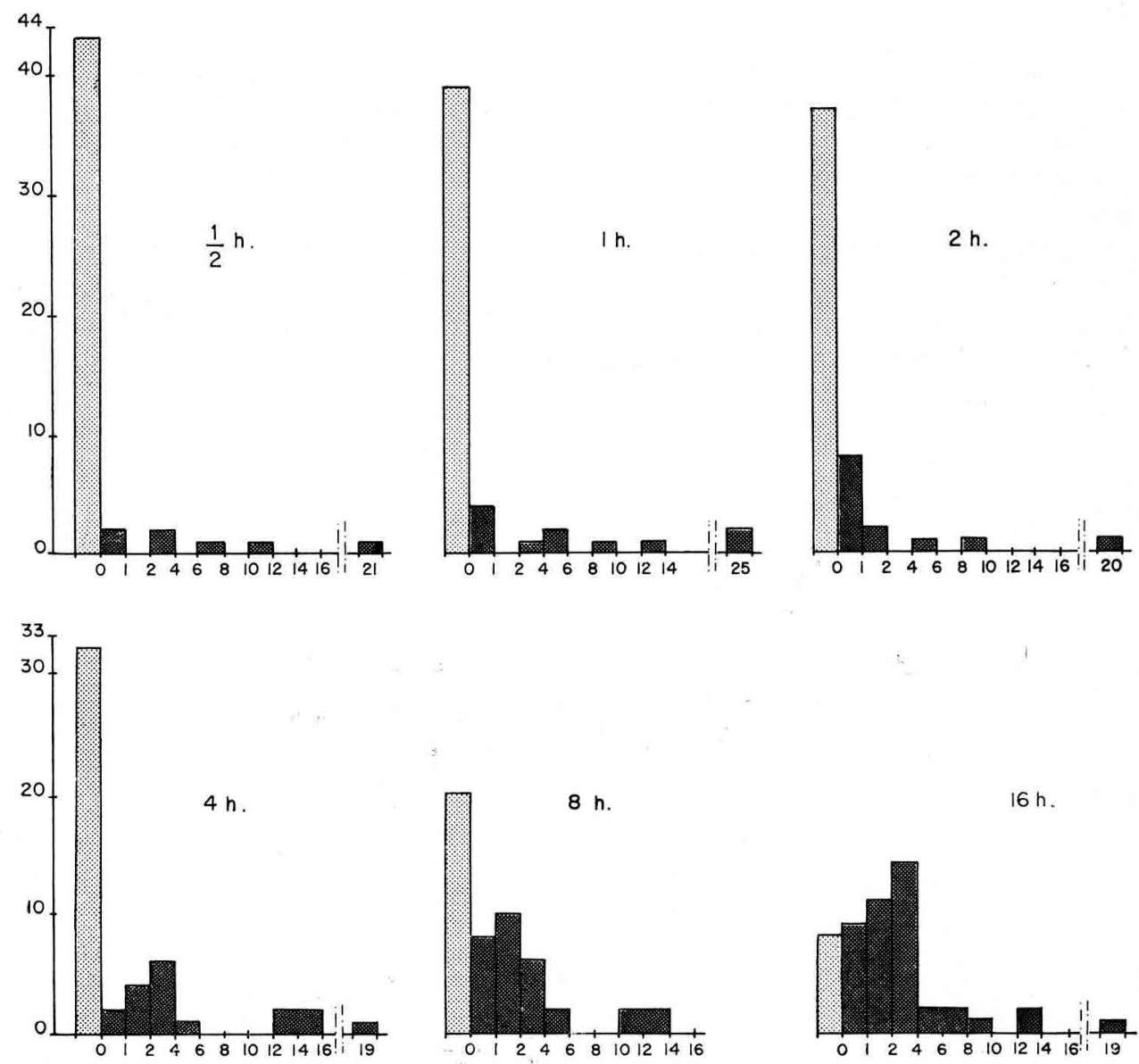

$16 \mathrm{~h}$.
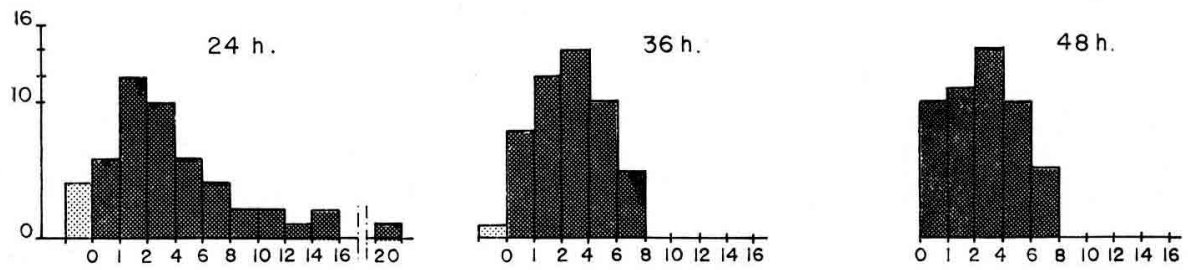

En ordonnée: Nombre d'abeilles "receveuses"

En abscisse: Radioactivité en pourcentage de lo radioactivité initiole de l'abeille "donneuse"

\section{Abeilles non radioactives}

Abeilles rodiooctives

Cette légende est valable pour l'ensemble des histogrammes

FIG. 3. - Répartition de la radioactivité de 50 abeilles receveuses en fonction de la durée des échanges avec une abeille donneuse 
faiblement radioactifs. Au bout de $4 \mathrm{~h}$ et $8 \mathrm{~h}$ le pourcentage d'abeilles radioactives est $36 \mathrm{p}$. Ioo et $60 \mathrm{p}$. Ioo respectivement. En mesurant le nombre d'abeilles radioactives, on constate que tout d'abord leur répartition est très hétérogène, quelques abeilles ayant une radioactivité très élevée et d'autres une radioactivité extrêmement faible ( $\left.{ }^{(}\right)$.

Après 24 heures, $92 \mathrm{p}$. Ioo des individus deviennent radioactifs mais la répartition de la radioactivité est encore hétérogène. Grâce à la régulation secondaire, la répartition au bout de 36 heures devient normale et moins hétérogène. Pour une période plus longue, de 48 heures, la répartition s'homogénéise en présentant un pic pour les faibles unités d'échanges $\left({ }^{2}\right)$ (fig. 4 ).

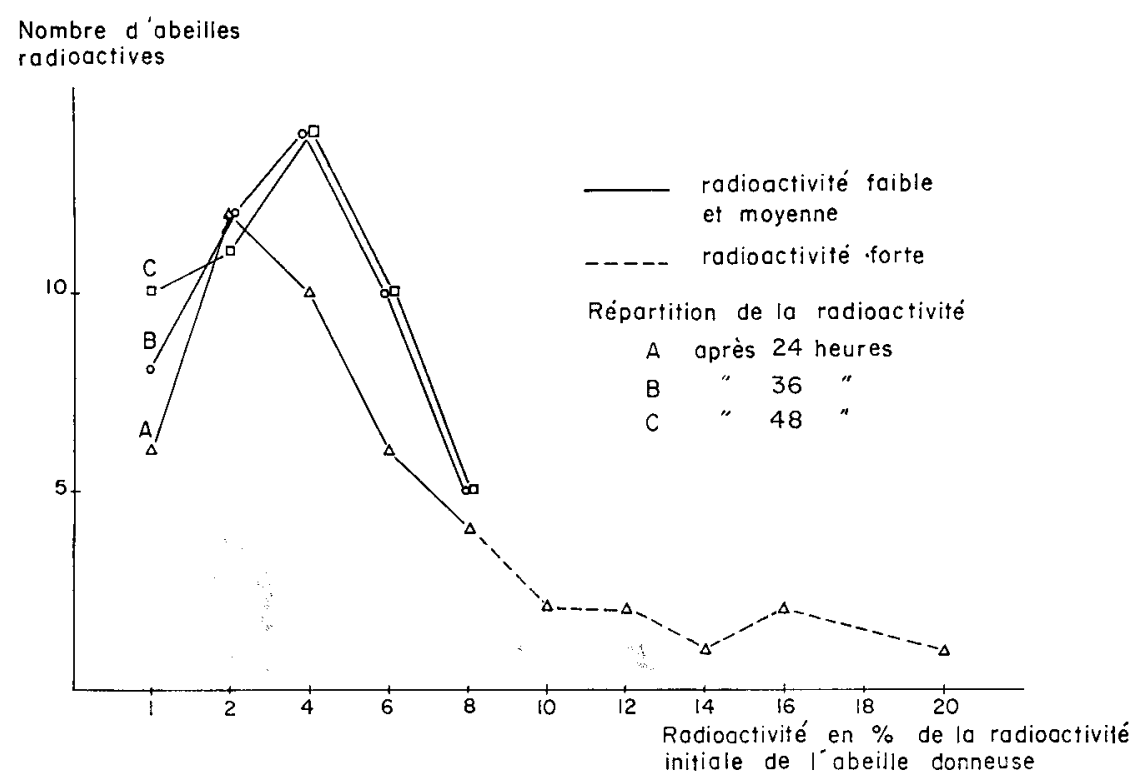

FIG. 4. - Evolution de la répartition de la radioactivité entre les 50 receveuses, nourries par une seule donneuse radioactive, en fonction du temps

\section{L'infuence de la température sur la trophallaxie chez les ouvrières d'abeille}

La température a une influence importante sur les activités de l'Abeille. Il est très rare qu'une abeille fasse un travail lorsque la température n'est pas comprise entre ro et $3^{\circ} \mathrm{C}$. Mais les abeilles ont la capacité remarquable de régulariser leur température. Dans une ruche contenant du couvain, l'abeille maintient une température de $35^{\circ} \mathrm{C}$ sur le couvain. En hiver, la température du thorax des abeilles oscille entre 20 et $35^{\circ} \mathrm{C}$, quelle que soit la température ambiante. Normalement elle reste aux environs de $29-3 \mathrm{I}^{\circ} \mathrm{C}$. Aussi nous avons voulu préciser l'influence des variations de la température sur les échanges de nourriture entre les jeunes abeilles. Nous tovons choisi pour cette étude les trois températures suivantes : $23^{\circ} \mathrm{C}, 3 \mathrm{I}^{\circ} \mathrm{C}$ et $37^{\circ} \mathrm{C}$. $\mathrm{L}$ ' $h y g r o-$

(1) On considère que l'intensité des échanges entre les receveuses est proportionnelle à leur radioactivité.

(2) Nous appelons unité d'échange le pourcentage de radioactivité des receveuses. 


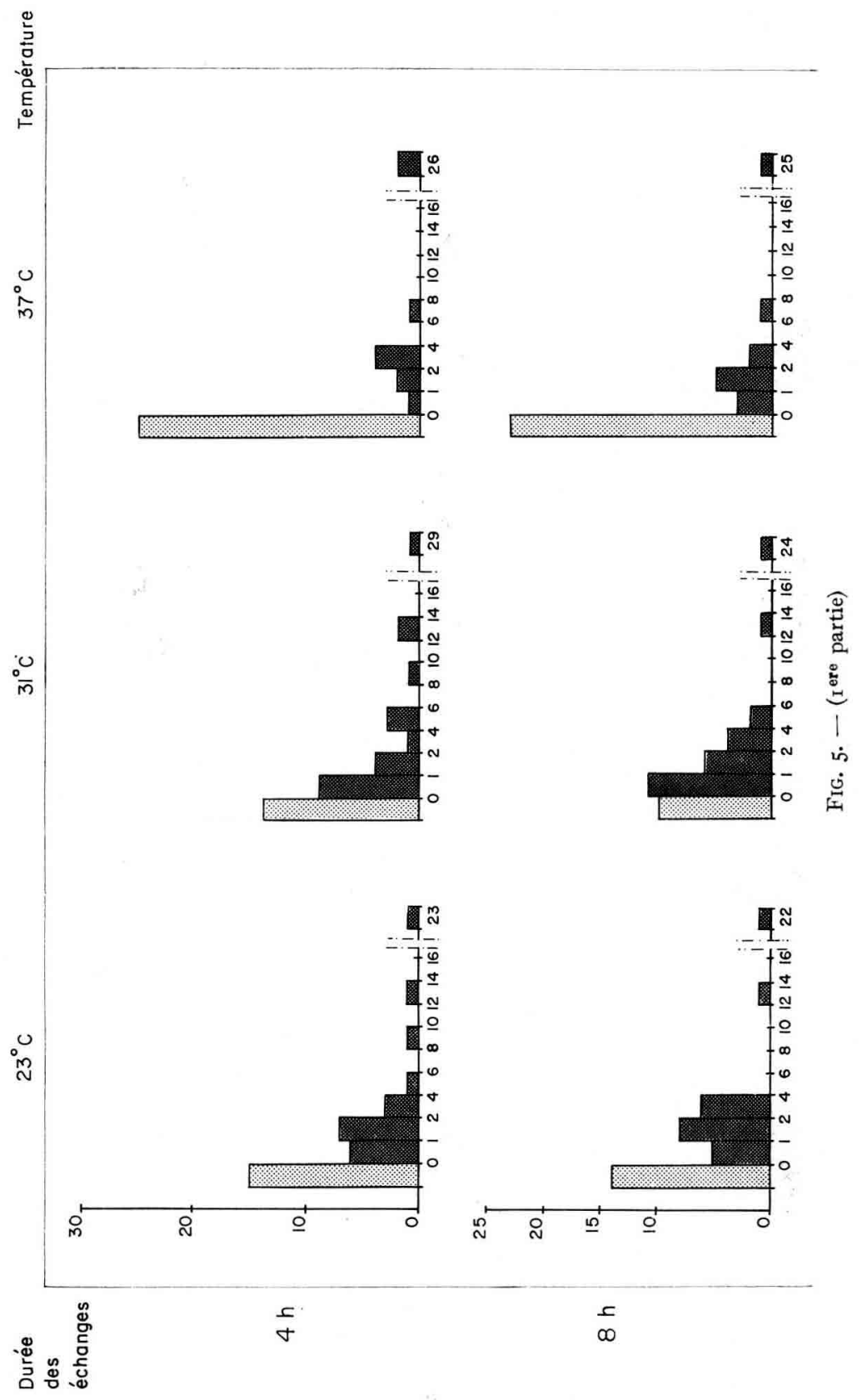


métrie a été toujours $7^{\circ} \mathrm{p}$. Ioo dans tous les cas. Dès leur naissance les abeilles sont élevées et gardées dans les cagettes à l'intérieur d'une étuve aux températures suivantes : $23^{\circ} \mathrm{C}, 3{ }^{\circ} \mathrm{C}$ et $37^{\circ} \mathrm{C}$. Nous avons utilisé pour nos expériences des abeilles âgées de 5 - 6 jours.

$23^{\circ} \mathrm{C}$
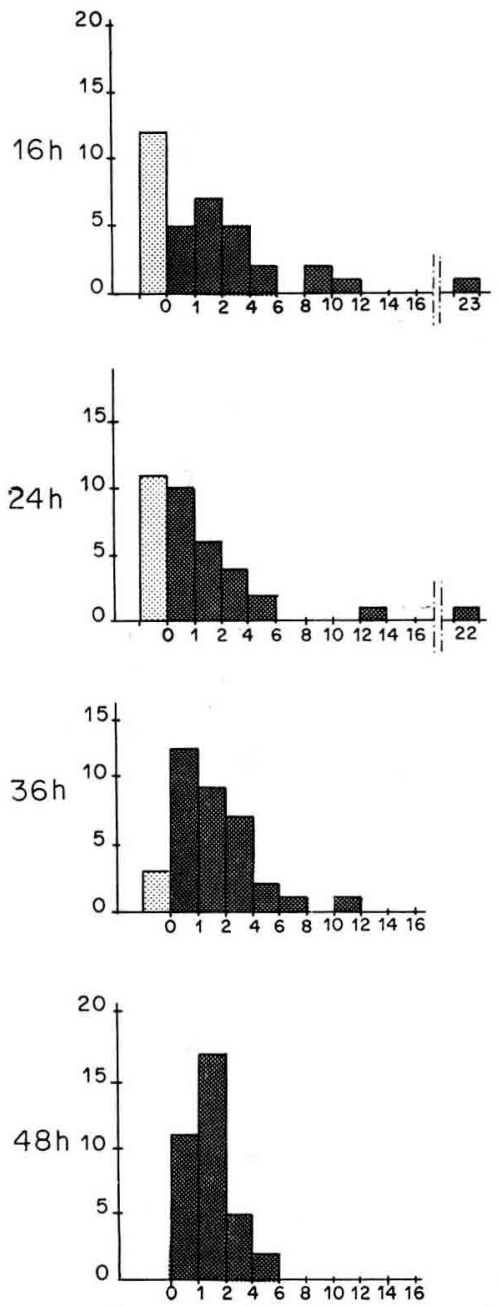

$31^{\circ} \mathrm{C}$
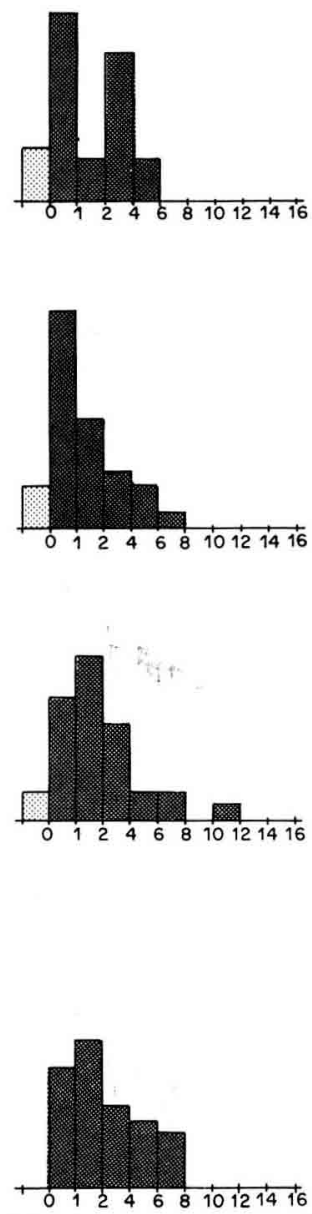
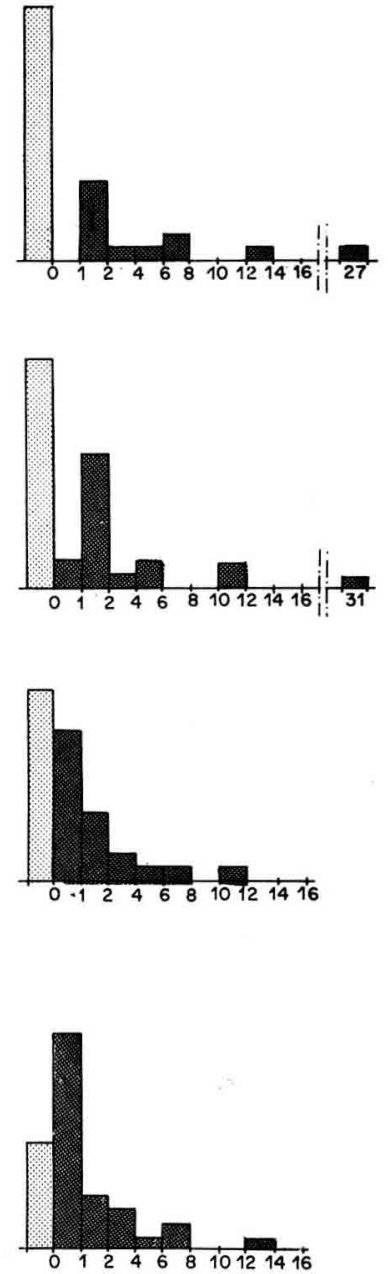

FIS. 5. - Réfarition de la radioachivité de 35 receveuses en fonction de la température 'l de la durée des échanges ar'tr une donmeluse

L'abeille donneuse qui a subi le même traitement a été nourrie avec du miel radioactif de la manière déjà décrite. Après avoir mesuré sa radioactivité, nous l'avons mise avec 35 abeilles receveuses dans une cagette "Liebefeld ". Nous avons mis du sucre candi et de l'eau dans chaque cagette. La cagette est placée dans l'étuve réglée à la température de $23^{\circ} \mathrm{C}, 31^{\circ} \mathrm{C}$ ou $37^{\circ} \mathrm{C}$ stuivant le cas. Pour chacune de ces températures 5 répétitions ont eu lieu. 
La répartition de la radioactivité a été mesurée après les durées d'échange suivantes : $4,8,16,24,36$ et 48 heures.

Des histogrammes (fig. 5) montrent l'évolution de la répartition de la radioactivité pendant 4 à 48 heures d'échanges en fonction de trois températures : $23^{\circ}, 3 \mathrm{I}^{\mathrm{e}}$ et $37^{\circ} \mathrm{C}$.

Résumant les résultats de cette figure, nous pouvons dire que la répartition de la radioactivité est sensiblement la même après 4 heures ou après 8 heures, mais il y a beaucoup plus d'abeilles non radioactives à $37^{\circ} \mathrm{C}$. Après un long contact avec la donneuse il y a beaucoup plus d'abeilles qui deviennent radioactives dans tous les cas. Ce phénomène est plus rapiđe à $3^{\circ} \mathrm{C}$ qu'à $23^{\circ} \mathrm{C}$ ou $37^{\circ} \mathrm{C}$. Il y a moins d'abeilles nonradioactives à $23^{\circ} \mathrm{C} q u^{\prime}$ à $37^{\circ} \mathrm{C}$. On voit que l'homogénéisation de la distribution de la radioactivité est faible à haute température $\left(37^{\circ} \mathrm{C}\right)$. Avec une durée d'échange de 48 heures, toutes les abeilles deviennent radioactives aux températures de $3 \mathrm{I}^{\circ} \mathrm{C}$ et $23^{\circ} \mathrm{C}$. Mais à $37^{\circ} \mathrm{C}$, il y a encore des abeilles non-radioactives.

Nous avons tracé les courbes représentant l'augmentation du taux d'abeilles radioactives au cours des 48 heures, pour les 3 températures 23,3 I et $37^{\circ} \mathrm{C}$ (fig. 6).

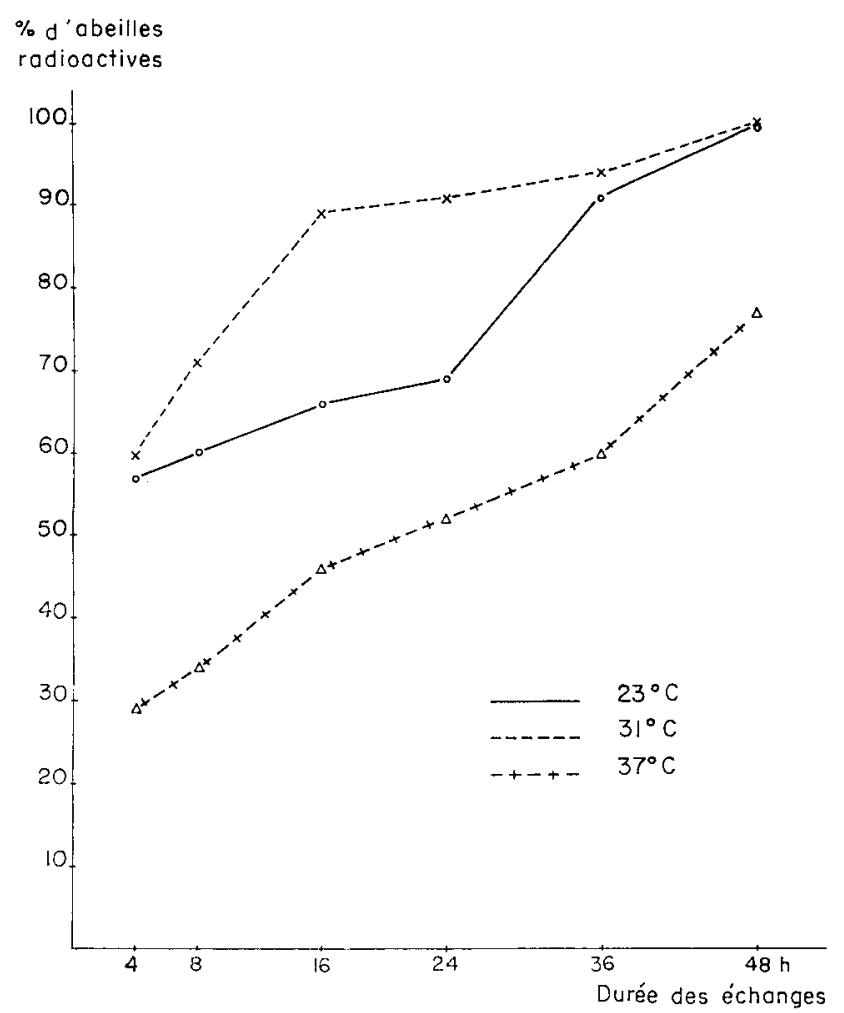

FIG. 6. - Evolution en fonction de la lempéralure du pourcentage d'abeilles ayant reçu de la nourriture radioactive d'une setule donneuse dans un groupe de 35

Nous remarquons :

$I^{0}$ que les taux d'abeilles radioactives les plus forts apparaissent à la température de $31^{\circ} \mathrm{C}$, alors que les plus faibles s'observent à $37^{\circ} \mathrm{C}$;

$2^{\circ}$ que la vitesse moyenne des échanges est identique à $3^{\circ}$ et $23^{\circ} \mathrm{C}(57$ et 60 p. Ioo 
d'abeilles radioactives au bout de 4 heures et roo p. Ioo au bout de 48 heures aux deux températures) ;

$3^{\circ}$ que la vitesse des échanges est beaucoup plus élevée les 24 premières heures à $3 I^{\circ} \mathrm{C}$ qu'à $23^{\circ} \mathrm{C}$.

Nous pouvons dire que la température ne produit pas les mêmes effets sur les échanges de nourriture et sur la consommation de nourriture. Ainsi FREE et SPENCERBooth (I958) ont mis en évidence l'augmentation de la prise de nourriture lorsque la température s'abaisse de $40^{\circ} \mathrm{C}$ à $I^{\circ} \mathrm{C}$, alors que nous avons observé les échanges de nourriture optimaux à $3^{\circ} \mathrm{C}$.

\section{Infuence de l'acclimatation à différentes températures}

Le phénomène de l'augmentation du métabolisme en fonction de la température est complexe chez 1'A beille du fait de la régulation thermique sociale. L'acclimatation à différentes températures, hautes ou basses, modifie très généralement le métabolisme des Insectes, quand on mesure celui-ci à une température moyenne, et perturbe leur mode de réaction aux changements thermiques. Les réactions d'acclimatation sont très variées et se traduisent aussi bien par une montée des échanges lors d'une exposition à des températures élevées ou basses (Formica rufa, Stomoxys calcitrans, Byrrhus pilula) que par une baisse dans les deux conditions (Ephestia kiihniella, Forficula auricularia) (AGRELL, I947).

FREE et SPENCER-BOOTH (I960) ont montré que les abeilles acclimatées à la même température au cours de leur expérience $\left(20^{\circ} \mathrm{C}\right.$ et $\left.35^{\circ} \mathrm{C}\right)$ ont consommé moins de nourriture le second jour que le premier jour.

L'acclimatation à $35^{\circ} \mathrm{C}$ d'abeilles préalablement maintenues à $20^{\circ} \mathrm{C}$, entraîne une plus forte consommation de nourriture que l'acclimatation à $20^{\circ} \mathrm{C}$ d'abeilles préalablement à $35^{\circ} \mathrm{C}$.

Cependant, si GunN et HopF (I943) ont trouvé que la température d'acclimatation a une influence sur l'activité de Ptinus tectos, Meli,anby (I939) a trouvé qu'elle n'en avait pas sur celle de Cimex lectularius.

Aussi nous avons voulu étudier l'influence de l'acclimatation à deux températures différentes sur les échanges de nourriture chez 1'Abeille. Nous avons choisi pour ces études, une température basse de $23^{\circ} \mathrm{C}$ et une température haute de $37^{\circ} \mathrm{C}$.

Les abeilles naissantes sont mises à l'étuve à $30^{\circ} \mathrm{C}$ pendant deux jours. Ces abeilles ont permis de réaliser deux séries d'expériences. Dans une première série elles sont maintenues à la température de $23^{\circ} \mathrm{C}$ et placées ensuite à $37^{\circ} \mathrm{C}$. Flles sont gardées en étuve pendant deux jours pour chacune de ces températures.

Dans la deuxième série, les abeilles sont maintenues à la température de $37^{\circ} \mathrm{C}$ et ensuite à $23^{\circ} \mathrm{C}$. Elles sont mises en étuve pendant deux jours à chacune de ces températures. Lorsque les abeilles des deux séries ont été acclimatées aux températures décrites, nous avons étudié les échanges de nourriture. Une "donneuse " est placée dans chacun de ces lots et mise en contact arec 35 " receveuses " traitées de la même façon. Elles sont gardées à l'étuve dans les conditions de l'expérience, c'est-à-dire à $23^{\circ} \mathrm{C}$ ou $37^{\circ} \mathrm{C}$. Nous avons étudié les échanges de nourriture en mesurant la réparti- 
tion de la radioactivité au bout de différentes périodes : 4, 8, I6, 24 et 36 heures. Les résultats sont résumés dans la figure 7 .

Au bout de 4 heures, nous voyons que la répartition de la radioactivité est très hétérogène dans chaque cas. Il $\mathrm{y}$ a de très nombreuses abeilles non-radioactives, quelques-unes faiblement ou fortement radioactives. La figure 8 montre les courbes de pourcentage d'abeilles radioactives. Nous voyons que dans le cas où les abeilles sont acclimatées d'abord à $37^{\circ} \mathrm{C}$, ensuite à $23^{\circ} \mathrm{C}$, le pourcentage d'abeilles radioactives est assez élevé (77 p. roo). Mais dans le cas oì les abeilles sont acclimatées d'abord à $23^{\circ} \mathrm{C}$ et ensuite à $37^{\circ} \mathrm{C}$, le pourcentage d'abeilles radioactives est faible (26 p. IOO).

Au bout de 8 heures, la répartition de la radioactivité devient homogène. Ce phénomène s'observe mieux dans le deuxième cas (quand les abeilles sont placées

Abeilies acclimotées successivement pendant 2 jours:

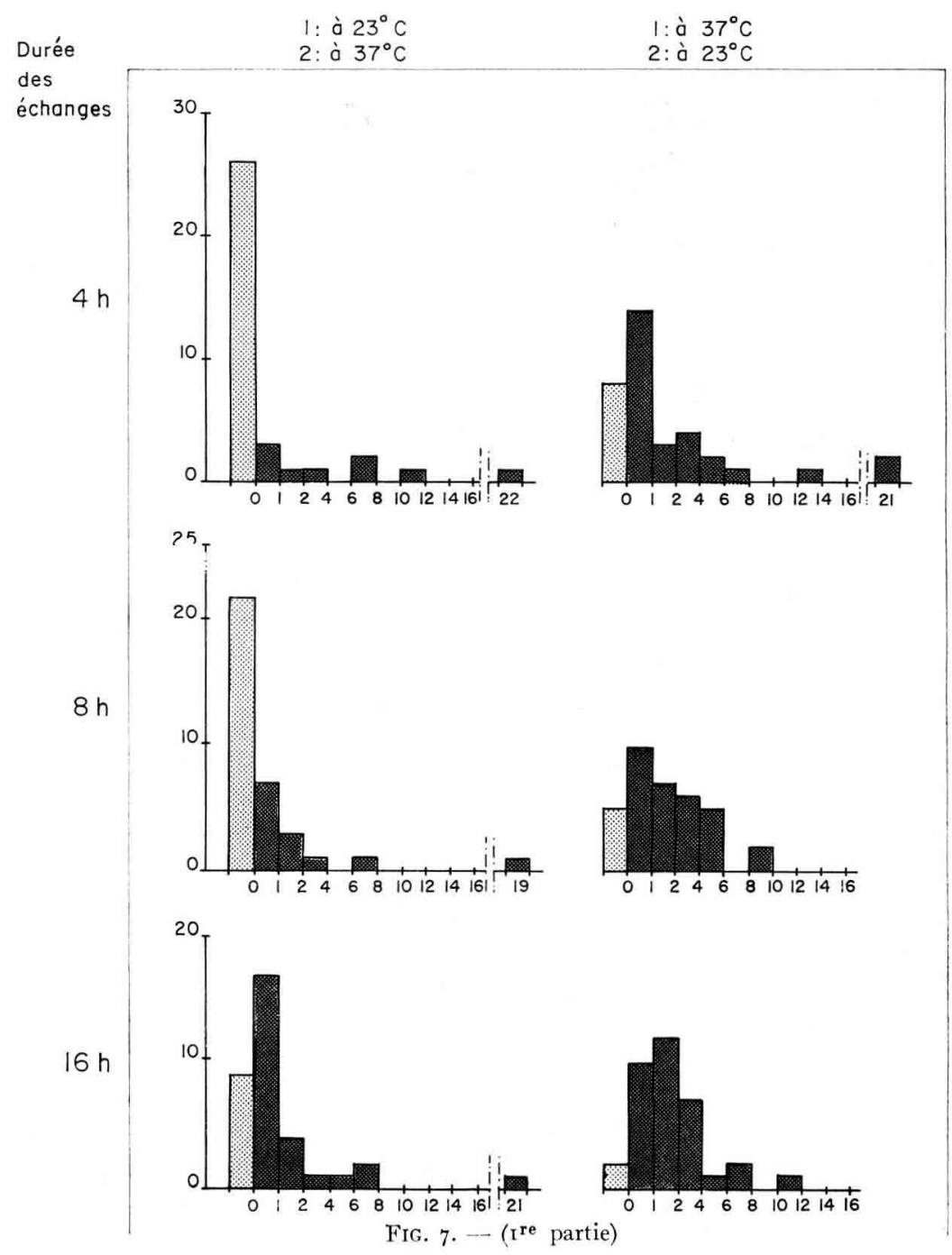



1: $23^{\circ} \mathrm{C}$
1: ̊̀ $37^{\circ} \mathrm{C}$
2: $\dot{\mathrm{a}} 37^{\circ} \mathrm{C}$
2: ¿̀ $23^{\circ} \mathrm{C}$
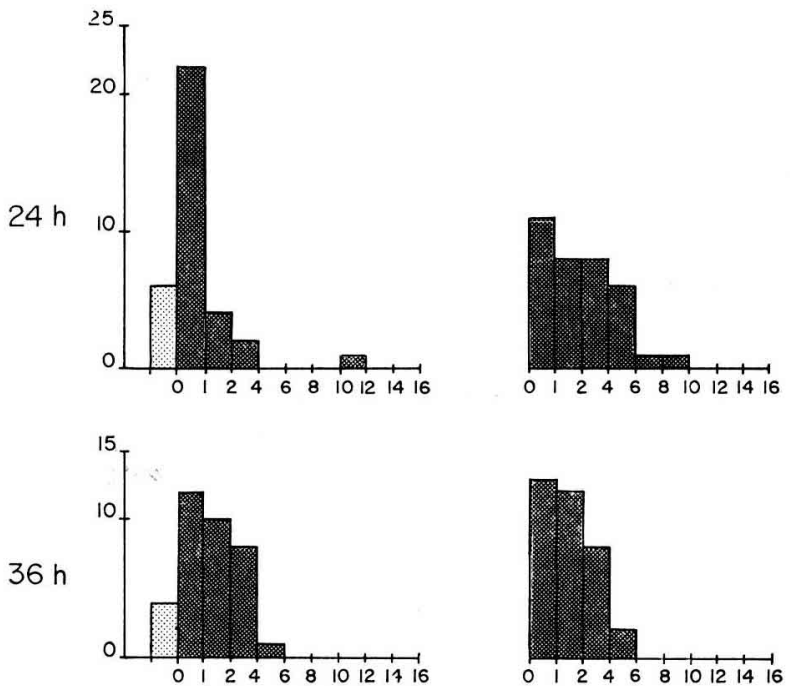

FIG. 7. - Répartition de la radioactivité de 35 receteuses selon les conditions d'acclinatation et selon la durée des échanges anec une donneuse soumise au méme traitement

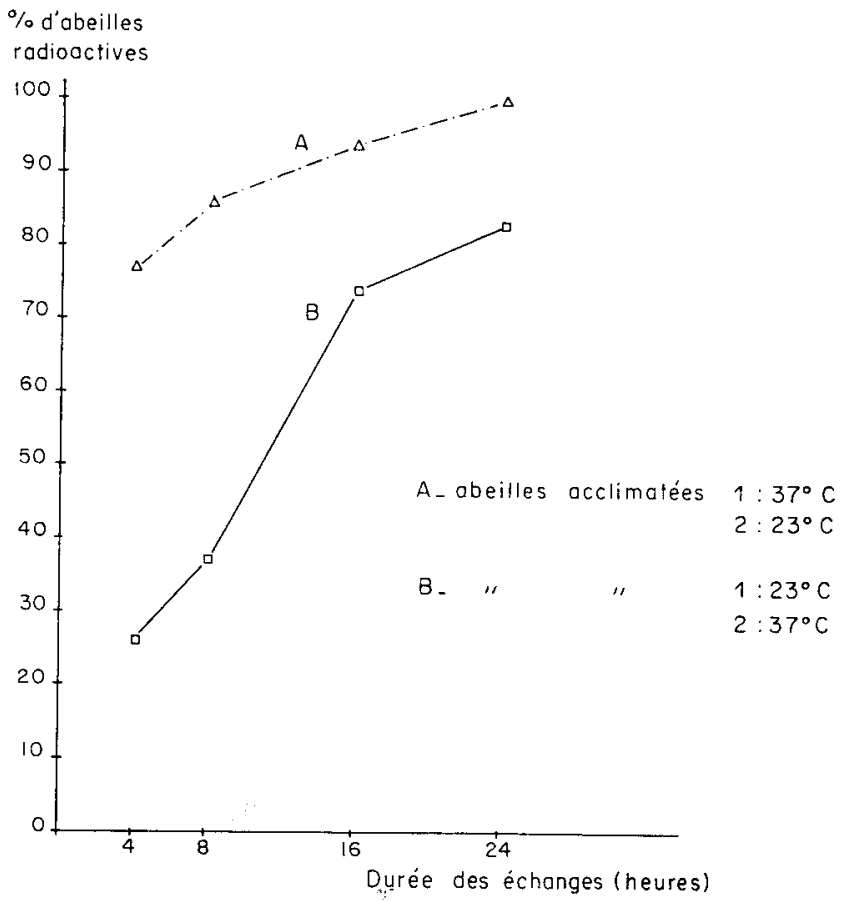

FIG. 8. - Courbes montrant l'infuence de l'acclimatation des abeilles à deux températures différentes et de la durée des échanges sur le pourcentage des abeilles recezeuses devenues radioacives 
d'abord à $37^{\circ}$, puis à $23^{\circ}$ ). On constate qu'il y a 86 p. roo d'abeilles faiblement ou moyennement radioactives.

Quand la durée des échanges augmente, c'est-à-dire, pour des durées de I6, 24 et 36 heures, la répartition de la radioactivité devient de plus en plus homogène. Mais pour chaque durée, nous voyons que le phénomène est plus net chez les abeilles placées d'abord à $37^{\circ} \mathrm{C}$. I lans ce cas, toutes les abeilles deviennent radioactives au bout de 24 heures, tandis que dan; le deuxième cas, il y a encore des abeilles nonradioactivers (II,4 P. IOO).

Fn comparant les résultats globaux, nous pouvons dire que la répartition de la radioactivité est plus rapide chez les abeilles qui ont été acclimatées d'abord à $37^{\circ} \mathrm{C}$, puis à $23^{\circ} \mathrm{C}$. L' acclimatation de $1^{\prime}$ Abeille à deux températures différentes a un effet sur les échanges de nourriture.

En nous basant sur le travail de Frek et SPExCER-BOoTh (Ig60) concernant les effets d'acclimatation des abeilles à la même température et à deux températures différentes sur la consommation de nourriture, nous présenton; (figure 9) l'en-

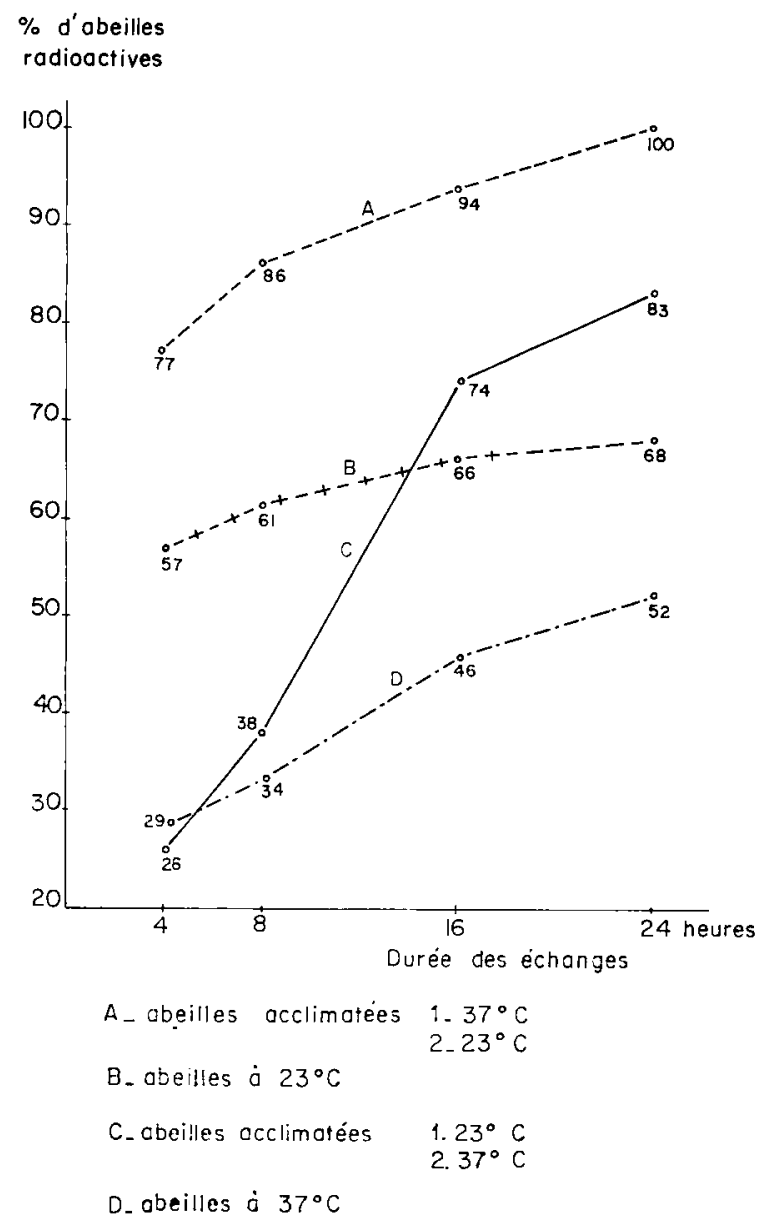

Fic. 9. --. Comparaison des pourcenlages l'abeilles radioactives pour deux lempératures et deux types dactimatalion 
semble des courbes des échanges de nourriture à une même température $\left(23^{\circ} \mathrm{C}\right.$ ou $37^{\circ} \mathrm{C}$ ) et après une acclimatation des abeilles à ces deux températures, successivement.

Si nous comparons les courbes $\mathrm{A}$ et $\mathrm{B}$, nous voyons que le pourcentage d'abeilles radioactives est plus élevé pour toutes les durées d'échange dans le cas où les abeilles sont acclimatées. On observe le même phénomène avec les courbes $\mathrm{C}$ et $\mathrm{D}$. Même les vitesses de transmission de la radioactivité sont plus grandes chez les abeilles acclimatées à 2 températures différentes que chez les abeilles maintenues à la même température. On constate qu'il y a Ioo p. Ioo d'abeilles radioactives au bout de 24 heures dans le cas où les abeilles sont acclimatées d'abord à $37^{\circ} \mathrm{C}$, puis à $23^{\circ} \mathrm{C}$, et seulement 68 p. Ioo dans le cas où les abeilles sont maintenues à la même température $\left(23^{\circ} \mathrm{C}\right)$.

Au bout de 24 heures, il y avait 83 p. roo d'abeilles radioactives dans le cas ò̀ les abeilles sont acclimatées à $23^{\circ} \mathrm{C}$ puis à $37^{\circ} \mathrm{C}$ au lieu de $5^{2} \mathrm{p}$. Ioo d'abeilles radioactives dans le cas oì elles avaient été maintenues toujours à la température de $37^{\circ} \mathrm{C}$.

Ainsi nous confirmons que l'acclimatation à $23^{\circ} \mathrm{C}$ d'abeilles préalablement maintenues à $37^{\circ} \mathrm{C}$, entraîne une plus forte intensité d'échanges de nourriture que l'acclimatation à $37^{\circ} \mathrm{C}$ d'abeilles préalablement maintenues à $23^{\circ} \mathrm{C}$.

\section{IV. - L'INFLUFNCE DU NOMBRE DES ABEILLES PRÉSENTES \\ DANS UN GROUPE SUR LA RÉPARTITION DE LA NOURRITURE}

Chauvin et Grassé (I944) ont montré que les Insectes sociaux, et spécialement les Abeilles, ne supportent pas l'isolement et meurent en très grand nombre quand on les sépare de leur groupement social.

Chauvis (I952) a étudié l'effet de groupe en administrant du sirop de sucre à $20 \mathrm{p}$. IoO comme nourriture aux abeilles, isolées ou groupées. Il a constaté que la mortalité était inversement proportionnelle à l'importance du groupe, surtout pour les groupes de I0, 20 et 30 abeilles; dans les groupements de densité inférieure elle restait supérieure ou égale à celle des abeilles isolées.

La durée de vie des abeilles en groupe, dans des conditions normales ou seminormales, a été étudiée par de nombreux auteurs, tels que NickEL et MaUrizio (revue dans Maurizio, I946). Le travail de Chauvin et Grassé (I952) a démontré que les abeilles isolées vivent en moyenne moins de $\delta$ jours et qu'il faut un nombre minimum de 30 individus pour retrouver une longévité normale. Ils ont montré que la longévité accrue provient d'un effet du groupement fondé sur un échange continuel de substances vitaminées dans la Société.

Nous avons pensé qu'il était nécessaire de rechercher l'influence du nombre des ouvrières présentes sur les phénomènes que nous étudions.

\section{Infuence du nombre des "receveuses"}

Les études de GösswaLd et KLofT (1963) ont porté sur le genre Formica ( $F$. rufa L., $F$. polyctena FOERST., $F$. pratensis RETz (syn. $F$. nigricans EM., $F$. cordieri IBONDR). Ils ont observé que si 1'on place une ouvrière, venant de se nourrir, dans un groupe d'individus à jeun, la donneuse apporte directement par régurgitation du contenu du jabot la majeure partie de la nourriture de $6-8$ ouvrières. La première receveuse de nourriture agit comme une donneuse secondaire et ainsi de suite, les échanges de 


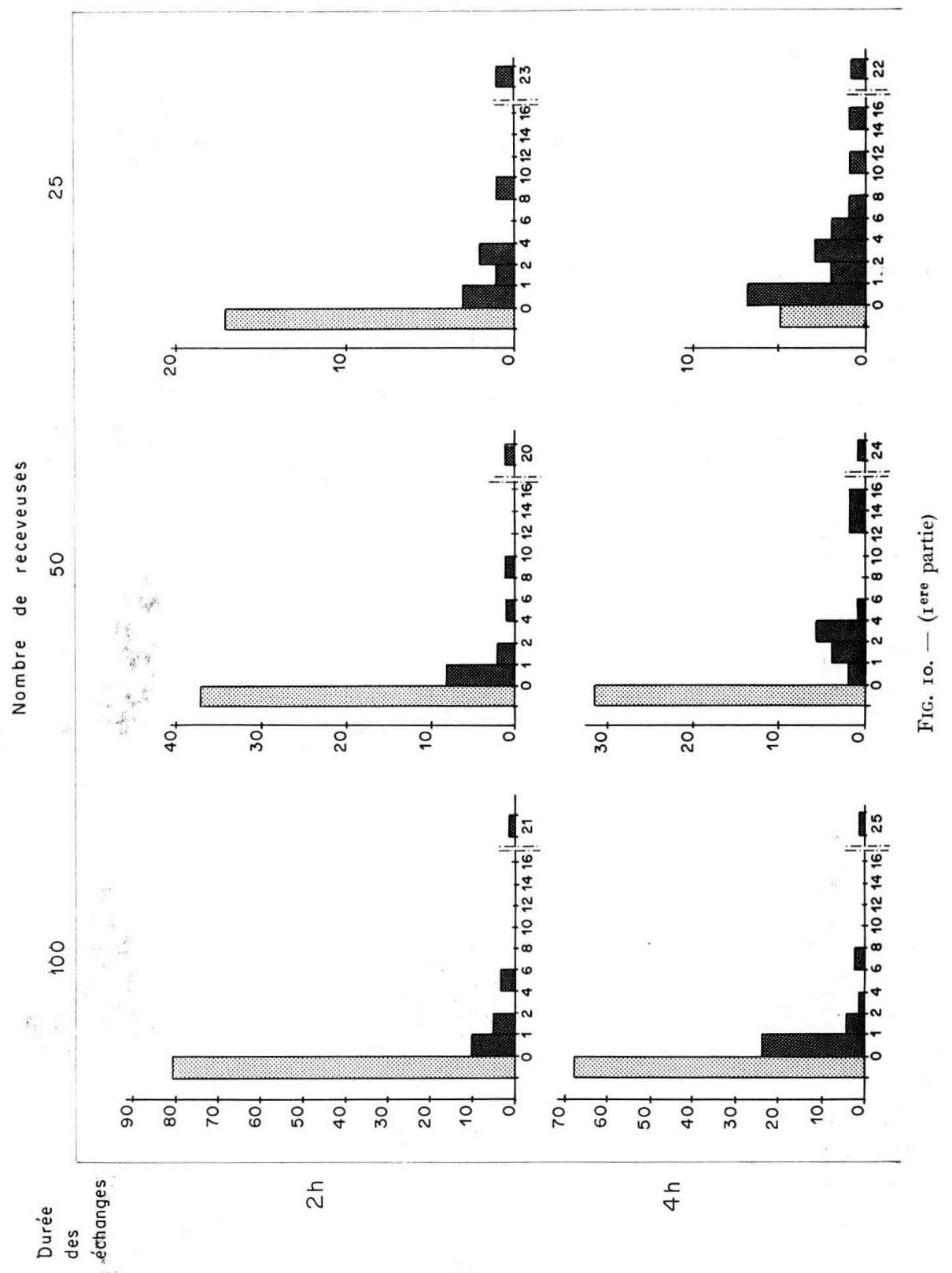



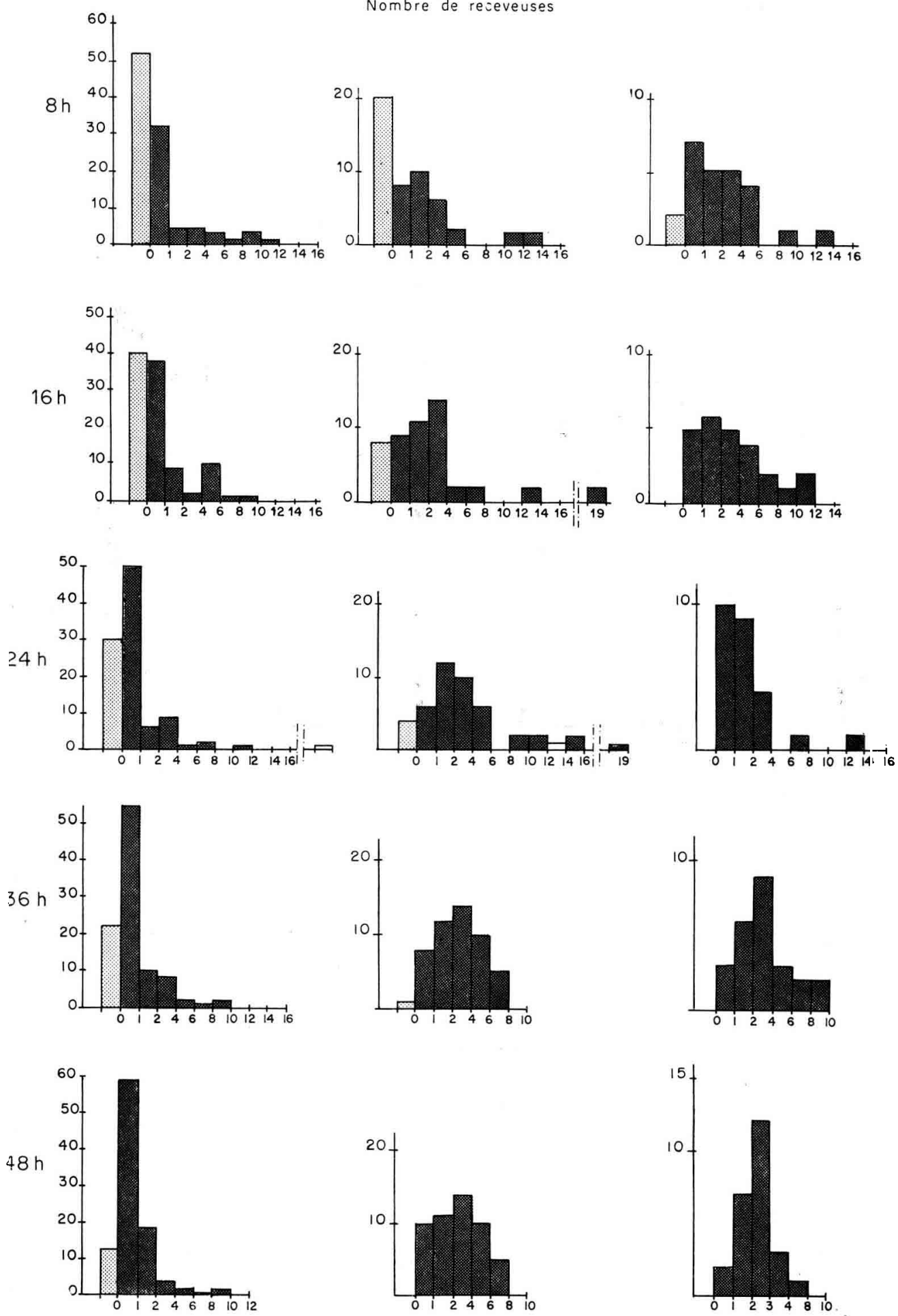

FIG. Io. Répartition de la radioactirité des receveuses

"n fonclion da nombre de celles-ci el de la dwre des échanges avec une donneuse 
nourriture s'effectuent dans une chaîne alimentaire multilatérale. Ils ont trouvé que 80 ouvrières peuvent profiter du contenu d'un seul jabot. Chez les ouvrières d'abeille domestique ils ont trouvé que le contenu d'un jabot était distribué à 50 individus (la consommation individuelle de nourriture étant plus forte que chez les fourmis $($ jabot $\rightarrow$ intestin moyen $\rightarrow$ résorption)). A température constante, la répartition de la nourriture est une fonction exponentielle du temps jusqu'à un maximum (environ 80 individus au bout d'un certain temps). Ils ont constaté que la plus haute fréquence d'échange de nourriture est atteinte à $25-30^{\circ} \mathrm{C}$. Plus le groupe d'individus est important et plus nombreux sont les individus qui deviennent radioactifs.

En ce qui concerne les abeilles, l'influence du nombre des receveuses sur les échanges de nourriture n'avait pas été étudiée avant que nous commencions notre travail.

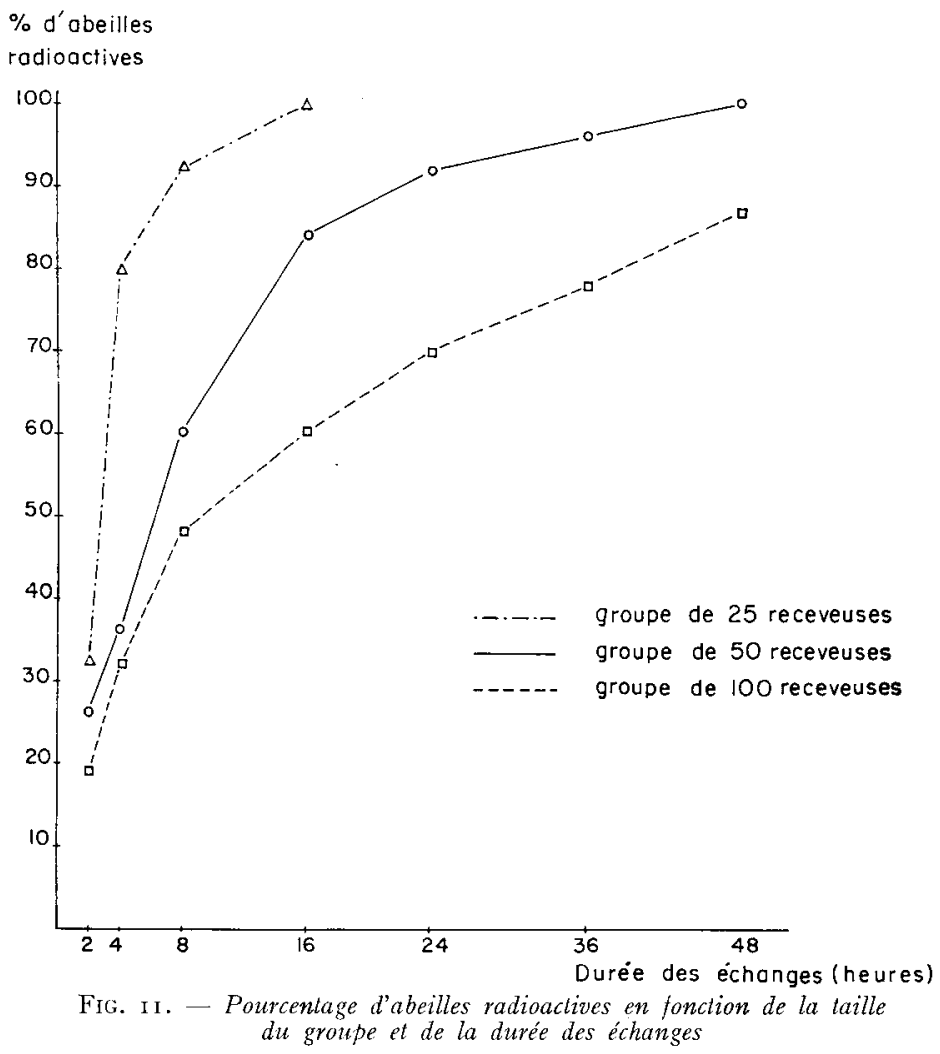

Des abeilles âgées de 5-6 jours ont été utilisées pour nos expériences. Une abeille marquée de la manière déjà décrite a été introduite dans des groupes d'abeilles receveuses plus ou moins importants. Nous avons choisi les nombres de receveuses : roo, 50 et 25 . La donneuse et les receveuses ont été mises dans la cagette de Liebefeld et gardées à l'étuve pendant les périodes de 2, 4, 8, I6, 24, 36 et 48 heures.

Nous avons étudié la répartition de la radioactivité au bout de chacune de ces périodes sur les individus préalablement sacrifiés. L,es figures ro et I m montrent la distribution de la radioactivité entre les Ioo, 50 et 25 receveuses. 
Afin de nous rendre compte de l'hétérogénéité de la radioactivité nous avons dressé le tableau 4 à partir de ces histogrammes. Dans ce tableau, nous considérons qu'entre $o$ et 2 p. Ioo, la radioactivité est faible, entre 2 et 8 p. Ioo, elle est moyenne, entre 8 et $\mathrm{I}_{4}$ p. Ioo, elle est forte.

TABLEAU 4

Répartition de la radioactivité en fonction du nombre des receveuses et durće des échanges

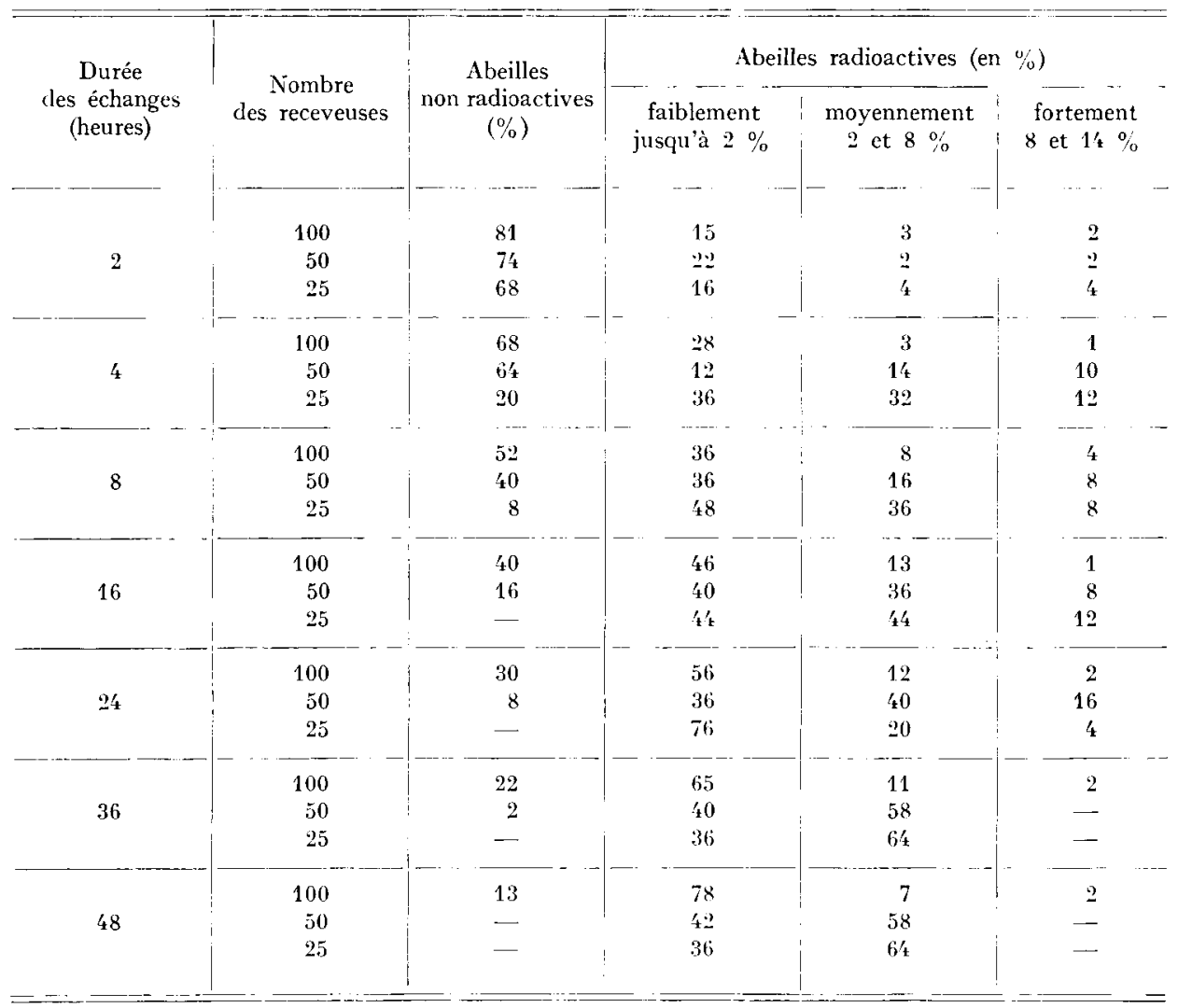

Ia comparaison des résultats au bout de chaque période, c'est-à-dire $2,4,8$, I $6,24,36,48$ heures, nous permet de dire que la répartition de la radioactivité est plus rapide dans le groupe de 25 receveuses que dans les groupes de 50 et roo. Au bout de 16 heures, toutes les receveuses du groupe de 25 deviennent radioactives.

Dans les groupes de 50 et roo la répartition est plus lente. Au bout de 48 heures, toutes les receveuses du groupe de 50 deviennent radioactives, mais dans le groupe de $I 00$ receveuses, il y en a encore $\mathrm{I} 3 \mathrm{p}$. Ioo qui ne sont pas radioactives.

Lorsque la durée des échanges augmente, la répartition de la radioactivité est de plus en plus homogène dans tous les cas. La vitesse de répartition diminue successivement pour les groupes de 25,50 et Ioo receveuses. 
Comme la consommation individuelle de nourriture est forte chez l'Abeille, le groupe de 25 recevetuses est nourri plus facilement par une donnetse que les groupes plus importants.

\section{Influence du nombre des "donneuses "sur la répartition de la radioactivité chez les receveuses}

ALIBERT (I959) a montré qu'il fallait mettre un termite radioactif au contact de Io termites normaux pour que le phosphore puisse se répartir dans tout le groupe en 30 heures environ. Elle a montré que la rapidité et l'importance des échanges « alimentaires " variaient avec le nombre d'individus peuplant la colonie des termites. Les colonies plus âgées groupant 200 à 300 individus montrent un ralentissement des échanges alimentaires.
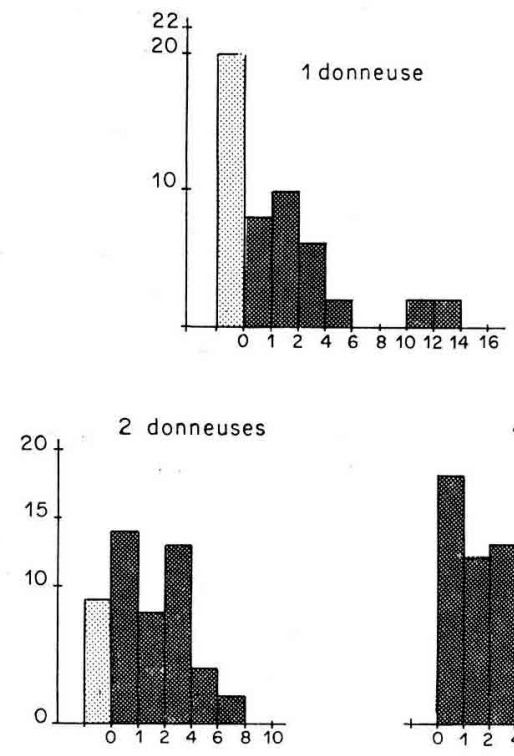

4 donneuses
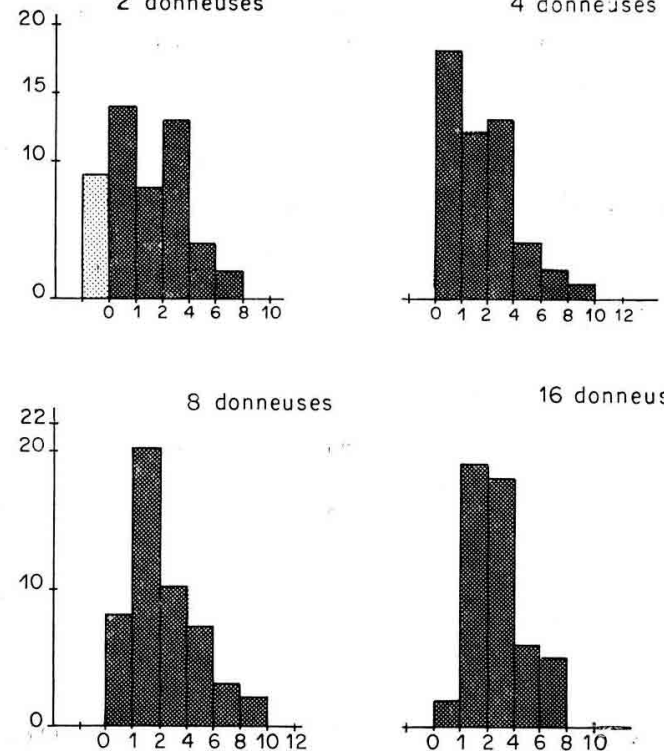

16 donneuses

FIG. I2.- Réparlition de la radioactivité de 50 receveuses en foncion du nombre de donneuses après 8 heures d'échanges

Gösswal,D et KL,OFT (I963) ont montré que le taux de distribution de nourriture chez les fourmis augmente progressivement avec le nombre des donneuses.

KNEITz (I96I) a étudié, chez Formica rufa, la répartition de la nourriture. Il a 
montré que si on augmente l'offre de nourriture par l'introduction de $\mathrm{I}, 2,4,8$ ou I 6 individus donneurs marqués dans un groupe de receveuses, de même importance, la répartition de la radioactivité est meilleure lorsque les donneurs sont plus nombreux.

Nous avons fait des expériences pour étudier dans quelle proportion la répartition de nourriture augmentait.

Quatre séries d'expériences ont été faites avec différents nombres de donneuses. Nous avons choisi comme nombre de donneuses marquées $2,4,8$ et I6, le nombre de receveuses a toujours été 50 . Ia répartition de nourriture parmi ces dernières a été comparée avec celle obtenue avec une seule donneuse marquée dans un groupe de 50 receveuses. Nous avons étudié l'échange de nourriture au bout de 8 heures en mesurant la radioactivité des individus préalablement tués. La figure I2 montre la distribution de la radioactivité entre les 50 receveuses à la fin des échanges.

Afin de nous rendre compte de l'hétérogénéité de la radioactivité nous avons dressé le tableau 5 à partir de ces histogrammes. D'après le tableau nous voyons que dans les cas où nous avons placé une ou deux donneuses, un certain nombre d'abeilles n'est pas contaminé (surtout lorsqu'il n'y a qu'une donneuse). D'autre part, l'hétérogénéité de la répartition des abeilles radioactives décroît lorsque le nombre des donneuses augmente, la meilleure homogénéité est obtenue en plaçant dans la cagette I6 abeilles donneuses. Ainsi l'augmentation de la vitesse de la transmission de nourriture résulte de l'accroissement du nombre de donneuses.

TABLEAU 5

Répartition de la radioactivité entre les "receveuses" en fonction du nombre des "donneuses"

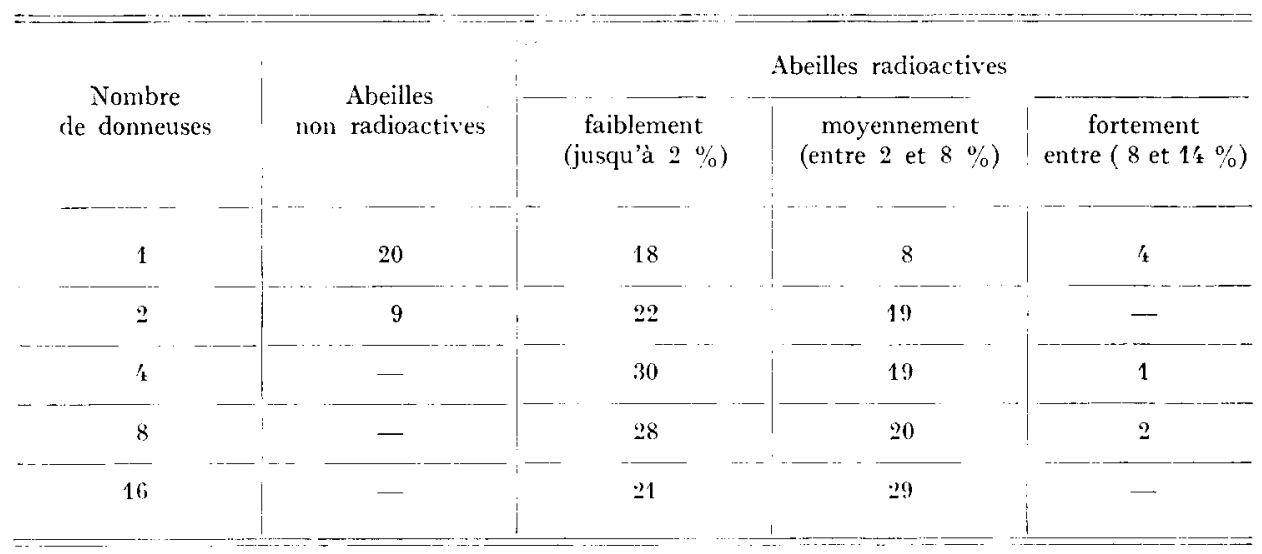

V. - LES F́CHANGES DE NOURRITURE ENTRE, DES OUVRIËES

\section{APPARTENANT A DES COLONIES DIFFÉRENTES}

Le problème des échanges de nourriture entre deux ou plusieurs colonies d'insectes sociaux a souvent attiré l'attention des chercheurs qui ont voulu en étudiant ce comportement, caractériser le degré de fermeture de la colonie. 
L'utilisation des radio-isotopes a ainsi permis de mettre en évidence des phénomènes qui seraient restés ignorés sans aucun doute.

On peut ainsi citer un certain nombre de travaux portant sur les Fourmis. KANNowski (I959) a voulu savoir en utilisant le ${ }^{32} \mathrm{P}$ pour marquer des ouvrières de Lasius minutus, si les "monticules " de terre apparents à l'air libre étaient l'cuvre d'une seule colonie ou de plusieurs. Au cours de cinq essais, il fut possible de préciser qu'une colonie pouvait posséder selon les cas un seul ou plusieurs " monticules ». Quand plusieurs de ces structures sont en connection, la radioactivité apparaît parmi des ouvrières occupées à la construction, six à huit heures après le marquage initial.

MORTREUIL et BRAIER (I962) ont étudié, à l'aide du radio-phosphore, le domaine vital de plusieurs fourmis africaines, en particulier de Pheidole megacephala F. Ces recherches réalisées dans le but de préciser le rôle joué par les fourmis dans le développement d'une cochenille Pseudococcus brevipes CKLr, dans les plantations d'ananas, ont permis de préciser le rôle et les dimensions du réseau dense de galeries superficielles ou profondes servant de liaison entre le nid principal et les nids secondaires et des chemins d'exploitation des végétaux.

Les fourmilières polygynes de Formica polyctena ont la propriété de former très facilement des colonies filles reliées à la colonie mère et entre elles par des pistes souvent très nettes où circulent une grande quantité de fourmis transportant des proies, du couvain ou même des reines (RAIGNIER, I940). La transmission de radioisotopes fournis à une colonie sous forme de solution dans un liquide sucré a été observée par GössWAL, et KLOF'T ( 1964 ) à plusieurs reprises ; 1'exemple le plus remarquable étant la transmission de la radioactivité à plus de 200 mètres, à partir d'une colonie artificiellement renforcée de Formica polyctena.

En I 960, GösswaLD et KLOFT ont découvert les échanges entre Fourmis d'espèces différentes, appartenant toutes au genre Formica (polyctena, rufa, pratensis). Les échanges paraissent aussi faciles de polyctena à rufa que dans le sens opposé.

Cependant, ces auteurs, bien qu'ayant souvent obtenu au laboratoire des échanges de nourriture entre individtus appartenant à différentes espèces, n'ont pu faire les mêmes observations sur le terrain. Chauvin, Courtors et LecomTe (Ig6r) ont, par contre, observé de tels échanges. Au cours du marquage d'une colonie de Formica polyctena, il était possible d'observer une transmission indéniable intéressant trois colonies de $F$. rufa situées à une cinquantaine de mètres. Cette transmission observée à deux reprises est certaine, les expériences de contrôle ayant démontré qu'il ne pouvait s'agir d'une contamination fortuite.

Par la suite, CourTors et LECOMTE (I962), en effectuant le marquage d'une colonie de $F$. polyctena, ont pu constater un phénomène intéressant de division du travail. Dans ce dernier cas, le sirop de sucre contenant le radio-élément n'a pas été placé sur le dôme de la fourmilière, mais à l'extrémité d'une piste, à environ $5^{0}$ mètres du point de départ. Dans ces conditions, il est frappant de constater la relative pauvreté des échanges entre les ouvrières travaillant sur les autres pistes. Ces échanges sont d'autant plus réduits que les pistes se trouvent plus éloignées de celle où la substance radioactive a été distribuée.

Iin i963, Chauvin et LEcomte, profitant de la période courte de ${ }^{198} \mathrm{Au}$, ont entrepris une étude systématique des échanges de nourriture dans un complexe de colonies de $F$. polyctena en pleine évolution. De la fin de mai au début octobre, il fut 
possible d'effectuer quatre marquages. Il semble que la tendance à donner de la nourriture varie selon les colonies, d'autre part il n'y a pas de corrélations marquées entre l'activité des ouvrières sur les pistes de jonction et les quantités de radioisotopes transportées. Ce qui s'accorde bien avec l'idée " d'équipes de travail " distinctes à l'intérieur d'un même nid.

Chauvin et Liecomte (I964) ont observé que le transport d'isotopes ( ${ }^{198} \mathrm{Au}$ ) entre les colonies filles de Formica polyctena, à partir d'une des colonies marquées suit des voies préférentielles, malgré l'activité des butineuses plus ou moins également réparties entre les fourmilières. Certaines colonies procèdent à des échanges actifs de glucides et d'isotopes, d'autres ne reçoivent rien ou presque rien. Le transport est limité d'ailleurs à une petite fraction de la quantité totale qui a été distribuée.

Le niveau d'activité des échanges entre une fourmilière-mère et une fourmilièrefille néoformée est extraordinairement élevé. La relative indépendance des échanges et du nombre de fourmis présentes sur les pistes doit être signalée une fois de plus, puisque entre la fourmilière-mère et la fourmilière-fille n'existait aucune circulation de fourmis nettement décelable alors que les échanges étaient pourtant actifs (CHAUVIN et L,ECOMTE, I965).

En I966, ces mêmes auteurs ont étudié de la même façon les échanges de matériel protidique s'effectuant entre fourmilières de Formica polyctena. Ceux-ci sont beaucoup moins actifs que les échanges glucidiques.

Montagner et Courtors (I963) ont montré chez les Vespides le rôle essentiel de l'olfaction ou de la gustation, dans la reconnaissance des individus de la même société. Étudiant l'influence de l'odeur sur les échanges alimentaires entre les nourrices et les soeurs d'une part et les étrangères venant de la même espèce, mais issues de colonies différentes, ils ont démontré l'existence d'une attraction préférentielle des nourrices vers les ouvrières sœurs, en compétition avec les ouvrières étrangères. Ėn I966 MoNTAGNé étudiant le rôle de la chimiosensibilité a constaté que les nourrices sont toujours massées du côté des sœurs et que, de part et d'autre, il règne une grande fébrilité : les insectes tentent continuellement d'entrer en communication par leurs antennes et leurs mandibules. İ̀n revanche, les ouvrières étrangères ne sont pas l'objet d'une telle attraction, les nourrices ne venant les contacter que sporadiquement.

In ce qui concerne les abeilles dont les colonies sont de type fermé, on a souvent mis en relation l'agressivité intraspécifique et la rareté des échanges alimentaires entre colonies avec des différences d'odeur. I a même hypothèse a d'ailleurs été faite en ce qui concerne les fourmis.

Un certain nombre de chercheurs, dont VON BUTTEI-REEPEN (I900), PHIIIPS (I928), Herrod-Hempsai, (I930) et Snelgrove (I940) pensent que toute colonie d'abeilles possède sa propre odeur (qui provient de l'odeur individuelle du corps de ses membres), ce qui peut expliquer le mécanisme de l'identification cles individus d'une colonie entre enx.

Cependant, KaImUs et RiBibaxns (I952) ont reproduit et complété les expériences de VON Frisch et Rösch (1920) et ont montré que les butineuses d'une colonie d'abeilles après avoir trouvé une source de nourriture abondante, émettent une odeur remarquablement persistante, plus attractive pour les butineuses de leur propre colonie que pour celles des autres.

Kalmus et RibBands (I952) ont montré dans leurs expériences effectuées avec les butineuses que les abeilles de chaque colonie ont leur propre odeur que les buti- 
neuses reconnaissent et préfèrent à celles produites par les membres des autres colonies.

KHALIFMAN (I955) signale dans un de ses ouvrages que les abeilles distinguent leurs sœurs d'abeilles provenant d'une autre ruche. Il s'appuie pour cela sur une expérience consistant à mettre dans une cagette triple dont les compartiments sont séparés par des grilles, trois lots d'abeilles : un dans le compartiment central avec nourriture à sa disposition ; les deux autres constitués, l'un par les abeilles venant de la même ruche, l'autre venant d'une autre ruche, dans les compartiments latéraux dépourvus de nourriture. Il constate qu'en vingt-quatre heures la mortalité est trois fois moins importante chez les sœurs que chez les étrangères; cette différence s'annulant au bout de trois jours.

L,ECOM'TE (I96r) s'est livré à une étude des relations pouvant exister entre l'odeur commune supposée et 1'agressivité entre colonies. De ses conclusions nous tirons que la reconnaissance d'une ouvrière par une autre en tant qu'étrangère s'effectue bien grâce à des stimuli olfactifs. Lorsqu'on place des ouvrières en provenance de la même ruche dans deux cagettes, il se crée une différenciation qui varie proportionnellement avec le temps passé depuis la séparation et qui se répercute sur l'intensité des phénomènes agressifs lors de la réunion.

La différenciation se crée quand les ouvrières des deux groupes n'échangent pas de nourriture et seulement dans ce cas. Deux groupes d'ouvrières capturées dans la même ruche et pourvues de la même qualité de nourriture ne se reconnaissent qu'au bout de quelques jours de séparation. Des nourritures très différentes n'accélèrent pas ce processus de différenciation.

La reconnaissance serait donc, selon ce travail, sous la dépendance d'une substance distribuée en même temps que la nourriture au moment de la trophallaxie.

DELVERT-SALLERON (I963) a repris ces recherches en essayant de savoir s'il existait une différence dans les échanges de nourriture selon que des ouvrières séparées par une cloison appartiennent ou non à la même ruche. Cet auteur a utilisé la nourriture solide, marquée au moyen du ${ }^{32} \mathrm{P}$. Mais des résultats très hétérogènes ont été obtenus. Il n'a pas été possible de démontrer une préférence quelconque des abeilles nourrices pour leurs sœurs ou pour des abeilles étrangères. Ses résultats contradictoires montrent qu'on ne peut accepter comme règle générale les conclusions de KHALIFMAN (I955) qui laissent supposer que, dans tous les cas, les échanges de nourriture entre ouvrières de même ruche s'effectuent plus aisément qu'entre des ouvrières appartenant à des ruches différentes. L'hétérogénéité des résultats de DELVERT-SAIL_ERON (I963) laissait supposer l'existence de conditions expérimentales défectueuses ou des variations de comportement suivant la provenance des abeilles.

Pour améliorer la technique d'expérimentation et les conditions expérimentales, nous avons procédé à l'étude des échanges de nourriture entre les abeilles provenant de deux ruches différentes. Notıs avons étudié le comportement d'un lot d'ouvrières mis en présence de deux lots d'abeilles, l'un venant de la même ruche, l'autre venant d'une ruche étrangère. L'incorporation d'isotope à la nourriture nous permettait de contrôler les échanges, mieux sans doute que 1'estimation de la mortalité (KHALIFMAN, I955).

Pour ce genre d'expérience, nous avons employé des cagettes à trois compartiments, dont les deux compartiments extrêmes communiquent avec celui du milieu par l'intermédiaire de grilles perforées. 
Nous appelons les abeilles qui sont dans le compartiment central les " donneuses". Les abeilles qui viennent de la même ruche que les "donneuses " sont les " sœeurs". Elles sont dans un des deux compartiments latéraux. Les abeilles qui viennent de 1'autre ruche sont les " étrangères " placées dans l'autre compartiment latéral. L,e nombre d'abeilles dans chaque compartiment est le même. Nous avons pris une quinzaine de " clonneuses ", "socurs " et "étrangères " qui ont été élevées dans l'étuve (donneuses et souurs ensemble et étrangères dans une autre cagette).

DELVER'I-SAIIILROX (I963) avait utilisé du candi radioactif comme nourriture dans le compartiment central. Dovaul's ( I960 a) a comparé la pollution externe de l'abeille lorsque le radio-isotope est introduit dans une nourriture solide (candi) ou dans une nourriture liquide (sirop du sucre). Cette étude a montré que les pattes de l'abeille deviennent radioactives à cause des fragments de sucre marqué qui s'y sont collés, dans le cas où on utilise le candi. L'utilisation de nourriture liquide a permis d'éviter cette contamination. Le nourrisseur de miel radioactif (décrit dans le chapitre "Matériel et Méthode ") permettait de réduire encore les chances de contamination.

DELVFRT-SAIIIERON (Ig63) n'a pas mesuré la radioactivité initiale des donneuses, et d'autre part a localisé le candi radioactif pendant toute l'expérience dans le compartiment central.

A la fin de l'expérience, elle a mesuré les échanges de nourriture entre donneuses sœurs et étrangères après les avoir tuées avec l'acétate d'éthyle.

Dans ce cas on ne peut déterminer la proportion réelle de radioactivité distribuée, les donneuses continuant à absorber la nourriture marquée pendant toute la durée de l'expérience. Donc, nous avons utilisé la nourriture liquide et le nourrisseur spécial. Les abeilles "donneuses " ont d'abord été nourries avec du miel radioactif dans une cagette "Liebefeld ". Nous avons mesuré ensuite la radioactivité de chaque "donneuse" vivante avant 1 'introduction dans le compartiment central de la cagette expérimentale.

Ayant mis en place les "donneuses " nous avons introduit séparément les "sœurs " et les "étrangères" dans les deux compartiments latéraux (schéma).

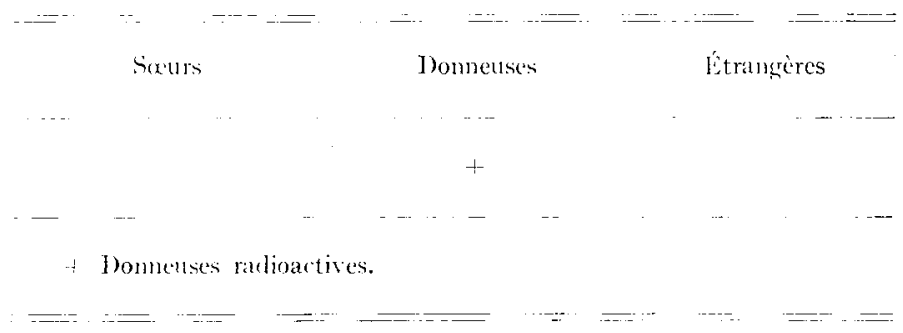

Du candi normal a été placé dans le compartiment central à la disposition des donneuses. Les abreuvoirs d'eau ont été mis dans les trois compartiments. La cagette expérimentale a été gardée dans 1'étuve à $30^{\circ} \mathrm{C}$ pendant $8,16,24,48$ et 72 heures.

Nous avons répété les expériences quatre fois pour chaque durée des échanges.

A la fin de l'expérience nous avons tué toutes les abeilles de la cagette avec de l'acétate d'éthyle, afin de mesurer la radioactivité de chaque individu.

Pour pouvoir comparer les résultats de deux essais successifs, nous avons mesuré pour les 3 lots d'abeilles la radioactivité de chaque individu puis nous avons fait la somme totale de la radioactivité. Ensuite, nous avons converti les données en pourcen- 
tage par rapport à la radioactivité totale des " donneuses " de la même expérience. Ces pourcentages nous ont donné des grandeurs comparables d'un essai à l'autre.

Comme les lots d'abeilles présentaient des mortalités différentes, nous avons évalué la radioactivité moyenne par lot en ne tenant compte que des chiffres obtent1s par le comptage des abeilles vivantes.

I.es résultats ont été représentés par des surfaces (fig. I3).

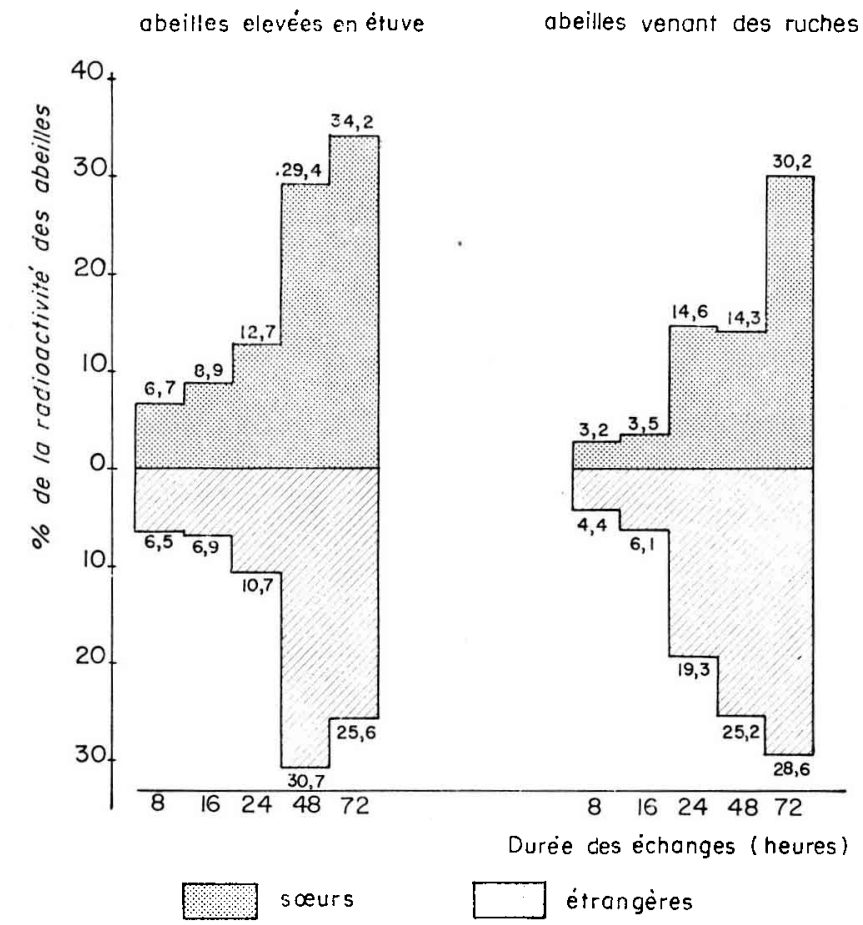

FIG. I. - Comparaison des échanges des abeilles en fontion de leur durée

Surface pointillée, pourcentage de la radioactivité moyenne des abeilles scurs (S), Surface hachurée, pourcentage de la radioactivité moyenne des abeilles étrangères $(\mathbf{E})$.

Ces pourcentages sont établis par rapport à la radioactivité initiale des donneuses.

Par exemple, dans l'expérience 5, à la fin de l'expérience, il y avait :

I4 sœurs totalisant 2 I 704 coups/mn ;

I3 étrangères totalisant I5 946 coups/mn.

I a radioactivité totale des $I_{5}$ donneuses était $I_{47} 650$ coups/minutes au début de l'expérience. Nous calculons en pourcentage le chiffre trouvé pour les sours et les étrangères, par rapport à celui trouvé pour les donneuses.

Soit, pour les sceurs : $\quad \frac{2 \mathrm{I}}{\frac{704}{147650}}=\mathrm{I} 4,7$ p. 100

Pour les étrangères : $\quad \frac{15946 \times 100}{147} \times \frac{1050}{650}$ p. I00 


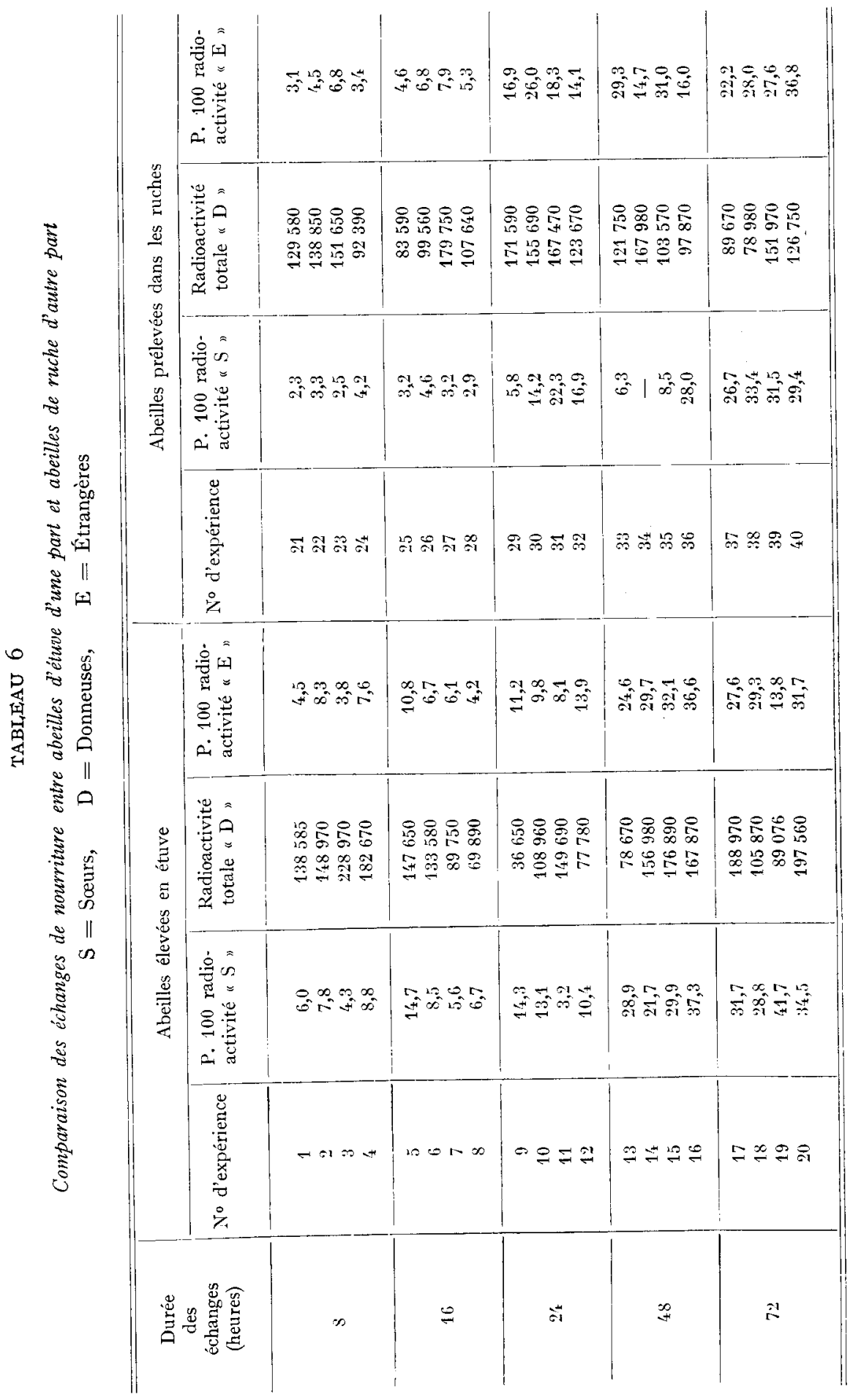


Dans cette expérience, nous dirons que les sours représentent 14,7 p. roo de la radioactivité des " donneuses " tandis que les étrangères n'en représentent que Io,8 p. IоO.

\section{A - Expériences d'une durée de 8 heures}

Huit essais ont été faits dans ces conditions, 4 sur des abeilles élevées dans l'étuve et 4 sur des abeilles butineuses venant des ruches.

En faisant la moyenne du taux de radioactivité des abeilles " donneuses ", " sœurs " et " étrangères ) dans les huit essais, on obtient les chiffres suivants (en p. IOo):

6,7 et 3,2 pour les sœurs,

6,5 et 4,4 pour les étrangères.

Le I $^{\text {er }}$ chiffre de chaque série correspond aux abeilles d'étuve, 1e $2^{\mathrm{e}}$ aux abeilles de ruche.

Les différences de radioactivité entre les deux lots ne sont pas très importantes, mais il semble, d'après les résultats globaux, que les sœurs se font plus facilement nourrir que les étrangères quand elles sont jeunes et prélevées dans l'étuve. Au contraire nous voyons que les étrangères se font plus facilement nourrir que les sœurs lorsqu'elles proviennent de ruches.

\section{$\mathrm{B}-$ Expériences d'une durée de 16 et 24 heures}

Les huit expériences effectuées montrent une petite différence entre les deux lots. La figure I3 montre les résultats obtenus avec des abeilles élevées en étuve et des abeilles venant des ruches. Dans le premier cas, le pourcentage de la radioactivité calculé par rapport à la radioactivité moyenne des donneuses est, au bout de 16 heures et 24 heures respectivement, 8,9 et I 2,5 p. Ioo pour les sœurs ; 6, 9 et Io,7 pour les étrangères. Dans le second cas, pour une durée d'échanges de I 6 heures et 24 heures, les étrangères ont une radioactivité supérieure à celles des sœurs : 6, I p. Ioo et I9,3 p. Ioo contre $3,5 \mathrm{p}$. Ioo et I 4,6 p. Ioo. Il apparaît donc que les résultats de ces expériences rejoignent ceux des expériences d'une durée de 8 heures.

\section{$\mathrm{C}$ - Expériences d'une durée de 48 heures}

L'expérience $\mathrm{n}^{\circ} \mathrm{I} 4$ a donné chez les étrangères un pourcentage de radioactivité supérieur à celui des sceurs dans le cas des abeilles élevées en étuve. Chez les abeilles venant des ruches, nous voyons que dans l'expérience $n^{\circ} 36$ les sœurs ont un pourcentage de radioactivité nettement supérieur à celui des étrangères. Toutes les autres expériences (6 sur 8) ont montré une légère supériorité de la radioactivité chez les sœurs dans le cas où les abeilles sont élevées en étuve. Au contraire, le pourcentage de la radioactivité a été nettement supérieur chez les étrangères dans le cas des abeilles de ruches.

\section{$\mathrm{D}$ - Expériences d'une durée de 72 heures}

Une expérience sur 4 que nous avons faites avec les abeilles élevées en étuve, montre un pourcentage de radioactivité très légèrement supérieur, chez les étrangères, à celui des sœurs. Chez les abeilles venant des ruches, trois expériences indiquent un pourcentage de radioactivité supérieur chez les søurs. 
En conclusion des 4 expériences, nous pouvons dire que les étrangères sont aussi bien nourries que les sœurs jusqu'à un certain point.

Pour conclure nous pensons indispensable de réfléchir sur le résultat le plus frappant de ces essais : la différence qui existe entre abeille d'étuve et abeille de ruche. Dans le premier cas, nous voyons au moins dans les premières 24 heures, une préférence très nette des "donneuses " pour les sœurs, tandis qu'il est possible d'observer le phénomène inverse dans le second cas.

Il n'est pas impossible d'attribuer cette différence à l'influence de l'âge des individus. Nos abeilles d'étuve étaient âgées de 6-8 jours alors que celles prélevées dans la ruche devaient être plus âgées, 20 jours et plus pour la plupart, compte tenu de notre technique de prélèvement. Il faudrait donc admettre l'acquisition par l'ouvrière d'une capacité de demande de nourriture qui viendrait influencer les "préférences " des donneuses.

Cette hypothèse sera reprise dans notre conclusion générale.

\section{VI. - TRANSIT INTESTINAI, E'T LOCAIISATION DU PHOSPHORE 32 \\ DANS LE CORPS D'UNE ABEILIF}

Chez les Abeilles, la trophallaxie est non seulement caractérisée par le transfert de nourriture provenant du jabot mais aussi par celui des sécrétions glandulaires. Pour étudier ce phénomène, particulièrement la contamination des substances glandulaires, il est nécessaire de marquer les régurgitations par un radioélément qui puisse circuler et se fixer dans le corps de l'abeille en participant à son métabolisme. Nous avons choisi le radio-isotope ${ }^{32} \mathrm{P}$ pour différentes raisons déjà exposées.

De plus l'importance du phosphore dans le métabolisme général et la circulation de phosphates dans l'hémolymphe de l'Insecte est depuis longtemps connue.

Dès I934 Hoskins et HARRISON ont montré qu'il existait chez l'ouvrière d'abeille une circulation des phosphates qui sont sécrétés dans l'intestin moyen et réabsorbés dans l'intestin supérieur (d'après RoEder, I953) chez Periplaneta. Roan (I950) montre que le ${ }^{32} \mathrm{P}$ se concentre dans la lumière de l'intestin antérieur lorsqu'il a été injecté sous forme de tétraéthylpyrophosphate.

Le passage inverse de la lumière du tube digestif vers l'hémolymphe a été mis en évidence chez de nombreux insectes par divers chercheurs (LINDSAY et CRAIG, I942; HASSE'T, I954).

Chez les Insectes sociaux, GösswaLn et KLOFT (I958, I960) ont montré que le ${ }^{32} \mathrm{P}$ ingéré par des Fourmis se concentrait assez rapidement dans leurs glandes salivaires. Une excrétion cuticulaire de ${ }^{32} \mathrm{P}$ est de même mise en évidence par les auteurs (KLOFT, I960), spécialement chez la reine des fourmis (BERWICK, I955)

La non-toxicité du phosphore pour les insectes est certaine lorsqu'il est administré à doses raisonnables (FUlLER, RIEGERT et SPINKS, 1954, sauterelle ; BABERS, MitLIN et SHortino, I956 mouche, blatte, ; HuQUE, I960 sauterelle, blatte) bien qu'il puisse provoquer à la longue une baisse de fertilité.

C'est après avoir considéré tous les avantages du ${ }^{32} \mathrm{P}$ : sa bonne tolérance par l'Abeille, son importance dans le métabolisme de l'insecte et son passage probable au niveau des substances glandulaires, que nous avons été amené à le choisir. 
Les groupes d'abeilles (élevées en étuve) possédant chacun une reine, sont contaminés par ingestion directe du phosphore mêlé à la nourriture dans le nourrisseur déjà décrit.

Au bout d'un temps exprimé en heures, après l'ingestion de phosphore, chaque individu de ce groupe a été disséqué pour isoler les organes et les glandes nourricières et mandibulaires. La radioactivité de chaque échantillon est calculée en pourcentage de la radioactivité totale de l'abeille mesurée aussitôt après la dissection, effectuée à sec, parce qu'il existe une absorption des rayonnements par la cuticule.

Les tableaux 7 et 8 montrent le transit de ${ }^{32} \mathrm{P}$ respectivement chez les ouvrières et les reines.

Le passage $d u{ }^{32} \mathrm{P}$ à travers $\mathrm{l}^{\prime}(x$ sophage est très rapide. La contamination du jabot est maximum $\left(t_{0}+\mathrm{I} / 2 \mathrm{~h}\right),\left(t_{0}+\mathrm{I} \mathrm{h}\right)$ chez les ouvrières et $\left(t_{0}+\mathrm{I} \mathrm{h}\right),\left(t_{0}+2 \mathrm{~h}\right)$ chez les reines.

La radioactivité des échantillons des glandes mandibulaires, hypopharyngiennes, salivaires et thoraciques reste faible et inférieure à celles des autres parties du tube digestif.

La contamination de l'estomac augmente en même temps que diminue celle du jabot. Elle est maximum vers $\left(t_{0}+8 \mathrm{~h}\right)$. A partir de $\left(t_{0}+3^{6} \mathrm{~h}\right)$, elle diminue. Par suite la radioactivité de l'intestin augmente légèrement et reste plus ou moins stationnaire durant les jours suivants.

L'hémolymphe commence à être faiblement contaminée vers $\left(t_{0}+4 \mathrm{~h}\right),\left(t_{0}+8 \mathrm{~h}\right)$. La radioactivité des échantillons commence à augmenter légèrement et devient assez forte à $\left(t_{0}+\mathrm{I} 6 \mathrm{~h}\right)$. A partir de $\left(t_{0}+24 \mathrm{~h}\right)$, la radioactivité de 1'hémolymphe reste constamment forte.

Pendant les échanges alimentaires, les sécrétions des substances glandulaires passent d'une abeille à l'autre. Comme la nourriture du tube digestif est assimilée pendant les périodes d'ingestion, ces substances glandulaires assimilent la nourriture, mais plus lentement chez les reines que chez les ouvrières. L'activité totale des substances glandulaires se maintient chez les ouvrières et les reines dans une proportion de 2 à $6 \mathrm{p}$. Ioo de la radioactivité de l'insecte pendant les heures qui suivent l'ingestion.

Les glandes mandibulaires deviennent radioactives vers $\left(t_{0}-8 \mathrm{~h}\right)$ chez les ouviières et $\left(t_{0}+24 \mathrm{~h}\right)$ chez les reines.

Les glandes hypopharyngiennes commencent à devenir radioactives à partir de $\left(t_{0}+4 \mathrm{~h}\right)$ chez les ouvrières et $\left(t_{0}+30 \mathrm{~h}\right)$ chez les reines. Leur contamination reste très faible en comparaison de celle de l'hémolymphe ou d'autres organes.

L,es glandes salivaires sont aussi radioactives vers $\left(t_{0}+4 \mathrm{~h}\right)$ chez les ouvrières. Dans le cas des reines, elles deviennent radioactives vers $\left(t_{0}+60 h\right)$. Leur contamination chez les reines reste très faible ainsi que celle des glandes mandibulaires.

Les glandes thoraciques deviennent radioactives vers $\left(t_{0}-i-8 \mathrm{~h}\right)$ chez les ouvrières.

GösswaI,D et KI,OFT ( $195^{8}$, r 960 ) ont montré que la contamination des substances glandulaires chez les Fourmis conmence faiblement I à 2 heures après l'ingestion de nourriture et n'est importante qu'au bout de 24 à 48 heures.

Nos résultats montrent que ce phénomène est plus important chez les ouvrières que chez les reines. Les glandes hypopharyngiennes, salivaires et mandibulaires commencent à devenir radioactives plus vite $(2 \mathrm{~h}-4 \mathrm{~h})$ dans le cas des ouvrières. Chez 

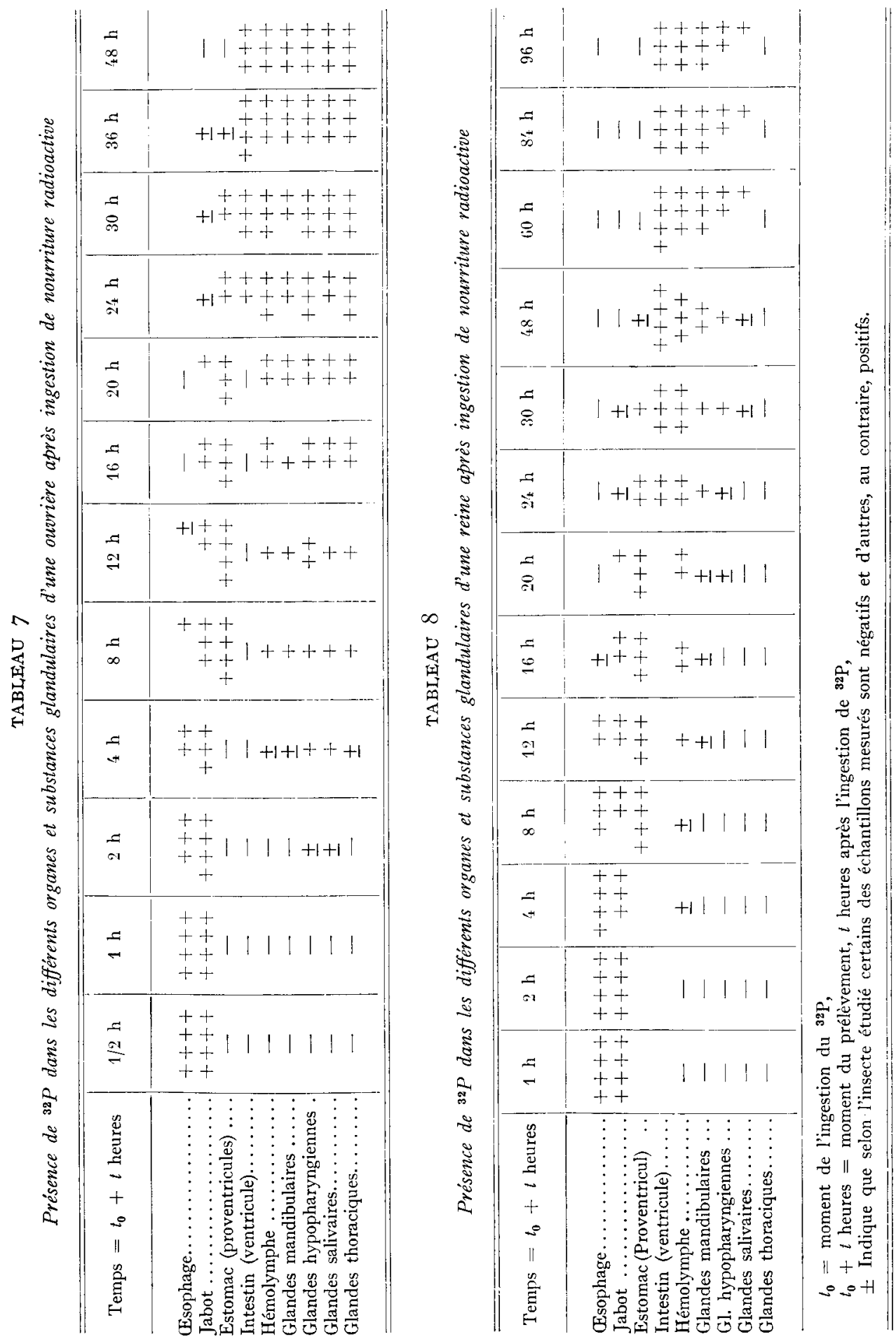
les reines, la contamination des glandes mandibulaires n'apparait qu'après I6 heures et n'est importante qu'au bout de 40 heures. Comme les glandes hypopharyngiennes et salivaires sont petites chez les reines, nous observons que la radioactivité est également très faible par rapport à celle des glandes mandibulaires.

Cette partie de notre travail ne constitue sans doute qu'une étude préliminaire qui montre que les échanges des substances glandulaires peuvent être distingués de ceux concernant la nourriture proprement dite. Ceci semble particulièrement possible à réaliser en ce qui concerne les reines, du fait de la relative lenteur du passage du radioélément dans les glandes.

\section{VII. -- ÉCHANGE DE NOURRITURE ENTRE, LES OUVRIŸRES} ET IES REINES VIERGES ET FÉCONDES D’ “ APIS MELLIFICA " L.

GöSSWALD et KLOF'T (I963), utilisant la nourriture marquée au radioélément, ont observé que les reines fécondes d'Apis mellifica distribuent le contenu radioactif de leur jabot aux ouvrières.

CourTors, LECOMTE et $a l$. (I96I) ont constaté, en étudiant les échanges de nourriture à l'intérieur de la ruche durant l'hiver, que l'emplacement où se trouvait située la reine jouait un rôle très important. Ils ont expérimenté en utilisant la ruche de Chauvin, ruche à cadre unique de grandes dimensions occupée par une population de 3 à 4000 abeilles. Au moment des essais, la grappe hivernale était bien formée, et c'est sur la périphérie de cette grappe qu'un nourrisseur contenant du miel marqué avec ${ }^{198} \mathrm{Au}$ fut placé. Un petit nombre d'abeilles, 5 à Io selon les essais, put pénétrer dans ce nourrisseur et après que ces abeilles furent nourries, le nourrisseur fut retiré et les abeilles rentrèrent en communication avec l'ensemble de la population. La quantité de radioéléments introduite par ces butineuses dans la ruche ne dépassait pas quelques microcuries. A partir de ce moment, la surface de la paroi de la ruche fut explorée méthodiquement en fonction d'un quadrillage au moyen de deux scintillateurs et il fut ainsi possible de suivre le déplacement des abeilles porteuses du miel marqué et aussi la diffusion de ce miel dans la population. Les trois essais ont donné des résultats très parallèles. Contrairement à ce qu' on aurait pu attendre, les échanges de nourriture ne se font pas à partir du nourrisseur vers le centre de la grappe, il apparaît de manière certaine que les ouvrières, après avoir rempli leur jabot de miel, se dirigent très rapidement vers le centre de la grappe, c'est à partir du centre de la grappe, lieu où se trouve la reine, que s'effectue la diffusion de la nourriture à travers l'ensemble de la population.

Cependant Douaulit (Ig66) a montré que durant la belle saison l'emplacement du couvain joue le rôle de centre distributeur. La présence de la reine ne semble pas importante.

SALLERON (1963) a étudié les échanges entre reines et ouvrières et l'existence d'un transfert de radioactivité des reines aux ouvrières parait démontrée. Quand on connaît le rôle important que joue la reine dans les colonies par les substances qu'elle sécrète, on conçoit l'intérêt primordial qu'offre la possibilité d'avoir des données numériques sur 1 'importance des échanges par voie buccale. Il semble en être de même 
dans les colonies expérimentales très restreintes composées d'une vingtaine d'ouvrières, et les mesures effectuées montrent de manière indéniable que les échanges directs avec la reine ne sont le fait que d'un très petit nombre, parfois deux individus seulement. C'est à partir de ces deux individus que la radioactivité administrée à la reine par l'expérimentation se retrouve dans l'ensemble de la population.

La demande des ouvrières en "substance royale " est un des facteurs importants pour le maintien de la cohésion, non seulement chez les Abeilles mais aussi chez les Fourmis et les Termites (BUTI.ER, I954).

CASTLE (I934), Light (I944) et al., ont décrit comment des termites ouvriers recherchent constamment une substance sur le corps de leur reine en la léchant. SCHNEIRLA (1953) a montré que les Fourmis guerrières cherchent également quelque chose sur leurs reines. Il a montré aussi que leurs ouvrières distinguaient entre les reines vierges, âgées ou fécondées.

STUMPER (1956) décela aussi l'existence d'une substance attractive chez Lasius aliessus et Pheidole pallidula. Plus la reine est volumineuse, plus son léchage par les ouvrières est intense. Des supports (papiers-filtre, éponge, moelle de sureau) imbibés d'extraits de reines fécondes, ont montré un pouvoir d'attraction très net sur les ouvrières.

GösswaLD et KI,OFT (1963) ont démontré que les reines vierges jeunes et vieilles, de Formica polyctena absorbent directement le miel radioactif en même quantité que les ouvrières.

A l'aide de ${ }^{32} \mathrm{P}$, GösswaL, et KLOF'T (I960) ont étudié, dans des conditions expérimentales bien définies, les échanges de liquide proventriculaire entre ouvrières de Formica. Les ailés +9 (les sexués) prennent aussi une part active dans la distribution de nourriture. Il en est de même pour les $q 9$ qui n'ont plus leurs ailes. La méthode des isotopes leur a permis de montrer qu'en présence d'un nombre suffisant d'ouvrières, les reines ne sont pas nourries de liquide proventriculaire, mais de liquide salivaire. Les larves sexuées dans les mêmes conditions sont, elles aussi, nourries exclusivement de salive.

WILSON et EISNER (1957) utilisant ${ }^{131}$ I ont observé chez certaines espèces de Formica, que les reines dans les grandes colonies sont peu attirées par la nourriture radioactive du jabot de la butineuse introduite. En utilisant le ${ }^{32} \mathrm{P}$, Gösswal,D (I959) a montré que le facteur responsable en est la transmission de substances glandulaires. Ces substances ne peuvent être marquées avant que le radiophosphore ingéré ne soit assimilé par tout le corps. Ce processus commence I-2 heures après l'ingestion et dure 24 à 48 heures, selon la température (GösSWAI,D et KI.OFT, I958, I960).

NaARmann (1963) a mis au point une technique permettant de distinguer les échanges qui concernent la transmission de la nourriture distribuée aux fourmis, et celle de substances sécrétées par différentes glandes. Des ouvrières sont d'abord isolées durant 48 heures, puis mises en contact avec des ouvrières. A ce moment, elles sont nourries avec une nourriture normale et mises en contact avec des ouvrières affamées. Des mesures effectuées sur ces dernières permettent de vérifier la disparition totale de toute radioactivité dans les régurgitations des donneuses. Par la suite, apparait une radioactivité qui est attribuée aux sécrétions des glandes pharyngiennes.

Gösswald et KLOFT (1959) ont recherché quels sont, dans une colonie, les individus capables de s'alimenter par eux-mêmes. Ils ont constaté que ni les soldats, ni 
les larves du premier stade n'ingèrent de nourriture brute, non plus que les individus au stade pré-imaginal ni les sexués ailés avant le vol nuptial. Les larves du second stade ne se nourrissent que fort peu directement si même elles le font.

Par contre, les sexués imaginaux fonctionnels semblent rester capables toute leur vie de se nourrir de nourriture brute. Les larves âgées et les jeunes nymphes jouent le rôle principal en tant que "donneuses ", tandis que les jeunes larves, les nymphes âgées, les sexués et les soldats sont les "receveuses " de la nourriture. Pendant les deux jours qui précèdent et suivent la mue, les individus observés cessent totalement de s'alimenter et de participer aux échanges (GösswaL, I962).

LECOMTE (I963) utilisant ${ }^{198} \mathrm{Au}$ a démontré une trophallaxie indirecte dans la colonie de Bourdons, Bombus hypnorum. Une colonie de Bombus hypnorum, composée d'environ $5^{\circ}$ ouvrières, une reine et plusieurs jeunes sexués, est maintenue dans une cage de $25 \mathrm{~m}^{3}$. Une ouvrière a reçu, à l'aide d'une pipette, une dizaine de millimètres cubes de miel contenant quelques microcuries de ${ }^{198} \mathrm{Au}$. Cette ouvrière a été relâchée et par la suite, les bourdons, butinant dans la cage, ont été examinés au moyen d'un scintillomètre portatif. Une heure après le marquage, 6 individus sur 9 se révélaient positifs. La nourriture ingérée par une seule ouvrière se diluait avec une très grande rapidité dans la population six heures après le marquage. La reine avait activement participé à cette distribution et un examen de l'intérieur du nid a permis de constater qu'un "Pot à miel " était fortement radioactif, c'est par cet intermédiaire que les échanges étaient effectués.

Mais les rapports qui existent entre la reine et les ouvrières d'abeilles sont mal connus. Aussi avons-nous décidé de procéder au marquage de la nourriture des reines.

Les jeunes abeilles étaient capturées sur des rayons et maintenues avec la reine dans les cagettes déjà décrites. Pour choisir les reines, le test d'attractivité décrit par PaIn (I959) est effectué en comptant toutes les 30 secondes (pendant 5 minutes) le nombre de jeunes ouvrières attirées auprès des reines (vierges ou fécondes). Pour l'appréciation des résultats nous effectuons la moyenne des nombre maxima d'abeilles attirées dans les différentes cagettes. Lej reines qui attirent des nombres maxima d'abeilles ont été choisies pour nos expériences.

Pour rendre les reines radioactives, nous les avons introduites avec des ouvrières dans une cagette contenant du miel radioactif. Les ouvrières assurent alors le nourrissement de la reine. Cette méthode présente des inconvénients : les ouvrières en léchant le corps de la reine l'enduisent des produits radioactifs qui se trouvent sur leur langue, ainsi la reine devient radioactive, non par suite d'échanges trophiques mais parce qu'elle est polluée extérieurement. Nous avons alors essayé de la laisser se nourrir ellemême. Pour cela le phosphore rađioactif ${ }^{32} \mathrm{P}$ lui a été donné mélangé à du miel.

Il y a des cas où les receveuses deviennent radioactives par suite d'une contamination extérieure. Pour confirmer le passage de la nourriture aux receveuses, nous avons coloré le miel avec du bleu de méthylène. Par dissection, nous pouvons ainsi retrouver le miel coloré dans le tube digestif et confirmer que l'échange a eu lieu.

Nous avons étudié les échanges de nourriture dans les deux cas suivants:

I $^{0}$ échanges entre les ouvrières d'âge variant de 2 à 9 jours et soit une reine vierge, soit une reine féconde ;

$2^{\circ}$ échanges entre une reine vierge, une reine féconde et des ouvrières d'âge variant de 2 à 9 jours. 
L,es abeilles qui sont marquées avec la radioactivité sont les "donneuses " et les abeilles qui reçoivent la nourriture sont les "receveuses".

Dans le premier cas, les ouvrières sont les "donneuses " et la reine vierge, ou féconde est la "receveuse "; et dans le deuxième cas, soit la reine vierge, soit la reine féconde est la "donneuse ", et les ouvrières sont les "receveuses".

Les expériences furent conduites de la manière suivante :

$1^{\text {er }}$ cas : 15 ouvrières ont été introduites dans une cagette et nourries avec du miel contenant le radio-isotope. Après que ces abeilles eurent ingurgité une certaine quantité de miel, le miel fut remplacé par du candi ordinaire et la cagette replacée dans l'étuve pendant $I_{5}$ à 30 minutes.

Ia radioactivité du sirop absorbé par chacune de ces donneuses fut ensuite mesurée dans les conditions décrites ci-dessus, puis ces abeilles introduites dans une autre cagette à deux compartiments. Ensuite nous avons fait la somme totale de la radioactivité initiale de toutes les donneuses. Puis, nous avons placé soit la reine vierge, soit la reine féconde selon le cas, dans un autre compartiment séparé par une plaque de plastique perforé. Pendant l'expérience, d'une durée de 24 heures, des observations fréquentes étaient faites pour savoir si des échanges avaient lieu. Il n'y avait pas de nourriture dans les compartiments sauf de l'eau. Au bout de 24 heures, nous avons sacrifié les abeilles pour les passer individuellement sous le compteur. Les expériences ont été conduites avec des abeilles d'âge variant de 2 à 9 jours. Les expériences projetées avec des abeilles d'un jour n'ayant pu être réalisées car celles-ci étaient incapables de s'alimenter par elles-mêmes.

Après avoir mesuré la radioactivité du cadavre de la reine, nous l'avons disséqué dans une solution concentrée de phosphate de soditum. Une goutte de cette solution, placée dans le château de plomb, après utilisation, n’était pas radioactive. Dans ces conditions, nous avons pensé que la dissolution du phosphate radioactif était insignifiante.

La présence de miel coloré au bleu de méthylène, dans le tube digestif de la reine confirme qu'il y a eu un passage de nourriture.

$2^{e}$ cas : dans ce cas-là, soit la reine vierge, soit la reine féconde était la "donneuse ".

Après avoir nourri la reine avec le miel contenant le radioélément, nous avons mesuré sa radioactivité par la méthode décrite. Puis, nous avons laissé cette reine dans la cagette. I5 ouvrières d'âge connu ont été introduites dans l'autre compartiment. Cette cagette a été ensuite placée à l'étuve et l'expérience a été poursuivie comme dans le premier cas, mais pendant 36 heures.

Après avoir sacrifié les ouvrières et mesuré leur radioactivité, nous les avons disséquées dans les mêmes conditions que les reines. La présence de miel coloré en bleu dans le tube digestif des ouvrières confirme le passage de la nourriture.

L.es tableaux 9 et Io résument les résultats de nos expériences. Dans le premier tableau, les $I 5$ ouvrières âgées de 2 à 9 jours sont les " donneuses " et la reine vierge ou la reine féconde est la "receveuse".

Dans le deuxième tableau la reine vierge ou la reine féconde est la "donneuse » et les 15 ouvrières âgées de 2 à 9 jours sont les " receveuses ». 
Les échanges de nourriture sont étudiés selon la formule $\frac{A}{\mathrm{C}^{d}}$, la signification des symboles de cette formule se trouve à la page ${ }^{2} 5^{2}$.

\section{TABLEAU 9}

Échanges de nourriture entre : $1^{\circ}$ les ouvrières "donneuses " et la reine vierge "receveuse", $2^{\circ}$ les ouvrières "donneuses "et la reine féconde "receveuse"

\begin{tabular}{|c|c|c|c|c|}
\hline \multirow{2}{*}{$\begin{array}{c}\text { Age } \\
\text { des ouvrières } \\
\text { " donneuses " } \\
\text { (jours) }\end{array}$} & \multicolumn{2}{|c|}{ Reine vierge " receveuse" } & \multicolumn{2}{|c|}{ Reine féconde "receveuse" } \\
\hline & $\frac{\mathrm{A}}{\mathrm{C}^{d}}$ & $\begin{array}{l}\text { Moyenne } \\
\frac{\mathrm{A}}{\mathrm{C}^{d}}\end{array}$ & $\frac{\mathrm{A}}{\mathrm{C}^{d}}$ & $\begin{array}{c}\text { Moyenne } \\
\frac{\mathrm{A}}{\mathrm{C}^{d}}\end{array}$ \\
\hline 2 & 9,$3 ; 6,5 ; 4,4 ; 8,5$ & 7,2 & 4,$4 ; 4,6 ; 4,4 ; 4,5$ & $t_{4}, 4$ \\
\hline 3 & 10,$4 ; 10,7 ; 7,7 ; 5,6$ & 8,6 & 5,$4 ; 6,3 ; 8,4 ; 6,6$ & 6,7 \\
\hline 4 & 4,$0 ; 12,9 ; 7,9 ; 11,6$ & 9,1 & 3,$8 ; 4,7 ; 6,5 ; 5,5$ & 5,1 \\
\hline 5 & 6,$5 ; 8,3 ; 10,7 ; 14,8$ & 10,0 & 11,$7 ; 7,9 ; 10,5 ; 9,1$ & 9,8 \\
\hline 6 & 13,$8 ; 14,4 ; 12,8 ; 11,9$ & 13,2 & 16,$0 ; 9,0 ; 13,1 ; 11,7$ & 12,4 \\
\hline 7 & 16,$6 ; 12,5 ; 13,6 ; 11,8$ & 13,6 & 9,$5 ; 15,8 ; 13,5 ; 11,9$ & 12,6 \\
\hline 8 & 10,$5 ; 6,2 ; 15,5 ; 16,8$ & 11,5 & 6,$3 ; 16,6 ; 20,8 ; 10,6$ & 12,5 \\
\hline 9 & 13,$5 ; 14,1 ; 15,3 ; 12,8$ & 13,9 & 9,$5 ; 12,5 ; 14,6 ; 18,6$ & 13,8 \\
\hline
\end{tabular}

\section{TABLEAU IO}

Échanges de nourriture entre : $1^{\mathrm{o}}$ une reine vierge "donneuse " et les ouvrières "receveuses", $2^{\circ}$ une reine féconde "donneuse " et les ouvrières "receveuses"

\begin{tabular}{|c|c|c|c|c|}
\hline \multirow{2}{*}{$\begin{array}{c}\text { Age } \\
\text { des ouvrières } \\
\text { " receveuses" } \\
\text { (jours) }\end{array}$} & \multicolumn{2}{|c|}{ Reine vierge "donneuse " } & \multicolumn{2}{|c|}{ Reine féconde " donneuse " } \\
\hline & $\frac{\mathrm{A}}{\mathrm{C}^{d}}$ & $\begin{array}{l}\text { Moyenne } \\
\qquad \frac{\mathrm{A}}{\mathrm{C}} \bar{d}\end{array}$ & $\frac{A}{C^{d}}$ & $\begin{array}{c}\text { Moyenne } \\
\frac{\mathrm{A}}{\mathrm{C}^{d} d}\end{array}$ \\
\hline 2 & 11,$6 ; 12,8 ; 10,6 ; 9,9$ & 11,2 & 9,$8 ; 7,8 ; 5,8 ; 4,6$ & 5,2 \\
\hline 3 & 6,$7 ; 6,8 ; 9,7 ; 8,9$ & 8,0 & 5,$6 ; 7,3 ; 4,8 ; 2,9$ & 5,1 \\
\hline 4 & 8,$2 ; 9,2 ; 8,2 ; 5,5$ & 7,7 & 5,$9 ; 6,9 ; 8,4 ; 11,7$ & 8,2 \\
\hline 5 & 8,$1 ; ; 5,8 ; 7,1 ; 8,1$ & 7,3 & 8,$2 ; 11,2 ; 9,3 ; 7,8$ & 9,1 \\
\hline 6 & 4,$8 ; 4,4 ; 5,6 ; 9,8$ & 6,1 & 8,$6 ; 9,0 ; 6,9 ; 9,0$ & 8,4 \\
\hline 7 & 5,$9 ; 3,7 ; 6,7 ; 4,9$ & 6,5 & 6,$9 ; 7,8 ; 9,8 ; 13,3$ & 9,4 \\
\hline 8 & 21,$7 ; 23,4 ; 16,8 ; 17,4$ & 19,8 & 9,$4 ; 8,4 ; 6,9 ; 11,2$ & 8,9 \\
\hline 9 & 17,$0 ; 28,9 ; 19,0 ; 16,7$ & 20,4 & 13,$1 ; 12,9 ; 12,8 ; 7,7$ & 11,6 \\
\hline
\end{tabular}

\section{Analyse statistique des résultats}

Pour l'interprétation statistique des résultats, nous avons utilisé l'analyse de la variance et l'analyse de corrélation.

Analyse de la variance

Elle porte sur les chiffres correspondant à la radioactivité distribuée par les ouvrières "donneuses ", soit à la reine vierge, soit à la reine féconde (tableau 9),

Annales de l'Abeille. - 1967 . 
ou par la reine vierge ou féconde, comme "donneuse " aux ouvrières " receveuses » (tableau ro).

L'ensemble des résultats après l'analyse statistique est reporté dans les tableaux II, $A$ et $B$, où figurent les valeurs ainsi déterminées pour chaque reine. Nous voulions savoir l'influence de l'âge des ouvrières et de l'état des reines sur les échanges de nourriture. Pour cela nous avons utilisé le test F de Snedecor et nous donnons cidessous les résultats pour chaque lot.

Les valeurs de F sont significatives pour "État des reines ", "L'âge des ouvrières " et " l'Interaction des facteurs -- 1'âge des ouvrières et État des reines " dans les deux tableaux I , A et B.

\section{TABILEAU II $\mathrm{A}$}

Analyse de la variance

Fichanges de nourriture entre les ouvrières "donneuses " $c$, 10 la reine vierge "receveuse ", $2^{\circ}$ la reine féconde "receveuse "

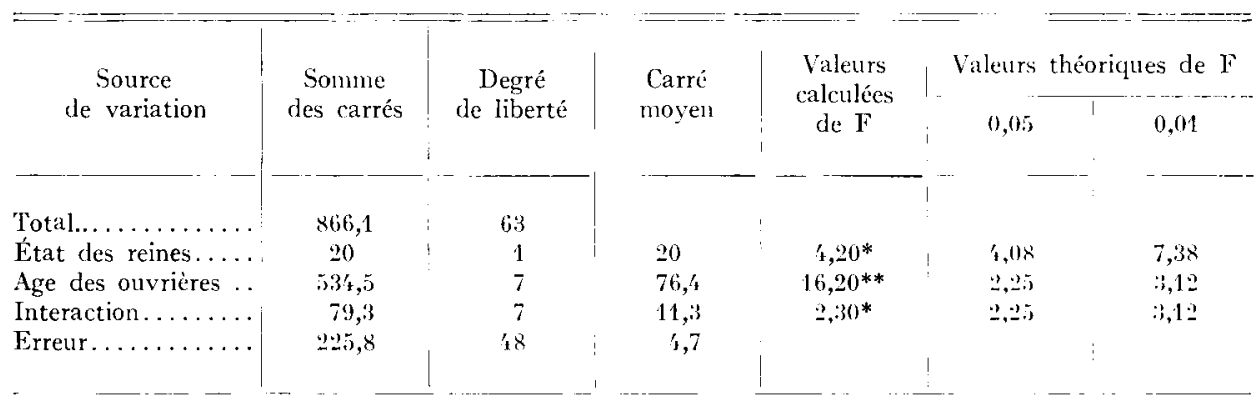

La valeur de F calculée pour les ¿ tableaux est significative au seuil de 5p p. 100 (indiquée prar un astérisque) ou hautement significative au seuil de 1 p. 100 (incliquée par deux astérisques).

\section{TABI,EAU II B}

Échanges de nourriture entre la reine vierge "donneuse", la reine féconde "donneuse " et les ouvrières "receveuses"

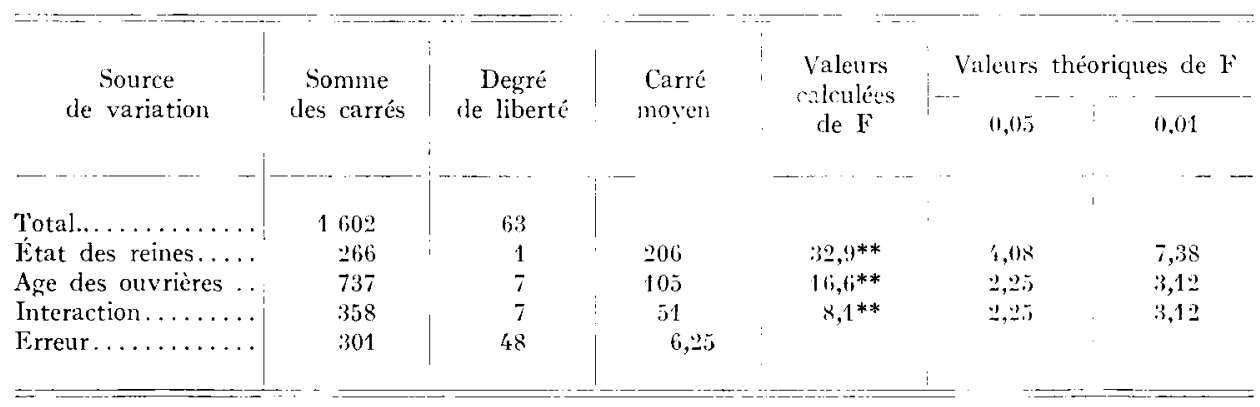

En examinant les différences se rapportant à " l'état des reines ", nous pouvons conclure que la différence est significative dans le tableau I I A ; hautement significative dans le tableau I I B. C'est-à-dire, qu'il existe une différence entre les résultats obtenus avec une reine vierge et une reine féconde. 
Les différences se rapportant à " l'âge des ouvrières " sont hautement significatives dans les deux tableaux. L'âge des ouvrières joue donc un rôle très important lors de l'échange de nourriture entre les ouvrières et la reine vierge et la reine féconde. "L'interaction " des facteurs " âge des ouvrières et état des reines ", c'est-à-dire leur influence réciproque est significative dans le tableau I I $\mathrm{A}$, hautement significative dans le tableau II B.

L'étude statistique démontre qu'il y a eu interaction entre les deux facteurs : "l'âge des ouvrières et l'état des reines". Ceci revient à dire que dans le I er cas, la rađioactivité est différente suivant l'âge des ouvrières "donneuses ", mais que cette différence varie selon l'état des reines. Ensuite, dans le $2^{\mathrm{e}}$ cas, la radioactivité est différente selon l'état des reines " donneuses " suivant l'âge des ouvrières "receveuses ".

Une interaction signifie que la différence due à l'état de reine varie suivant l'âge des ouvrières et vice versa.

Comme l'analyse de variance nous a montré une influence de 1'âge des ouvrières sur les échanges, nous avons complété cette analyse en recherchant s'il existait une corrélation entre l'âge et la radioactivité.

L'analyse de corrélation nous a donné un résultat hautement significatif, c'està-dire que, plus les ouvrières " donneuses " sont âgées, plus la valeur de $\frac{A}{\mathrm{C}^{d}}$ augmente, donc, plus faible est l'échange.

Analyse de corrélation.

Dans le tableau I I l'âge des ouvrières " donneuses " variant en âge de 2 et 9 jours et la radioactivité de la reine vierge, reine féconde " receveuse » sont les deux variables comparables.

Dans le tableau Io 1'âge des ouvrières " receveuses " variant en âge de 2 et 9 jours et la radioactivité des ouvrières "receveuses " sont les deux variables comparables.

I,es deux variables dans chaque cas peuvent représenter comme ci-dessous :

Tableau II : l'âge des ouvrières " donneuses $» \ldots \ldots \ldots \ldots \ldots \ldots \ldots \ldots \ldots$

la radioactivité de la "r€ceveuse ", soit la reine vierge, soit la reine féconde $\ldots \ldots \ldots \ldots \ldots \ldots \ldots \ldots \ldots \ldots \ldots \ldots \ldots \ldots \ldots \ldots$

Tableau ro: l'âge des ouvrières "receveuses $) \ldots \ldots \ldots \ldots \ldots \ldots \ldots \ldots$ X

la radioactivité des ouvrières " receveuses $n . \ldots \ldots \ldots \ldots \ldots$ Y

Pour savoir s'il existe une corrélation entre ces deux variables $X$ et $Y$, nous calculons la somme des carrés pour les $\mathrm{X}\left(\mathrm{S} x^{2}\right)$, la somme des carrés pour les $\mathrm{Y}\left(\mathrm{S} y^{2}\right)$ et la somme des produits ( $\mathrm{S} x y)$.

Les deux "sommes des carrés " $\mathrm{S} x^{2}$ et $\mathrm{S} y^{2}$ se calculent en déduisant de la somme des carrés des X (ou des $\mathrm{Y}$ ) le "terme de corrélation " obtenu en divisant le carré de la somme des $\mathrm{X}$ ou $\mathrm{Y}$ par le nombre $n$ de données.

Le tableau I2 indique les calculs pour les données des tableaux 9 et Io. L'expression "somme des produits " est une abréviation pour " somme des produits des écarts des $\mathrm{X}$ par les écarts des $\mathrm{Y}$ sur la moyenne des $\mathrm{Y}$ ". Nous utilisons l'expression Covariance $\mathrm{P}=\mathrm{S} x y=\sum \mathrm{XY}-\frac{\left(\sum \mathrm{X}\right)\left(\sum \mathrm{Y}\right)}{n}$ où $n$ est le nombre d'observations. 


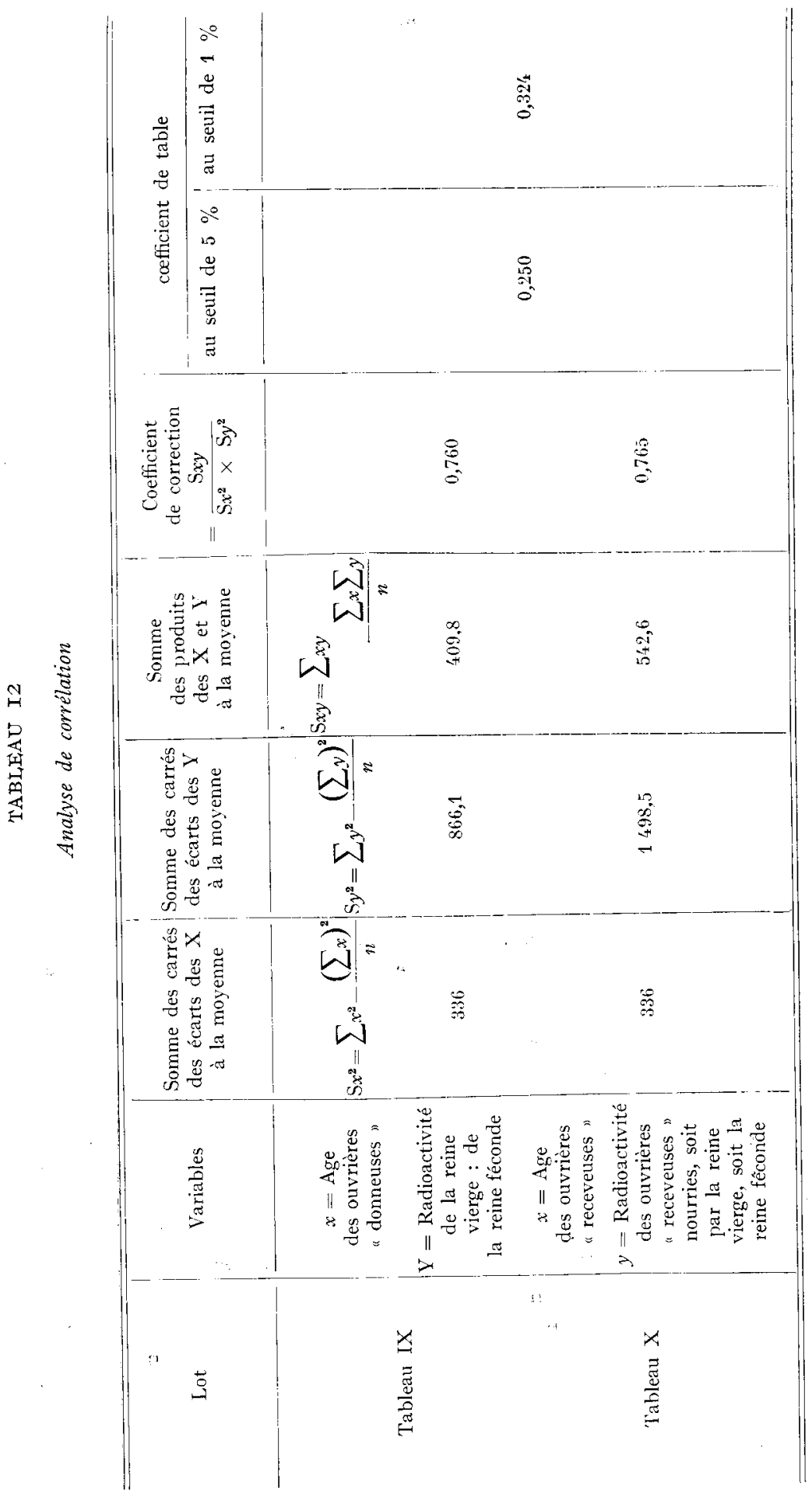


Nous faisons la somme des produits des données appariées et.nous en déduisons, un " terme de corrélation" calculé en divisant par le nombre de paires de données le produit des sommes des données en $\mathrm{X}$ et des données en $\mathrm{Y}$.

Le coefficient de corrélation $r=\frac{\mathrm{S} x y}{\sqrt{\mathrm{S} x^{2} \times \mathrm{S} y^{2}}}$ qui représente la covariance divisée par la racine carrée des produits $\mathrm{S} x^{2}$ et $\mathrm{S} y^{2}$.

I orsque la valeur absolue de $r$ est comprise entre $o$ et $I$, il y a une certaine corrélation entre les deux séries de variables, plus ou moins forte, selon qu'il reste plus ou moins de I. Si $r>0$, la corrélation est positive, c'est-à-dire que les plus grandes valeurs de $\mathrm{Y}$ correspondent aux plus grandes valeurs de $\mathrm{X}$.

I)ans nos lots, le test $r$ est significatif pour 5 p. roo et I p. I0o, il existe donc une corrélation entre l'âge et la radioactivité des abeilles.

Dans le tableau 9 , il existe une corrélation entre l'âge des ouvrières « donneuses » et la radioactivité distribuée, soit à la reine vierge, soit à la reine féconde " receveuse ".

Dans le tableau Io il existe une corrélation entre l'âge des ouvrières " receveuses " et la radioactivité distribuée par la reine vierge ou la reine féconde "donneuse " aux ouvrières " receveuses".

Plus les ouvrières " donneuses " et " receveuses » sont âgées, plus la mesure de la radioactivité $(A)$ est grande, et donc l'échange est faible. Mais dans le tableau ro, où les ouvrières sont les " receveuses " nous voyons qu'au début, c'est-à-dire entre l'âge 2-3 jours, 1'échange avec la reine vierge est faible.

'Les relations avec l'âge des ouvrières sont très sensiblement parallèles en ce qui concerne les échanges dans le sens ouvrières $\rightarrow$ reine que les reines soient fécondées ou vierges, ainsi que dans le sens reine $\rightarrow$ ouvrières quand cette dernière est fécondée.

Mais on observe une évolution différente quand il s'agit d'une reine vierge donneuse. Dans ce cas les échanges sont au maximum quand les ouvrières sont âgées d'environ 6 jours.

\section{CONCLUSION GÉNÉRALE}

L'utilisation des radio-isotopes dans l'étude éthologique des insectes sociaux est relativement neuve et si, en ce qui concerne les Fourmis, les recherches de Gösswal, et son école (I956 à I963) et pour les Termites, les recherches de ALIBERT (I959 à I966) et McMAHAN (I963 à I966) et BowEN (I950) ont déjà atteint un certain développement, il n'en est pas de même en ce qui concerne les Abeilles qui ont été moins étudiées.

Un apport important de notre travail nous semble être l'adaptation de diverses techniques et la mise au point de techniques nouvelles sans lesquelles il n'était pas possible d'espérer obtenir des renseignements précis sur les modalités de la trophallaxie.

Après cette mise au point, qui s'est d'ailleurs poursuivie tout au long de notre étude il fut possible d'aborder différents problèmes que nous allons passer en revue.

\section{L'influence de l'âge sur les échanges entre ouvrières}

Nous avons pu mettre en évidence une influence très nette de l'âge sur l'intensité des échanges alimentaires. Lorsque nous avons utilisé des abeilles donneuses et rece- 
veuses de même âge nous constatons que les échanges sont très faibles à 2 jours et passent par un maximum vers 4 jours. Ceci confirme les résultats obtenus par observation directe par les auteurs cités dans le paragraphe II de ce travail.

Lorsque nous avons utilisé des abeilles donneuses et receveuses d'âge différent nous constatons encore la supériorité des ouvrières âgées de 4 jours.

En ce qui concerne celles-ci avec une ouvrière de 8 jours les échanges sont bien, en accord avec FREE (I957), plus intenses avec des ouvrières du même âge. Mais cette règle du maximum entre âges semblables semble comporter une exception, les abeilles donneuses âgées de 4 jours étant toujours plus actives.

Un autre fait mérite d'être signalé, le peu d'importance des transmissions vers les abeilles âgées d'un jour. Étant donné que celles-ci ne semblent pas capables de se procurer de la nourriture de manière directe on aurait pu s'attendre à une recherche active de la trophallaxie.

Ces faits sont évidemment à mettre en rapport avec les très nombreux travaux portant sur l'influence de l'âge vis-à-vis des différents comportements de l'ouvrière d'abeille. Il est bon de rappeler ici que le déterminisme rigide des fonctions par l'âge de l'individu tel qu'il se trouvait décrit dans les premiers travaux de Rösch s'est révélé par la suite beaucoup plus souple en fonction des circonstances et de ce que l'on a pu appeler les besoins de la colonie.

L,es échanges alimentaires ne font peut-être pas exception à la règle et l'influence de l'âge dans d'autres conditions expérimentales aurait pu revêtir un autre aspect.

Nous sommes très conscients de ce fait et pensons seulement avoir mis en évidence de manière certaine le rôle joué par l'âge sans vouloir attribuer à l'âge privilégié de 4 jours une trop grande importance.

\section{L'infuence de la durée des échanges}

Le laps de temps nécessaire pour que la distribution normale d'une nourriture marquée s'effectue dans une colonie constitue sans doute une caractéristique d'une société d'insectes.

Nous avons pu constater que les Abeilles se rapprochaient beaucoup à cet égard des Fourmis, tandis que les Termites sont caractérisés par une bien plus grande lenteur de la distribution.

\section{L'influence de la température}

Mais la vitesse des échanges n'est-elle pas sous la dépendance de la température? Bien entendu il s'agit ici de la température ambiante car nous savons qu'un groupe d'abeilles même restreint est capable de régulation thermique.

Nous avons choisi 3 températures : $23^{\circ}, 31^{\circ}$ et $37^{\circ} \mathrm{C}$ qui sont proches des températures normalement rencontrées dans la ruche. Le nid à couvain se trouvant à $35-34^{\circ} \mathrm{C}$ et les autres parties de la ruche entre cette valeur et $20^{\circ} \mathrm{C}$. L'influence de la température s'est révélée très nette mais elle agit assez curieusement de manière différente sur la trophallaxie et sur la consommation de nourriture.

Tandis que les températures basses augmentent la consommation de nourriture, la trophallaxie est plus importante à $3 \mathrm{I}^{\circ} \mathrm{C}$ qu' $23^{\prime} 23^{\circ}$.

Les échanges sont également moins intenses à $37^{\circ} \mathrm{C}$ qu'à $32^{\circ} \mathrm{C}$, ce qui nous précise la température optimale en ce qui concerne le milieu ambiant et non le groupe lui- 
même puisque nous avons vu que selon Dovaurt (1967) les échanges avaient lieu de préférence sur le nid à couvain, c'est-à-dire aux environs de $35^{\circ} \mathrm{C}$. Rappelons que la température optimale pout Formica était de $15^{\circ} \mathrm{C}$ (selon KNEITZ, r96I).

\section{L'infuence de l'acclimatation}

Nous avons voulu également vérifier si la modification du métabolisme due à 1'acclimatation à une certaine température avait une influence sur la trophallaxie lors du transfert à une autre température.

Nous avons choisi $23^{\circ} \mathrm{C}$ et $37^{\circ} \mathrm{C}$ et avons observé que les échanges étaient plus élevés lors du transfert à $23^{\circ} \mathrm{C}$ d'abeilles élevées à $37^{\circ} \mathrm{C}$ que dans le cas inverse.

Nous obtenons encore des résultats différents de ceux concernant la consommation de nourriture puisque FREE et SPENCER-BOOTH (I960) ont montré que des abeilles passant de $20^{\circ} \mathrm{C}$ à $35^{\circ} \mathrm{C}$ consommaient plus que celles passant de 35 à $20^{\circ} \mathrm{C}$.

Il semble donc que des différences profondes entre les deux comportements : trophallaxie et prise de nourriture, soient révélés par l'action de la température.

\section{L'influence du nombre}

Étant donné l'importance des effets du groupement chez les Insectes sociaux il était tentant de chercher à savoir si la vitesse de répartition de la nourriture était liée à la dimension du groupe autrement que par la relation numérique entre la donneuse et les receveuses.

Mais chaque abeille receveuse peut se comporter ensuite en donneuse et transmettre de la nourriture marquée. D'autre part les dilutions successives rendent les comptages d'autant moins comparables si bien que les résultats obtenus sont difficiles à interpréter. Nous nous contenterons d'observer, qu'en accord avec GösswaLD, la nourriture régurgitée peut se retrouver dans un grand nombre d'individus (87 p. Ioo d'un groupe de roo en $3^{8}$ heures).

En ce qui concerne le nombre des donneuses l'analyse des résultats laisse apparaître des différences considérables entre l'appétit de différents individus. Le nombre des receveuses fortement marquées étant sans relation avec le nombre des donneuses.

\section{Les échanges de nourriture entre des onvrières appartenant $\grave{a}$ des colonies différentes}

Dans ce chapitre nous avons repris les travaux de DELVERT-SAILERON (I96I) en essayant d'améliorer les techniques.

Nous avons tout d'abord confirmé ses résultats, c'est-à-dire qu'en utilisant des abeilles jeunes élevées en étuve nous avons montré que les échanges entre sœurs étaient plus intenses qu'entre étrangères, au moins pendant les premières 48 heures de vie semi-commune.

Mais en utilisant des abeilles provenant des ruches, d'âge inconnu, mais sans doute supérieur à 20 jours d'après leur aspect et la technique de récolte, nous avons obtenu des résultats inverses, c'est-à-dire que les étrangères échangent plus que les sœurs. 
DELVERT-SALLERON (I963) avait déjà signalé ce phénomène chez des ouvrières d'âge inconnu et seulement lors d'échanges durant plus de six jours.

Il semble donc légitime de penser que des abeilles âgées soient capables de "demander " de la nourriture et ceci de manière plus active quand elles sont en présence d'étrangères. Dans les relations trophallactiques il conviendrait peut-être de ne pas perdre de vue le fait que la receveuse peut tout aussi bien que la donneuse avoir un rôle actif.

C'est pour cette raison que MonTagner (I966) qui a étudié de très près ces phénomènes chez les guêpes du genre Vespa utilise le terme de " solliciteuse ".

\section{Transit et localisation $d u{ }^{32} P$}

Nous avons voulu voir s'il était possible de séparer la radioactivité en provenance de la nourriture régurgitée de celle contenue dans les différentes sécrétions échangées au moment de la trophallaxie et dont on connaît l'importance.

La distinction paraît possible, particulièrement chez les reines, du fait de la relative lenteur du passage du radioélément dans les glandes et il serait donc possible d'utiliser cette technique. Cependant il serait sans doute souhaitable dans l'avenir de rechercher parmi les radioéléments utilisables s'il n'en est pas qui puissent mieux remplir cet office du fait d'une affinité élective pour le tissu glandulaire.

\section{Échanges entre les ouvrières et les reines}

En ce qui concerne les échanges entre reines et ouvrières nous avons vu que ceuxci décroissent régulièrement en même temps que l'âge des ouvrières augmente. Une seule exception, le cas où la reine donneuse est vierge. Dans cette circonstance les échanges augmentent avec l'âge des ouvrières, passent vers un maximum quand celles-ci sont âgées de six jours puis décroissent.

De toute manière, en valeur absolue, les reines vierges effectuent des échanges moindres que les reines fécondes.

Pour expliquer le cas des reines vierges agissant comme donneuses on peut se reporter aux observations effectuées au cours de ces essais.

On constate en effet que les jeunes abeilles âgées de 2 à 4 jours sont immédiatement attirées par les reines fécondes ce qui doit faciliter les échanges de nourriture.

Par contre les reines vierges n'attirent que peu les jeunes abeilles. Ces reines seraient plus attractives pour des ouvrières de six jours. La décroissance des échanges observée par la suite serait de même nature que celle observée dans tous les autres cas. Le phénomène étant ainsi la conséquence de l'augmentation de l'attractivité des reines vierges en fonction de l'âge des ouvrières et de la diminution des échanges entre reines et ouvrières toujours en fonction de l'âge de ces dernières.

A $\mathbf{u}$ terme de ce travail, nous pensons avoir démontré la complexité des comportements en rapport avec la trophallaxie et les relations diverses qu'elles peuvent avoir avec d'autres points de la biologie de l'Abeille.

Il ne s'agit, bien entendu, que d'une approche de la question qui devrait être reprise par la suite pour être à même de connaître dans les détails la structure de comportements essentiels chez l'Insecte social. 


\title{
SUMMARY
}

\author{
STUDY BY YEANS OF RADIOISOTOPE $\mathrm{P}^{32}$ OF THE PART PLAYED BY VARIOUS \\ FACTORS ON THE FOOD-EXCHANGES IN A BEE-COLONY OF "APIS MELLIFICA
}

The exchange of food and other substances between individuals of the colony is one of the most important integrative mechanisms among social units. The labile equilibrium between one or a few sexuals and a very large number of non sexuals possessing a more or less latent sexual potentiality, as in case of worker honey bees, is maintained primarily through such nutrient exchanges.

The following is a study of trophallaxy, a phenomenon which is essential for the colony health and integration, in small honeybee colonies.

Introducing the use of radioactive tracers into the examination of different factors that govern this phenomenon, we have defined the optimum experimental conditions. The radioisotope used was Phosphorus 32 , incorporated into the food.

We have analyzed the following different factors which could have an influence on the food exchanges that take place between the bees.

The behavior of the worker bees in the mutual exchange of food appeared to be related to their age. Observations indicated that food transmission is null among bees of I day old and then it takes place regularly and increases gradually from the and day onwards, the maximum exchange being on the 4th day. However, the results obtained statistically for the second day are insignificant compared to the other days.

Fluctuations in the rate of transmission of food are observed in bees of various ages. The rate of food exchange reduced from the $5^{\text {th }}$ day onwards, the lowest being on the $7^{\text {th }}$ day. From the 8th day onwards, the results could not be of real value when compared with that of bees of varying ages.

The distribution rate of food transmission is influenced by duration, temperature and the number of individuals within the group.

Under conditions of constant temperature, food distribution continued along sequences of individuals in a branching-chain pattern with average cpm decreasing. By measuring not only the number of radioactive bees but also activity rate of each individual, we find that at first the distribution is very heterogeneous : some individuals with very high activities while others showing extremely low activities. Through often repeated secondary regurgitations, the distribution over a period of 48 hours results in a single-peak with preference to progressively smaller exchange units. In this way each individual of the group or the colony receives an adequate food supply.

The rate of food distribution at three different temperatures, $23^{\circ}, 31^{\circ}$ and $37^{\circ} \mathrm{C}$ at following periods of exposure $4,8,16,24,36$ and 48 hours have been studied. We found that $(a)$ the number of radioactive receptor bees is highest at $3 \mathrm{I}^{\circ} \mathrm{C}$, whereas it is lowest at $37^{\circ} \mathrm{C}(b)$ the average speed of food transmission is the same at $3 \mathrm{I}^{\circ} \mathrm{C}$ and $23^{\circ} \mathrm{C}(57 \mathrm{p}$. 100 and $60 \mathrm{p}$. roo of radioactive bees at the end of $4 \mathrm{~h}$ and $100 \mathrm{p}$. 100 for a period of $48 \mathrm{~h})(\mathrm{c})$ the speed of transmission is much faster the first 24 hours at $31^{\circ} \mathrm{C}$ than at $23^{\circ} \mathrm{C}$. The temperature does not produce the same effects on the food exchange and the consumption of food.

We have studied the influence of acclimatization of bees to two different temperatures one low, $23^{\circ} \mathrm{C}$ and the other high, $37^{\circ} \mathrm{C}$. The distribution of food is much higher and rapid in case of bees first kept at $37^{\circ} \mathrm{C}$ and later at $23^{\circ} \mathrm{C}$ for two days respectively than in the case of bees kept at $23^{\circ} \mathrm{C}$ and later at $37^{\circ} \mathrm{C}$, for two days in both cases.

Comparing the results with bees kept always at the same temperature during the experiment $\left(23^{\circ} \mathrm{C}\right.$ and $\left.37^{\circ} \mathrm{C}\right)$, we find that the food transmission is not only higher but also faster in cases where bees are under conditions of acclimatization to these two temperatures.

The study of transfer of radioactive $\mathrm{P}^{32}$ (by feeding) within an artificial colony of bees is an attempt to determine the general rate and extent of food exchange. Three different colony densities (25, 50 and 100 receptors bees) at different intervals of exposure $(2,4,8,16,24,36$ and 48 hours) to a single radioactive donor showed in a 25 member colony the fastest transmission rate, colony saturation reaching $100 \mathrm{p}$. 100 in 16 hours, while in the colonies of $5^{\circ}$ and 100 , for the same interval, there were only 84 p. 100 and 60 p. 100 of radioactive bees.

As the exposure period increases the distribution of radioactivity gets homogeneous in all the cases, the rapidity of the distribution decreasing successively in the colonies of $25,5^{\circ}$ and roo respectively.

Since the individual consumption of the food is high in bees, those in group of 25 have a better advantage in sharing the food of one radioactive donor bee. 
As the spread of radioactivity is analogous with the spread of food, there is a quantitative evidence that as the colony size increases, the average amount of a particular transmitted substance (in this case $\mathrm{P}^{32}$ ) received per bee decreases. This effect is due, doubtless, to chain transmission along longer sequences of non radioactive individuals in the larger group, following acquisition of primary donations from the original donor. The larger the colony, the greater the chances that, for a given time interval, some individuals will receive little food or none at all.

By introduction of $\mathrm{I}, 2,4,8$ and $\mathrm{I} 6$ radioactive donor bees each in a group of 50 receptor bees. it was shown for a certain period of time $(8 \mathrm{~h})$ that the distribution of radioactivity is heterogeneous with I donor, a certain number of receptor bees being non-contaminated. On the other hand, for the same exposure period the heterogeneity of the distribution reduces when the number of donor bees increases, the maximum homogeneity was obtained in a group consisting of $\mathrm{I} 6$ donor bees.

An important question is whether food exchange also takes place between bees from two different hives. Experiments carried out in artificially founded colonies in an incubator showed that the food transmission operates better among bees of the same origin than among those of different origin during first 24 hours of observations. Whereas, in experiments with bees coning from two different bee hives, this phenomenon is inverse. members of one hive showing a preference to mem. bers of the other hive.

Studies on the transfer of $\mathrm{P}^{32}$, ingested through food, and its translocation in different parts of the digestive tube of workers and queens, showed that food passes very rapidly through the oesophagus. The crop gets labelled within $\mathrm{I} / 2 \mathrm{~h}$ in case of workers and within $\mathrm{I} h$ in case of queens. The activity of the proventriculus increases in the same time as that of the crop decreases. Then the ventricule gets labelled slowly and the radioactivity remains more or less stationary in it during the following days.

In the meantime, incorporation (assimilation) of the radioactive material begins in different ways. Its incorporation into the mandibular and brood glands is of special interest. The approximate interval between the uptake of the tracer from the food to its assimilation in the inandibular, hypopharyngeal, salivary and the thoracic glands are shown. Circulating radioactivity have been detected by measuring the hæmolymph.

Studies on trophallactic behavior between the young worker bees of known ages and queens, virgin and mated, showed that the age relations of workers are parallel concerning the food exchanges occuring in the direction, Workers $\rightarrow$ queens, virgin and mated; mated queens $\rightarrow$ workers.

But, in case of virgin queens as donors, we observed that the food exchanges were maximum when the worker bees were approximately 6 days old.

\section{RÉFÉRENCES BIBLIOGRAPHIQUES}

Al.rbert J., i 959. Les échanges trophallactiques chez le Termite à cou jaune (Calolermes flavicollis) étudiés à l'aide du phosphore radioactif. C.R. Acad. Sci., 248, 1040-1042.

Alibert J., r960. Les échanges trophallactiques entre Termites sexués et larves de jeunes fondations de colonies et de sociétés plus âgées. Calotermes flavicollis FaBr. C. R. Acad. Sci., 250, 4205-4207.

Alibert J., I963. Les échanges trophallactiques chez un Termite supérieur. Contanination par le phosphore radioactif de la population d'un nid de Cubilermes fungifaber. Insectes soc., 10. I-I 2.

Alibert J., 1966. La trophallaxie ches le Termite à cou jaune (Calotermes flavicollis Farr.) étudiée à l'aide de radioélémenis. Thèse.

B.bers F. H., Mithin N., Shortino T. J., I956. The fate of radiophosphorus ingested by house flies and german cockroaches. J. econ. Entomol., 49 (6), 820-2.

BERWI: W., 1959. Untersuchungen über cuticulare Stoffabgabe bei Ameisen-Weibchen durchgeführt mit Radio-isotopen. Nalurerissenschaften, 46 (2 I), 6I0-6I I.

Bowen V. T., I950. Manganese metabolism of social Vespidac. J.exper. Zool., U.S. A., 115 (I), II 7-205. BitTEl-ReEpen H. von, igoo. Sind die Bienen "Reflexmaschinen "? Fxperimentelle Beiträge zum Biologie der Honigbiene. Biol. Zbl., 20, 1-82.

Castle G. B., r934. Termites and termite control. Berkeley : I'niv. California Press.

Chauvin R., 1952. Sur le déterminisme de l'effet de groupe chez les abeilles. Physiol. comp. Ecol., 2, 282-288.

Cinauvin R., ig62. Observations sur les pistes de Formica polyctena. Insectes soc., 9 (4), 3I I-32 I.

(Hauvin R., Courtois G., Lecomte J. i 96I. Sur la transmission d'isotopes radioactifs entre deux fourmilières d'espèces différentes (Formica rufa et Formica polyctena). Insectes soc., 8 (2), 99-107. 
Chauvin R., Courtols G., I.tecomte J., 1961. Sur les échanges entre fourmilières de deux espéces différentes mis en évidence par les radio-isotopes. C. R. Acal. Sci., 252, 4060-406I.

Cinalvin R., Grassé P. P., i 944. I'effet de groupe et la survie des neutres dans les sociétés animales. Rev. Sci., 7, 46I-464.

Chauvin R., Lecomte J., I963. Les ichanges sociaux du " deuxième degré " chez Formica polyclena. C. R. Acad. Sci., 257, 3049-305I.

Chauvin R., Leconte J., ig64. Sur les échanges du "deuxième degré "entre colonies filles de Formica polyclena étudiés au moyen des radio-isotopes. Insecles soc, 11 (2), 97-104.

Cinuvin R., L.f.comte J., i 965 . Évolution des échanges entre différentes colonies filles rle Formica polyctena, mesurée à l'aide des radio-isotopes. Inspcles soc., $12(3), 197-199$.

Cinauvin R., Lecomte J., I966. Échanges protidiques entre fourmilières de Formica polyclena, mesurés à l'aide de radio-isotopes. Insectes soc., 13 (I), I-4.

Courtois G., Lecomte J., Delvert-Sinlleron F., igor. Étude des échanges de nourriture à l'intérieur de la ruche entre les Abeilles ouvrières, Apis mellifica. C. R. Acal. Sci., 262, 1057-1059.

Colrtois G., Leconte J., r962. Étude des échanges de nourriture entre butineuses de Formica polyclena travaillant dans des secteurs différents mais appartenant à la même fourmilière. Insectes soc., 9 (4), 323-327.

Delvert-Salleron F., i g63. Étude au moyen de radio-isotopes des échanges de nourriture entre reines, mäles et ouvrières d'A pis mellifica L. Ann, Abeille, 6, 201-227.

DoolitTle, G. M., I89o. Large or small hive bees unloading the honey. Amer. Bee. J., 26 (30), 503 seulement.

Doolittle G. M., igo7. When do the field bees deposit their loads ? Amer. Bet. J., 487,29), 653-654.

Douault Ph., ig66 a. Étude de la contamination externe de l'Abeille Apis mellifica et de son milieu par un radio-isotope introduit dans la nourriture. Ann. A beille, 9 (I), 37-45.

Douault Ph., I 966 b. Amélioration d'une technique de recherche de la contamination de l'Abeille marquée au moyen d'un radio-isotope. Ann. Abeille, 9 (4), i6.5-I69.

Dovault Ph., r 967 . Influence du nid à couvain sur les crhanges de nourriture entre ouvrières d'abeilles (Apis mellifica). C. R. Acad. Sci., 264, 1092-1095.

FABRE J. H., 1879-1903. Souvenirs entomologiques. 1o vol., Paris (Édition illustrée, I920-1924). Delagrave.

FREE J. B., 1957. The transmission of food between worker honey bees. Brit. J. anim. Behav ., 5, 41-47.

Free J. B., Butler C. G., I955. An analysis of the factors involved in the formation of a cluster of honeybees (Apis mellifera). Behaviour, 7 (4), 304-316.

Free J. B., Spencer-Bootir Y., i958. Observations on the temperature regulation and food consumption of honey bees (Apis mellifera). J.exper. Biol., 35 (4), 930-937.

Free J. B., Spencer-Booti Y., ig6o. (hill-coma and cold death temperature of A is mellifra. Entomsl. exper. appl., 3, 222-320.

Frisch K. von, I947 a. Die Tänze der Bienen. I Hsche Zool. Z., 1 (I-2), I-48.

Friscr K. von, 1946 b. Die "Sprache" der Bienen und ihre Nutzanwendung in der Landwirtschaft. Experientia, 2 (10), 397-404.

Friscir K. V., RosciI G. A., I926. Neue Versuche über die Bedeutung von Duftorgan und Pollenduft für die Verständigung im Bienenvolk. Z. vergleich. Phy'siol., 4, 21-1.

Gösswald K. Einblicke in das Staatleben der Insekten auf Grund von radiobiologischen Studien. Natur und Volk, $89(7-8), 209^{-2}$ I 3 et $249^{-2} 59$.

Gösswald K., Ig62. In : Proc. interna. UNESCO-Symp. on Termites in the Mumid tropics. New Delhi, 1960 .

(;össwald K., KLoft W., I956. Untersuchungen über die Verteilung von radioactive markiertem Futter im Volk der Kleinen Roten Waldameise (Formica mia Pratensis minor). Waldhygiene, 1 (6), $200-202$.

(rösswald K., KLofT W., 1957. Neuere Lntersuchungen über die sozialen Wechselbeziehungen im Ameisenvolk, durchgeführt mit Radioisotopen. 3 Kongr. I. I. E. I. S., Paris.

(iösswald K., KLOFT W., t958. Radioaktive Isotope zur Erforschung des Staatenlebens der Insekten. Umschau, 24, 742-745.

Gösswald K., KLoFT W., I959. Zur Laboratoriumsprufung von Testilien auf lemitenfestigkeit mit Kalotermes flavicollis FABR. Entomol. exper. appl., 2, 268-278.

Gösswald K., KLofr W., i 960 . Untersuchungen mit Radioaktiven Isotopen an Waldameisen. Entomophaga, 5, 33-4I.

(jösswald K., Kloft W., tg6o. Neucre Untersuchungen über die sozialen Wechselheziehungen im Ameisenvolk, durchgeführt mit Radio-Isotopen. Zool. Beitr.. 5, 519.

Gösswald K., Kloft W., 1963. Tracer experimenis on food exchange in Anls and Termites. In : Radiation and radioisotopes applied to insects of agricultural importance. I. A. E. A., Vienne, 25-39.

Grassé P. P., Norrot Ch., 1945. La transmission des Flagellés symbiotiques et tes aliments des Termites. Bull. biol. Fir. Belg., 79, $273^{-292}$.

Grassi B., Sandias A., 1893. Constituzione e sviluppo dello societa dei Termidi. Atti Acc. Gioen., 6, I-75.

De Groot A. P., I953. Protein and amino acid requirements of the honeybee. Physiol. comp. AEc'., 3 , $197-285$. 
GunN D. L., Hopf H. S., I94I. The biology and behavior of Ptinus tectus BoIE (Coleoptera, Ptinidae), a pest of stored products. J. exper. Biol., 18, 278-305.

Hallund V., I956. Om biernes overvintring. Nord. Bitidskr. 8 (4), 106-I I3.

Hasset C. G., I954. Uptake of $\mathrm{P}^{32}$ by Periplaneta americana, Passage through the fore, mid and hindgut. Feder. Proc., 13 (I), 68.

HAYDAK M. H., r96r. Influence of storage on the nutritive value of pollens for newly emerged honeybees. Amer. Bee. J., 101 (9), 354-355.

Herrod-Hempsall W., I930. Beekeeping, new and old. British Bee. J.

Hoskins W. M., Harrison H. S., 1934. Buffers in Ventriculus and arsenic action, honeybee. J. econ. Eniomol., 27, 924-942.

HuQue H., ig6o. Studies on the persistence, decay and distribution radiophosphorus in Grasshopper and the madeira cockroach (in Radioisotopes and Radiation in Entomology. Proc. Symp. Bombay., p. I55-159. Intern. Atom. Agency, Vienne, 1962.

Isto Mina-Tsvetkova K. P., I953 a). Reciprocal feeding between bees. Pchelovodstwo, 1, $25^{-2}$.

Isto Mina-Tsverkova K. P., I 953 b). New data on the behavior of bees. Pchelovodstvo, 9, I 5-23.

Isto Mina-Tsvetkova K. P., i 958 . Contribution to the study of trophic relation in adult worker bees $17^{\mathrm{e}} \mathrm{in-}$ ternation. Beekeep. Congr. 1958 .

Kalmus H., RiBBANDS C. R., I952. The origin of the odours by which honey bees distinguish their companions. Proc. r. Soc., 140, 50-50.

Kannowski P. B., I959. The use of radioactive phosphorus in the study of colony distribution of the ant Lasius minutus. Ecology, 40 (I).

Kelier-Kitzinger Ruth, i935. Kann die erwachsene Arbeiterin der Honigbiene (Apis mellifica) Eiweiss verwerten? Z, vergleich. Physiol., 22 (1), ז-31.

Kinalifman J., 1955. Les Abeilles. Les conqueles de l'apidologie. La biologie de la ruche, Éd. de Langue étrangère, $248-249$.

KLOF' W., r 960. Technical problems of radio-isotope measurement in insect metabolism. Symp. Radioisotopes and Radiation in Entomology Bombay, International Atomic Energy Agency, Vienne, I962.

KNeitz G., I96r. Tracerversuche zur Futterverteilung Bei Waldameisen. Symposia Genetica et Biologica, 4 Congr. U. I. E. I. S. Pavia, 11, $3^{8-49 .}$

Lecomte J., г96r. Le comportement agressif des ouvrières d'Apis mellifica L. Ann. Abeille, 4, 165-270.

Lecomte J., I963. Études des échanges de nourriture de la colonie de Bourdons au moyen de radio-isotopes. C. R. Acad. Sci., 25\%, 3664-3665.

LEnsky Y., 196r. Les échanges de nourriture liquide entre abeilles aux températures élevées. Insectes soc., 8, 36I-368.

Light S. F., I944. Experimental studies on ectohormonal control of the developement of the supplementary reproductives in the termite genus Zootermopsis. 'Univ. Calif. Publ. Zool., 43, 413-454.

Lindauer M., I952. Iin Beitrag Zur Frage der Arbeitsteilung im Bienenstaat. Z. vergleich. Physiol., 34, 299-345, Bee World, 34, 63-74, 85-90.

Lindauer M., 1954. Temperaturregulierung und Wasserhaushalt im Bienenstaat. Z. vergleich. Physiol., 36, $39^{I-432}$.

Maurizio A., I946. Beobachtungen über die Lebensdauer und den Futterverbauch gefangen gehaltener Bienen. Beih. Schweiz. Bienentg., 2 (13), I-44.

Maurizio A., I954. Pollenernährung und Lebensvorgänge bei der Honigbiene. Landw. Jb. Schweiz., 68 (2), I $55-182$.

McMahan E., I953. A study of T'ermite feeding relationship üsing radioisotope. Ann. enlomol. Soc. Amer., 56, $74-82$.

McMahan E., I966. Food consumption within the Cryptotermes brevis colony (Isoptera : Kalotermidae). Ann. entomol. Soc. America., 59 (6), I I 3 I-I 137.

Mellanby K., I939. Low temperature and insect activity. Proc. r. Soc. (8), 127, 473-487.

Montagner H., I963. Contribution à l'étude du déterminisme des castes chez les Vespides. C.R. Soc. Biol., 157, 14-17.

Montagner A., i $964 a$. Comment caractériser le transit intestinal chez les Guêpes sociales. Les conséquences biologiques. C.R. Acad. Sci., 259, 2016-2019.

Montagner A., $1964 b$. Étude du comportement alimentaire et des relations trophallactiques des mâles au sein de la Société de Guêpes. Insectes, soc., 2, 301-316.

Montagner A., I966. Le mécanisme et les conséquences des comportements trophallactiques chez les guépes du genre Vespa. Thèse. Nancy.

Montagner H., Courtois G., I963. Données nouvelies sur le comportement alimentaire et les échanges trophallactiques chez les Guêpes sociales. C. R. Acad. Sci., 256, 4092-4094.

Mortrevil M., Brader. L. M., I962. Marquage radioactif des tourmis dans les plantations d'ananas. Radioisotopes and Radiations in Entomology. I. A. E. A., Vienne.

NAARManN H., I963. Untersuchungen über Bildung und Weitergabe von Drüsensekreten bei Formica (Hymenoptera, Formicidae) mit Hilfe der Radioisotopen Methode. Experientia, 19, 4I 2-4I3. 
Nixon H. L., Ribbands C. R., 1952. Food transmission within the honeybee community. Proc. r. Sac. (B)., 140, 43-50.

Oertel E., Emerson R. B., Wieeler H. E., I953. Transfer of radioactivity from worker to drone honeybees after ingestion of radioactive sucrose. Ann. entomol. Soc. Amer., 46, 496-498.

OHNESORGE-HUMPERdinck I., I953. Beobachtungen an Kopfdrüsen der Honigbiene. Nalurwissenchatfen, 40 (2), 6I seulement.

Pain J., I959. Étude de l'apparition de l'attractivité chez les reines vierges d'Abeille. C. R. Acad. Sci., 248, 321 I- 3212 .

Parn J., 1963. L'alimentation de la jeune abeille. Ann. Nutrit. Aliment., 17 (I), 307-312.

Pain J., I966. Nouveau modèle de cagettes expérimentales pour le maintien d'Abeilles en captivité. Ann. Abeille, 9, $7 \mathrm{r}-76$.

Perepelova V. I., 192.s. The nurse bees. Opytnaia Paseka, 3 (12), 551-557.

Phillips I. F., ig28. Beekueping. Macmillan, New York.

Raignier A., I948. L'économie thermique d'une colonie polycalique de la fourmi des bois Formica rufa Polyctena. Cellule 51, 291-368.

RÉaumur R. A., de, ${ }^{7} 734^{-1} 74^{2}$. Mémoire pour servir à l'histoire des Insectes, 6 vol. Paris.

RoEder K. D., I953. Insect Physiology. Edit. by Roeder, J. Wiley and Sons.

RösCH G. A., I925. Untersuchungen über die Arbeitsteilung im Bienenstaat. I. Die Tätigkeiten im normalen Bienenstaat und ihre Beziehungen zum Alter der Arbeitsbienen. Z. vergleich. Physiol., 2, $571-631$.

Roubaud E., 1916. Recherches biologiques sur les Guêpes solitaires et sociales d'Afrique. Ann. Sci. nat. zool., 1, I-160.

Sakagami S. F., I953. Untersuchungen über die Arbeitsteilung in einem Zwergvolk der Honigbiene. Jap. J. Zool., $11(\mathrm{I}), 117^{-1} 85$.

Schneirla T. C., I953. The army ant queen : keystone in a social system. Bull. Un. internation. Insectes soc., 1, 29-4I.

SENDLER O., 1940. Vorgänge aus dem Bienenleben vom Standpunkte der Entwicklungs-Physiologie. Z. wissensch. Zool., 153, $29-82$.

SNELgRove L. E., I940. The introduction of queen bees. Bleadon (Somerset), England.

Stumper R., 1956. Sur les sécrétions attractives des fourmis femelles. C. R. Acad. Sci., 242, 2457.

WHEELER W. M., rg18. A study of some ant larvae with a considerations on the origin and meanings of the social habits among Insects. Proc. Amer. Philos. Soc., 57, 293-343, I928. New York, Harcourt Brace, 378 p. The Social Insects.

Wilsox E. O., EISNERT T., I957. Quantitative studies of liquide food transmission in ants. Insectes soc., 4, $157-166$.

Woodrow A. W., I94I. Some effects of temperature, relative humidity, confinement and type of food on queen bees in mailing cages. U.S. A, Dept. agric. Bur. Entomol. Plant Quarantine, 529, I3.

WyatT C. R., 1958. Phosphorus compounds in insect development. Proc. 4th internation. Congr. Biochem. Vienne, 1958, 12, Biochem. Insects. London, New York, Paris, Los Angeles, Pergamon Press.

WyatT C. R., I961. Ann. Review Entomol., 6, 75.

WYATT C. R., 1963. Biochemistry of diapause, development und injury in silkworm pupae. In : Insect Physiology.' Proc.23 th ann. biol. Coll., 23-4I, V. J. Brookes, Corvalis (U.S. A.). 